NBER WORKING PAPER SERIES

RESEARCH IN ACCOUNTING FOR INCOME TAXES

\author{
John Graham \\ Jana Raedy \\ Douglas Shackelford \\ Working Paper 15665 \\ http://www.nber.org/papers/w15665 \\ NATIONAL BUREAU OF ECONOMIC RESEARCH \\ 1050 Massachusetts Avenue \\ Cambridge, MA 02138 \\ January 2010
}

We thank Justin Hopkins, Hyunseob Kim, Kevin Markle, Jenna Meints, and Jake Thornock for outstanding research assistance. We thank Ross Watts (the editor), an anonymous referee, Jeff Abarbanell, Scott Dyreng, Jonathan Forman, Mary Margaret Frank, Ed Maydew, Lillian Mills, Richard Sansing, Casey Schwab, Jeri Seidman, Stephanie Sikes, the Texas Tax Readings Group, and participants at the 2009 UNC Tax Symposium and the National Tax Association 2009 annual conference for helpful comments. The views expressed herein are those of the authors and do not necessarily reflect the views of the National Bureau of Economic Research.

NBER working papers are circulated for discussion and comment purposes. They have not been peerreviewed or been subject to the review by the NBER Board of Directors that accompanies official NBER publications.

(C) 2010 by John Graham, Jana Raedy, and Douglas Shackelford. All rights reserved. Short sections of text, not to exceed two paragraphs, may be quoted without explicit permission provided that full credit, including $\odot$ notice, is given to the source. 
Research in Accounting for Income Taxes

John Graham, Jana Raedy, and Douglas Shackelford

NBER Working Paper No. 15665

January 2010

JEL No. H25,M41,M48

\begin{abstract}
$\underline{\text { ABSTRACT }}$
This paper comprehensively reviews Accounting for Income Taxes (AFIT). The first half provides background and a primer on AFIT. The second half reviews existing studies in detail and offers suggestions for future research. We emphasize the research questions that have been addressed (most of which relate to whether the tax accounts are used to manage earnings, and whether the tax accounts are priced by equity market participants) and highlight areas that have not received much research attention. We close with a call for a theoretical framework, more study of the inconsistencies between research and practice, and improved econometrics.
\end{abstract}

John Graham

Duke University

Fuqua School of Business

One Towerview Drive

Durham, NC 27708-0120

and NBER

john.graham@duke.edu

Jana Raedy

Kenan-Flagler Business School

University of North Carolina, Chapel Hill

Campus Box 3490, McColl Building

Chapel Hill, NC 27599-3490

jana_raedy@unc.edu
Douglas Shackelford

University of North Carolina at Chapel Hill

Kenan-Flagler Business School

Campus Box 3490, McColl Building

Chapel Hill, NC 27599-3490

and NBER

doug_shack@unc.edu 


\section{Research in Accounting for Income Taxes}

\section{Introduction}

This paper reviews one of the more complex areas of financial reporting: accounting for income taxes (AFIT). Before this decade, AFIT and its implications for financial reporting and effective tax planning attracted limited attention in scholarly circles. ${ }^{1}$ However, in recent years, both financial accounting and tax researchers have begun to focus on AFIT, so much so that AFIT has become the most active area of accounting research in taxation. ${ }^{2}$ Almost all of the studies have been empirical, primarily testing the incremental information content of the tax accounts and their role in earnings management. To provide a structure for understanding this growing literature, we explain the essential principles that govern AFIT reporting, review extant studies, highlight key contributions, identify specific remaining questions of interest, and discuss weaknesses and opportunities of a more general nature.

To our knowledge, this is the first review of AFIT research. It is designed both to introduce new scholars to this field and to encourage active researchers to expand the frontier of AFIT. It is challenging to reach such a broad audience. Some readers have little or no understanding of the process by which firms account for income taxes in their financial statements (the income statement, balance sheet, statement of cash flows, and the statement of equity). For that group, we start the paper with a primer about the rules governing AFIT to facilitate an appreciation of the questions and findings that follow. Other readers thoroughly understand the accounting and are looking for structure and guidance in the

\footnotetext{
${ }^{1}$ Throughout the paper, we use the term "effective tax planning," to mean tax plans that consider all parties to a transaction, all taxes (explicit and implicit), and all costs (tax and non-tax). See Scholes et al. (2009) for elaboration.

${ }^{2}$ To calibrate the growing interest in AFIT research, we searched the titles of papers published during the last decade in the Journal of Accounting and Economics, the Journal of Accounting Research, and The Accounting Review for the word "tax" or any variant. We find that 35\% of the "tax" papers from 2004-2008 address AFIT issues, up from $22 \%$ of the tax papers from 1999-2003. One possible reason for this growth in AFIT studies is that, beginning in the 1990s, anecdotal information indicates that the tax accounts assumed an enhanced role in financial reporting, becoming instrumental to managing earnings and designing corporate tax shelters. In fact, some companies began to view the tax function as a profit center with a particular focus on managing the effective tax rate in the income statement (see Robinson et al. (forthcoming), Bryant-Kutcher et al. (2007) (2007), and Schmidt (2006), among others).
} 
research domain. These readers may wish to skip to Section 7, where we begin our analysis of the extant work and detail our suggestions for future research.

To narrow the scope of our analysis, we define AFIT research as work that evaluates the implications of financial reporting choices involving the income tax accounts. Examples include tests of AFIT's role in earnings management and its information content. We exclude from our analysis those studies that use the tax accounts to analyze other phenomena. For example, Mills (1998) tests whether differences in book and tax accounting affect Internal Revenue Service (IRS) audit decisions. Another excluded example is the ongoing work examining the association between differences in book and tax accounting and the cost of capital (e.g., Ayers et al. (2009); Dhaliwal et al. (2008), and Crabtree and Maher (2009)). While these papers are interesting and important, we exclude them from our analysis because they evaluate the impact of AFIT, rather than studying AFIT itself. We recognize that this delineation is somewhat arbitrary, but as with all literature reviews, we are forced to set boundaries for our analysis.

In addition, we do not discuss the sizeable literature that addresses tradeoffs between financial reporting and tax considerations. ${ }^{3}$ Although AFIT may involve tax planning considerations, we ignore issues related to the coordination of book and tax choices and refer readers to Shackelford and Shevlin (2001) and Hanlon and Heitzman (2009) reviews.

To date, most empirical AFIT research has focused on two major questions: (1) Do firms use the tax accounts to manage earnings? (2) Are the tax accounts priced in capital markets, and, if so, are they priced efficiently? Neither question is unique to tax accounting. Both questions have been explored in the context of numerous other components of the financial statements. In fact, the tax accounts were among the last accounts to be studied.

The fact that scholars have been somewhat slow to examine the tax accounts in addressing these questions of broad interest (i.e., earnings management and pricing) should not be construed as evidence

\footnotetext{
${ }^{3}$ See Shevlin (1987), Thomas (1988), Matsunaga et al. (1992), Guenther (1994), Collins et al. (1995), Beatty et al. (1995), Clinch and Shibano (1996), Hunt et al. (1996), Maydew (1997), Collins et al. (1997), Engel et al. (1999), and Keating and Zimmerman (1999), among many others.
} 
that AFIT studies are somehow less important. To the contrary, since corporate tax returns are confidential, the tax information in the financial statements is the primary (usually sole) source of information about a firm's corporate taxes. Thus, understanding the creation and role of tax information in the financial statements is critical for at least four reasons. First, taxes are a major expense for most companies (often exceeding one-third of pre-tax profits). Second, tax planning affects numerous activities of the firm (see Hanlon and Heitzman (2009) for many examples). Third, policymakers rely on the tax information in the financial statements to establish both tax and other policies. Fourth, because taxes are computed using a different measure of income (based on tax rules) than book income (based on accounting rules), they potentially provide additional information about the profitability of a firm. These four reasons are in addition to the usual scholarly interest in better understanding the factors (in this case, AFIT) that affect business decisions.

Although closely related to traditional corporate income tax research, recent AFIT work resembles mainstream financial accounting research more than it resembles “Scholes-Wolfson” tax research, which draws heavily from economics and finance. ${ }^{4}$ To test the tax accounts in the financial statements for earnings management and incremental content, AFIT scholars have imported research questions and designs mostly from the financial accounting field. Moreover, accountants have provided much of the technical tax expertise in the extant AFIT studies.

Indeed, one of the challenges facing the emerging field is developing producers and consumers of AFIT scholarship outside of the accounting community. We are encouraged that some economists and lawyers have already begun to focus on the implications of differences in book and tax accounting for manipulating financial statements and/or tax filings (e.g., Desai and Dharmapala (2006), Schön (2005), and Whitaker (2005)). We hope that our paper will expose even more non-accounting scholars to current AFIT research and guide them toward issues of interest in their fields.

\footnotetext{
${ }^{4}$ See Shackelford and Shevlin (2001), Graham (2003), and Hanlon and Heitzman (2009) (2009) for reviews of this literature.
} 
In addition, we hope to contribute to ongoing policy discussions among accounting regulators and tax policymakers. In particular, there is a growing debate about increasing the alignment between book and tax accounting. While many accountants oppose book-tax conformity and tend to dismiss its possibility, there is support among some economists and lawyers and it has spilled into Congressional testimony (e.g., Desai (2006) and Shackelford (2006)). We hope that this review will sharpen the focus for these ongoing policy discussions.

As mentioned above, we dichotomize the paper into a primer, which discusses the principles that govern AFIT (Sections 2-6), and a review of the scholarly studies in the field (Sections 7-9). Figure 1 depicts the organization of the paper. Appendix A categorizes the research studies that are examined in each section. Such grouping helps the reader quickly see the sometimes large number of papers that apply to a given AFIT topic. The "blank spots" in the Appendix A table highlight the areas in which little or no work has been undertaken to date, which we hope spurs research in these areas when practicable. Appendix B provides a glossary of accounting and tax terms. Appendix C lists examples of the book-tax differences that result when tax rules differ from GAAP financial statement rules. Appendix D details the rules that govern the reporting of deferred tax accounts.

In our attempt to reach a broad audience, we first cover the basic rules governing AFIT, beginning with a brief discussion of accrual accounting (see Section 2), which undergirds the entire financial accounting system. Section 3 shows that when the tax law accounts for transactions in the same manner as does financial accounting, AFIT is straightforward, intuitive, and relatively simple.

Complexities arise when book and tax treatment differ, e.g., measuring the rate of depreciation for property. Section 4 details the two types of differences between book and tax income: permanent and temporary. These book-tax differences ${ }^{5}$ can be complex and have been proposed as measures of both

\footnotetext{
${ }^{5}$ Words that are defined in the glossary at the end of the paper (Appendix B) appear in bold the first time they appear in the text.
} 
earnings manipulation and tax fraud. Studies show that the tax accounts can materially affect both income statements and balance sheets. ${ }^{6}$

Section 5 describes the income tax contingency account on the balance sheet, an estimate of the tax payments that are expected if the tax returns were to be audited. Recently enhanced disclosures of this estimate have spurred tests of the extent to which firms exploit the uncertainty in this estimate to manage earnings.

Section 6 closes the first part of the paper by discussing two questions of primary interest to many users of the tax information in the financial statements: (1) How well does the tax information in the financial statements approximate actual tax return information? (2) How well does the tax information in the financial statements aid in assessing the effectiveness of a firm's tax planning? The short answer to both questions is, "in many cases, poorly." As with all information in the financial statements, the tax accounts are designed to provide information about the financial condition of the firm. They are not intended to provide information about the firm's tax returns or the effectiveness of its tax planning. Consequently, attempts to infer confidential tax return information from the tax accounts in the financial statements can lead to erroneous and misleading conclusions. Nonetheless, we recognize that the financial statements often provide the only publicly available tax information. Thus, we discuss ways that researchers, policymakers, and other interested parties can use the tax information in financial statements to better approximate information in the tax return.

The second half of the paper reviews the extant scholarly studies and identifies unresolved questions. Table 1 summarizes the main findings from these papers and positions them in the literature, organizing them by tax accounts and research questions. The table highlights the primary topics of study and identifies those areas in which little research has been undertaken.

Section 7 focuses on the use of the tax accounts to manage earnings through the valuation allowance, the income tax contingency, and permanently reinvested foreign earnings. Extant empirical research indicates that managers appear to use the valuation allowance and the tax contingency

\footnotetext{
${ }^{6}$ Appendix 2.2 of Scholes et al. (2009) also provides a detailed discussion of accounting for income taxes.
} 
to meet or beat analysts' forecasts. Similarly, they appear to classify a portion of their foreign earnings as “permanently reinvested” to meet or beat analysts’ forecasts. However, the literature finds only weak support for the hypothesis that firms use these accounts to meet or beat other earnings targets or to smooth earnings.

Section 8 explores the pricing of tax information. Here, the evidence is more compelling. With the possible exception of the valuation allowance, the extant literature consistently shows that the capital markets impound information from the deferred tax accounts into prices in predictable ways. In addition, estimated taxable income has information content incremental to book income, but it appears that estimated taxable income is not fully and immediately impounded into market prices.

Section 9 explores a topic of increasing interest among policymakers and economists, increased alignment of accounting for book purposes and tax purposes. Proponents of book-tax conformity assert that it would mitigate overstatement of book earnings and understatement of taxable income. However, extant research identifies a potential cost—-the markets appear to glean information from the tax accounts, which would be eliminated under conformity.

Throughout the paper, we identify specific research questions and topics that deserve further study. In Section 10, we focus on five issues of general importance. Specifically, we discuss: (1) the need for a theoretical framework to interpret and guide empirical AFIT studies; (2) the inconsistencies between empirical findings implying that the tax information in the financial statements is useful and anecdotes of its poor quality and limited usefulness to practitioners; (3) the need to study the disaggregated components of book-tax differences; (4) the need to better understand whether some findings imply market inefficiency or whether they are driven by market imperfections; and (5) the research opportunities that may present themselves as the U.S. moves toward International Financial Reporting Standards (IFRS). Section 11 discusses econometric weaknesses that are common in AFIT research and proposes ways to mitigate their deleterious effects. Section 12 concludes. 


\section{Accrual Accounting}

Although AFIT requires expertise in both financial accounting and taxation, it is important to understand that AFIT is a financial accounting system. No tax statute mandates or governs AFIT. The purpose of all financial accounting is to provide useful information to stakeholders, such as investors and creditors. The specific purpose of AFIT is to present information about the firm's taxes, using the same Generally Accepted Accounting Principles (GAAP) that govern the reporting of other economic activities of the firm. ${ }^{7}$

GAAP accounting uses an accrual system as opposed to a cash system. ${ }^{8}$ Under a cash-basis system of accounting, revenues are recorded (i.e., included in the income statement) when cash is received and expenses are recorded when cash is paid out. Under an accrual-basis accounting system, revenue and expenses are recorded when a transaction happens. For example, assume that a firm sells 100 units of product for $\$ 1,000$ on credit in 2008 , but does not collect cash until 2009. Under a cash-basis system, the firm records revenue in 2009 because that is when it receives the cash. Under an accrualbasis system, the firm records revenue in 2008, when the transaction occurs.

Two principles govern the accrual-basis system of accounting. First, the revenue recognition principle states that revenue should be recognized (i.e., recorded) once it is realized or is realizable (i.e., the goods have been exchanged for cash or claims to cash) and earned (i.e., the firm has substantially

\footnotetext{
${ }^{7}$ U.S. GAAP is based on standards set by the Security and Exchange Commission (SEC), Financial Accounting Standards Board (FASB), and the American Institute of Certified Public Accountants (AICPA). The primary accounting pronouncements that affect AFIT in the United States are: (a) SFAS No. 109 - "Accounting for Income Taxes," (Financial Accounting Standards Board, 1992) (b) FIN 48 - “Accounting for Uncertainty in Income Taxes”, and (Financial Accounting Standards Board, 2006) (c) APB No. 23 (Accounting Principals Board, 1972) "Accounting for Income Taxes - Special Areas." Although these statements have been superseded by the recent FASB codification, which primarily includes these statements in FASB ASC topic 740, we refer to the legacy statements throughout the paper.

${ }^{8}$ Except for the smallest businesses, the accrual system is also required for tax purposes. Specifically, the Internal Revenue Code Section 448(c) mandates the accrual accounting method for tax purposes if a corporation exceeds $\$ 5$ million in gross receipts. The tax law does require cash accounting for some transactions, but a discussion of the conditions under which cash accounting is used is beyond the scope of this paper.
} 
accomplished what it must do to be entitled to the benefits of the revenue). ${ }^{9}$ Thus, in the previous example, the firm would recognize revenue in 2008, the year it was realized and earned. ${ }^{10}$

Second, the matching principle of accrual accounting states that an expense is generally recognized when the revenue to which it is related is recognized. ${ }^{11}$ Continuing the example above, assume the firm purchased and paid \$700 in 2007 for the 100 units it sold in 2008. Under the cash-basis system, the firm would recognize the expense of the goods in 2007 because that is when it paid cash. However, under the accrual system of accounting, the firm will record the expense in the same period that it records the related revenue (i.e., the firm will match the expense to the revenue) and thus it will record the expense in 2008.

The matching principle means that the income tax expense (also known as the income tax provision) reported in the income statement of the firm is not the actual income taxes paid by the firm in that period (as it would be under a cash-basis system). Rather, the income tax expense arises from matching the taxes paid in prior periods, paid in this period, or to be paid in future periods with the revenue that is recorded in this period. Likewise, any taxes paid in the current period that are not related to revenues recorded in the current period would not be included in the tax expense reported on the income statement.

Note that taxes are also included on the statement of cash flows. The tax item there is the actual taxes paid during the period. These taxes paid are net taxes paid during the current year, which include taxes from the current tax return, taxes required upon audit of tax returns from prior years, and refunds from tax returns filed in previous years. ${ }^{12}$ In short, in most cases the statement of cash flows measure does not report the actual taxes paid on the current year's tax returns.

\footnotetext{
${ }^{9}$ See FASB Concept Statement No. 5, "Recognition and Measurement in Financial Statements of Business Enterprises”, paragraphs 83 and 84 (Financial Accounting Standards Board, 1984).

${ }^{10}$ The FASB is currently reconsidering revenue recognition. However, no final pronouncements have been issued at the time of this writing.

${ }^{11}$ See FASB Concept Statement No. 5, "Recognition and Measurement in Financial Statements of Business Enterprises”, paragraphs 85 and 86.

${ }^{12}$ See Dyreng et al. (2008) for more discussion of the cash taxes paid on the statement of cash flows.
} 


\section{When Book and Tax Are the Same}

Despite the many differences between book and tax accounting, transactions are often accounted for in the same manner under GAAP and the tax law. In fact, book accounting is the default starting point for tax accounting. When GAAP computes revenues the same way as the tax law computes income and GAAP records expenses the same way that the tax law records deductions, AFIT is relatively straightforward and simple. ${ }^{13}$

For example, suppose Company A begins business in 2008 and bills, but does not yet collect, \$500 in revenue (and magically incurs no expenses). Assume that these sales transactions have identical treatment for both book and tax purposes and that the tax rate is 35\%, the current top statutory corporate income tax rate. In this case, the company will pay a tax of \$175 to the government. On the company’s GAAP-based income statement for 2008, it will report revenue of \$500 and income tax expense of \$175 (\$500*35\%). On the 2008 year-end balance sheet, the firm will report an asset (accounts receivable) of $\$ 500$ and a liability (taxes to be paid in 2009) of \$175. Since net income increases owners’ equity, the company will now have equity of \$325. The first column of Figure 2 presents the GAAP income statement and balance sheet for this example. ${ }^{14}$

AFIT's most widely followed statistic is the effective tax rate (ETR). The ETR is the income tax expense divided by NIBT (net income before taxes) and represents the portion of profits recorded in the period whose claimant is the government. Not surprisingly, in this simple scenario, the ETR is the statutory tax rate or 35\% (175/500).

\footnotetext{
${ }^{13}$ Revenue is the term for additions to book income; income is the term for additions to taxable income. Analogously, expense is the term for subtractions in computing book income; deduction is the term for subtractions in computing taxable income.

${ }^{14}$ The journal entries for this scenario would be as follows. First to record the sale, debit accounts receivable, an asset on the balance sheet, for $\$ 500$ and credit sales revenue, which is reported on the income statement, for $\$ 500$. To record the impact of income taxes, debit income tax expense, which is reported on the income statement, for $\$ 175$ and credit income taxes payable, a liability on the balance sheet for $\$ 175$. When the cash is collected, the accounts receivable will be removed from the books with a credit and cash, which is reported on the balance sheet, will be debited (i.e., cash increases). When the taxes are paid, the income taxes payable will be removed from the books with a debit and cash will be credited (i.e., reduced).
} 


\section{Book-tax Differences}

While there are many transactions where book and tax treatment are the same, often the treatment differs. These book-tax differences (BTDs) stem from tax legislation that mandates departures from GAAP accrual accounting for various economic, social, political, and administrative reasons. Reasons for these departures include attempts to alter corporate behavior (e.g., increase investment through accelerated depreciation), simplify the tax law (e.g., specify depreciation rates), and lower administrative costs by limiting discretion (e.g., specify when equipment is obsolete). Other departures include mandates for the cash method (e.g., warranties) and exclusion from tax treatment for some types of income (e.g., interest income from municipal bonds) and expenses (e.g., fines by the government).

AFIT is relatively straightforward and simple when book and tax are the same. When transactions are treated differently for GAAP and tax purposes, AFIT can quickly become complicated. The purpose of this section is to review the accounting rules governing the treatment of two forms of BTDs, permanent differences and temporary differences. We discuss permanent differences next and cover temporary differences immediately thereafter.

\section{a. Permanent Differences}

Permanent differences arise when an item (a) affects taxable income, but never affects book income; or (b) affects book income, but never affects taxable income. We have already mentioned an example of a permanent difference, municipal bond interest income, which is included in book income, but excluded from taxable income.

To show the effects of a permanent BTD, assume Company A is as described in Section 3 with one variant. Besides its sales revenue in 2008, Company A receives $\$ 40$ of municipal bond interest. Under GAAP, Company A’s NIBT is \$540; under the tax law, its taxable income is $\$ 500$. Since the $\$ 40$

will never be taxed, the municipal interest income is excluded from the calculation of income tax expense. In other words, income tax expense is computed as though there is no municipal bond interest. 
Consequently, the income tax expense is the same as it was in the first example. The computation is as follows:

$\begin{array}{lr}\text { NIBT } & \$ 540 \\ \text { Less permanent differences } & \underline{(40)} \\ & \$ 500 \\ \text { Statutory income tax rate } & \underline{\mathbf{3 5 \%}} \\ \text { Income tax expense } & \underline{\$ 175} \\ \text { Net income (after income taxes) } & \underline{\underline{\$ 365}}\end{array}$

See the second column in Figure 2 for the GAAP income statement and balance sheet under this scenario. $^{15}$

Because the municipal bond interest income increases NIBT without affecting the income tax expense, the ETR declines. In the first example (with no book-tax differences), the ETR was the statutory rate of 35\% (175/500). In the second example (with the exempt interest permanent difference), the ETR falls to $32.4 \%(175 / 540)$. In other words, the government has a smaller percentage claim on the firm's profits. Appendix C provides a list of common transactions that create permanent BTDs. Some reduce the ETR; others, such as nondeductible fines, increase the ETR.

The tax footnotes of the financial statements provide information about permanent differences through a reconciliation of the effective tax rate to the federal statutory tax rate. All significant reconciling items must be disclosed. The governing principal (SEC Reg S-X Rule 4-08(h)) defines significant as $5 \%$ of the statutory rate $(1.75 \%$ for a $35 \%$ statutory tax rate). This high threshold typically results in disclosure of only a handful of permanent differences for any given firm-year.

We are unaware of any computer-readable information about the rate reconciliation. In their studies of permanent differences, Seidman (2008) and Poterba et al. (2009) hand-collect information from the tax footnotes.

\footnotetext{
${ }^{15}$ The journal entries for this scenario would be as follows. First to record the sale, debit accounts receivable and credit sales revenue for $\$ 500$. To record the receipt of interest, debit cash and credit interest revenue for $\$ 40$. To record the impact of income taxes, debit income tax expense and credit income taxes payable for $\$ 175$.
} 


\section{b. Temporary Differences}

\section{i. General}

Temporary differences are the second, and more complicated, form of BTD. Temporary differences arise when the book treatment and the tax treatment for a transaction differ in a given year, but (ignoring the time value of money) have the same cumulative effect over the life of the firm.

For example, suppose that a machine costs $\$ 200$. Over the life of the machine, both total book depreciation and total tax depreciation must equal \$200. However, during any year in the life of the machine, book depreciation likely will never equal tax depreciation because the rate of depreciation for book and tax is rarely the same.

Book depreciation is based on the actual deterioration of the asset. Thus, if the machine is expected to deteriorate evenly over two years, then, during the first year, the firm will record $\$ 100$ of book depreciation expense. During the second year, the firm will again record \$100 of book depreciation expense.

The tax law ignores the deterioration of the machine in determining tax depreciation. Instead, statutory depreciation rates apply. For example, in this case, if the tax law requires $\$ 150$ of tax depreciation in the first year, then the firm will record a deduction on its tax return of $\$ 150(\$ 50)$ in the first (second) year. ${ }^{16}$

This difference between book depreciation and tax depreciation causes a difference between book income and taxable income. Furthermore, since the income tax expense reported on the financial statements is based on book income and the amount paid to the government is based on taxable income, the amount of income tax expense reported on the financial statements will differ from the amount paid to the government. This difference is attributable to temporary differences between book and tax treatment.

\footnotetext{
${ }^{16}$ Note that the life of the machine in this example is identical for book and tax, but the lives need not be the same.
} 


\section{ii. Deferred Tax Accounts}

Temporary differences give rise to deferred tax liability and deferred tax asset accounts. A deferred tax liability (DTL) represents the income taxes that are booked as a tax expense on the income statement in the current year, but that will actually be paid in future years. Therefore, a DTL represents a tax obligation that will be paid in future taxes. A deferred tax asset (DTA) represents amounts that reduce the income tax expense reported in the current year financial statements, but will not actually result in a reduction in taxes paid until future years. Therefore, a DTA represents a tax benefit or tax reduction that will occur in future years.

We provide simple examples of computing both DTLs and DTAs below. Recognize that the computation of deferred tax accounts is among the more complex features of AFIT. We direct interested readers to a more extensive discussion of the calculation of deferred tax accounts in Appendix D.

We start with an example of a DTL. Assume the same scenario as the example in Section 3. Company A has earned sales revenue of $\$ 500$ and has no permanent differences. Now assume that Company A also has additional revenue of $\$ 60$ in installment sales that have not yet been collected. These sales are considered revenue and accounts receivable for book purposes. Conversely, revenue will be recognized for tax purposes (creating taxable income) when the cash is collected. For tax purposes, no taxable income has been generated. Thus, for tax purposes, it is as though no sale occurred and, therefore, no accounts receivable should be recorded.

Under these assumptions, the book basis of assets (specifically, accounts receivable) is $\$ 60$ greater than the tax basis of assets (with zero accounts receivable). This excess of book asset over tax asset generates a DTL, which is measured as the difference in the book basis and the tax basis of the asset times the statutory tax rate or:

Book Basis of Assets

Tax Basis of Assets (not publicly observable)

Difference

Statutory income tax rate

Deferred Tax Liability
$\$ 60$

$\underline{\$ 0}$

$\$ 60$

$\underline{\mathrm{x} 35 \%}$ 
We already know that the income tax expense is the product of the statutory rate and book income adjusted for permanent differences. Since there are no permanent differences in this example, income tax expense equals $\$ 196$ (\$560* 35\%). Since the income tax payable is the amount that Company A owes the government this year, it is calculated as taxable income times the statutory rate (\$500*35\%). Thus, income taxes payable on the tax return equals $\$ 175 .^{17}$ The third column in Figure 2 presents the GAAP income statement and balance sheet for this scenario. ${ }^{18}$ The $\$ 21$ deferred tax liability represents the taxes that will actually be paid in the future.

Now, consider an example of a DTA. Assume Company A has sales revenue of $\$ 500$ and no permanent differences. Assume also that the company records, for book purposes, a product warranty liability of $\$ 110$. Under tax law, warranties create no deduction until cash is paid out. Thus, for tax purposes, it is as though no liability exists during the period before the cash is paid.

Thus, the book basis of the firm’s warranty liability (\$110) exceeds the tax basis for the warranty liability of $\$ 0$ (since there is no warranty liability on the tax books). This excess of book liability over tax liability gives rise to a deferred tax asset. The DTA is computed as follows:

$\begin{array}{lr}\text { Book Basis of Liabilities } & \$ 110 \\ \text { Tax Basis of Liabilities (not publicly observable) } & \$ 0 \\ \text { Difference } & \$ 110 \\ \text { Statutory income tax rate } & \underline{\mathbf{3} 5 \%} \\ \text { Deferred Tax Asset } & \underline{\$ 38.5}\end{array}$

Income tax expense is the book income (\$390) times the tax rate (35\%) which, in this case, equals $\$ 136.50$. Income tax payable is taxable income (\$500) times the tax rate (35\%), or $\$ 175 .{ }^{19}$ The fourth

\footnotetext{
${ }^{17}$ The journal entries for this scenario would be as follows: First to record the sale, debit (credit) accounts receivable (sales revenue) for $\$ 500$. To record the receipt of installment sale revenue, debit (credit) accounts receivable (installment sale revenue) for $\$ 60$. To record the impact of income taxes debit income tax expense for \$196, credit income taxes payable for \$175, and credit DTL for \$21.

${ }^{18}$ Continuing on with this example, assume that in the following year Company A collects the $\$ 60$ in installment sales. At this point, the revenue is reported on the tax return, and the company will need to pay taxes to the government on this amount. It has already been reported for book purposes, and thus the related income tax expense has also been reported. Thus, the only tax accounts that are affected are the DTL and the income taxes payable. The DTL will be removed from the books and the income taxes payable will be increased by the same amount. The journal entry is a debit (credit) to DTL (income taxes payable) for \$21.

${ }^{19}$ The journal entries for this scenario would be as follows. First to record the sale they would debit (credit) accounts receivable (sales revenue) for $\$ 500$. To record the warranty, they would debit (credit) warranty expense
} 
column in Figure 2 presents the GAAP income statement and balance sheet for this scenario. ${ }^{20}$ The $\$ 38.50$ deferred tax asset is the amount by which book tax expenses were reduced in the current year but that will not actually reduce taxes paid until some point in the future.

Note that in both of these examples of temporary differences the ETR is 35\%. Generally, only permanent differences result in an effective rate that is different from the statutory rate.

\section{iii. Valuation Allowance}

If a firm records a DTA, then it is required to evaluate whether, and, if so, how much, it expects to benefit from that asset. One reason that the company may not expect to realize the DTA's tax savings would be if it were to have no taxable income in the future, and consequently no need for the further tax reductions provided by the DTA. In time, the tax benefits would expire, never having reduced the firm's tax payments.

This is conceptually identical to the GAAP treatment of accounts receivables. GAAP requires accounts receivables (which arise from credit sales) to be recorded, net of an estimate of bad debts. This contra-asset account (or negative asset account) recognizes that not all receivables will be converted into cash. Analogously, GAAP requires DTAs to be booked, net of the tax benefits that are not expected to be converted to cash. The firm performs this netting process by recording a valuation allowance (VA). An increase to the VA results in an equal increase in the income tax expense recorded on the books. ${ }^{21}$

(warranty liability) for $\$ 110$. To record the impact of income taxes they would debit income tax expense for $\$ 136.50, \$ 136.5$, debit DTA for $\$ 38.50, \$ 38.5$, and credit income taxes payable for $\$ 175$.

${ }^{20}$ Continuing on with this example, assume that next year the company is required to pay out the warranty amount of $\$ 110$. Since the warranty expense, and thus the related income tax expense, has already been recorded on the books, the only tax accounts that are affected are the income taxes payable and the DTA. The DTA will be removed from the books and the income taxes payable will be reduced by the $\$ 38.50$ since the firm is now receiving the tax benefits of the warranty expense. The journal entry would be to debit (credit) income taxes payable (DTA) for $\$ 38.50$.

${ }^{21}$ There are two possible approaches to determining the VA balance, the impairment approach and the affirmative judgment approach. The impairment approach is to "recognize a DTA unless the likelihood of not realizing the future tax benefit is more than 50\%." The affirmative judgment approach is to "recognize a DTA if the likelihood of realizing the future benefit is more than 50\%”. Heiman-Hoffman and Patton (1994) demonstrate that, although there should be no difference in the end result under these two approaches, psychological biases cause the net DTA balance to be higher under the impairment approach than under the affirmative judgment approach. 
Generally Accepted Accounting Principles list four possible sources of income that managers should consider when they estimate how much of the DTA will not be recovered: (1) future reversals of existing taxable temporary differences, (2) future taxable income, (3) taxable income in carryback periods, and (4) the existence of tax-planning strategies (FASB, 1992). Firms must reevaluate the existing VA each time they prepare financial statements, increasing or decreasing the valuation allowance as circumstances change (e.g., new forecasts of future taxable income). Any change in the VA changes the firm's income tax expense and thus its effective tax rate. Thus, by overstating (understating) the valuation allowance, the firm can decrease (increase) its net income. We discuss empirical tests of managing earnings through the VA in Section 7.

\section{c. Preference for Permanent Differences Over Temporary Differences}

Anecdotal evidence suggests that managers value tax plans that produce permanent tax differences more than they value tax plans that produce temporary differences (even if the two plans have the same after-tax net present value) because permanent differences can reduce ETRs. For example, Neubig (2006) asserts that the business community was lukewarm toward the President's Advisory Panel on Federal Tax Reform's 2005 proposal to deduct fully and immediately the cost of capital investments because it would create a temporary difference (rapid depreciation) and leave the ETR unchanged. Instead, businesses strongly preferred a reduction in the statutory tax rate because it would create a permanent difference, thereby reducing the ETR. ${ }^{22}$ Similarly, Edgerton (2009) finds that investment tax credits, which reduce income tax expense, boost capital investment more than accelerated depreciation (for tax purposes), which does not reduce income tax expense. He infers that companies are more responsive to government policy that increases earnings than they are to government policy that does not increase earnings, even if cash flows are unaffected.

\footnotetext{
${ }^{22}$ Changing the rate of depreciation creates a difference in the timing of the depreciation for book and tax purposes, thus, having no effect on the ETR. Changing the tax rate has no effect on the timing of the deduction. Instead it lowers the tax rate and thus the ETR.
} 
The ability to structure a transaction that creates permanent differences is purported to be critical for designing effective tax shelters (Weisbach, 2002). ${ }^{23}$ In fact, Plesko (2004, p. 730) asserts that "The ideal tax shelter...reduces the amount of income reported to the [government], without affecting the amount of income reported to shareholders, and creates a permanent rather than temporary difference.” Moreover, besides reducing taxes without adverse book effects, transactions generating permanent differences can serve to boost earnings without increasing actual taxes (see U.S. Congress (2003), for details of such transactions at Enron).

\section{d. Descriptive Information}

There are two primary sources of information about BTDs. First, as mentioned above, the balance sheet includes net DTAs and DTLs, and the tax footnotes detail component information about the material deferred tax accounts and reconcile the ETR to the statutory tax rate. Second, some researchers can access confidential corporate tax returns through special arrangements with the IRS. Corporate tax returns include a reconciliation of book income and taxable income on Schedule M-1 and more recently Schedule M-3. This reconciliation includes both permanent and temporary differences. This section reviews some descriptive information that we know about BTDs, as found in these data sources.

Examining tax footnote information in the financial statements of all firms that were in the Fortune 50 during any year from 1993-2004, Poterba et al. (2009) analyze in detail the deferred tax accounts (which allows them to focus on temporary differences, which comprise $73 \%$ of total book tax differences in their sample). For every year, they find that more companies have net DTLs than have net DTAs. For example, in 2004 among their sample firms, 48 companies with net DTLs had an aggregate net balance of $\$ 224$ billion, while 25 companies with net DTAs had an aggregate net balance of \$62 billion. For some companies, the deferred accounts are very large. In 2004, 29\% of the net-DTL companies had net DTLs that exceeded 5\% of total assets, compared to only $8 \%$ of net-DTA firms that

\footnotetext{
${ }^{23}$ There is no widely accepted definition of a corporate tax shelter and tackling that elusive concept is beyond the scope of this paper. However, in this context, we use the term to refer to corporate tax plans that the Internal Revenue Service has deemed (or likely would deem) as illegal or abusive.
} 
exceeded that threshold. The authors find that the mean VA balance in their sample of Fortune 50 firms was $\$ 472$ million in 2004. This compares with a mean DTA balance related to credits and carryforwards of $\$ 859$ million. This indicates that over half of the DTA balance is not expected to provide a tax benefit.

Poterba et al. (2009) also report the components of deferred tax positions. They found that the largest sources of DTLs for their sample of 73 firms were property, plant and equipment with a mean of $\$ 2.3$ billion, other liabilities (mean of $\$ 0.7$ billion) and leases ( $\$ 0.6$ billion). The largest sources of DTAs were other assets ( $\$ 1.5$ billion), employee benefits ( $\$ 0.5$ billion), and tax credit and other carryforwards (\$0.5 billion). The DTLs from property, plant and equipment arose primarily from more rapid depreciation for tax purposes than for book purposes. DTAs from employee benefits are created by the cash-basis approach used in tax reporting versus the accrual-basis approach used in book reporting for deducting many forms of compensation, such as deferred wages.

The DTL components with the largest increases in their mean values from 1993 to 2004 were subsidiary-related items (up 4160\%), pensions (up 1156\%), merger and acquisition-related (up 474\%), and intangible assets (up 457\%). Property, plant and equipment, the largest DTL in total dollars, grew a relatively modest $66 \%$. The DTA component with the largest increase in its mean value was tax credits and other carryforwards, up 264\%.

Manzon and Plesko (2001) attempt to identify the factors that create BTDs. They analyze financial statement data from 1988-1999 for two samples: a panel of 178 firms, and an unbalanced sample with 10,702 firm-years. They measure BTDs as the difference between domestic book income (defined as NIBT from domestic sources) and an estimate of taxable income (defined as the current federal tax expense grossed up by the statutory tax rate). ${ }^{24}$ They find that an increase in sales and the amount of

\footnotetext{
${ }^{24}$ Note that Manzon and Plesko (2001) measure of taxable income is not the number on the firm's tax return. Rather, as they acknowledge, it is a tax measure estimated from the financial statements, which can be problematic. This imperfect measure of tax, arising from their inability to observe confidential tax returns, hampers their study and the many others that attempt to use tax disclosures in the financial statements to estimate taxable income or taxes paid. Throughout this paper, we distinguish between "estimated taxable income" and actual taxable income, reserving the term "taxable income" to describe the actual taxable base from the actual tax return. See Section 5 for a detailed discussion of the difficulties with using tax information in the financial statements to estimate taxable income.
} 
plant, property and equipment cause book income to exceed their estimate of taxable income. Both factors are consistent with growing firms investing in tax-favored assets, such as depreciable property. (However, as noted by Shevlin (2007), these factors can explain activities that are unrelated to sheltering as well as explain tax shelter activity). Manzon and Plesko (2001) conclude that the primary factor causing their estimate of taxable income to exceed book income is a permanent difference, the amount of pre-1993 goodwill. ${ }^{25}$

Using confidential tax returns, Plesko (2002) examines Schedule M-1 for all U.S. corporate tax returns from 1996-1998. (As mentioned above, Schedule M-1 reconciles book net income and taxable income and thus includes both permanent and temporary differences. Plesko (2002) reports that total book-tax differences (aggregated across all U.S. corporate tax returns) were \$159 billion in 1998, 20\% of aggregated net income before income taxes. Two industries contain $88 \%$ of the BTDs: the finance, insurance, real estate and rental and leasing sector (\$81 billion); and the information sector (\$58 billion). In both sectors, the ratio of BTDs to NIBT was $49 \%$, which was the highest across industries. The aggregated 1998 Schedule M-1s show:

- income subject to tax, but not on the books, of $\$ 377$ billion,

- income on the books, but not on the tax return, of $\$ 472$ billion,

- $\quad$ expenses on the books, but not deducted on the tax return of \$698 billion, including $\$ 125$ billion of depreciation, and

- deductions on the tax return that were not expensed of $\$ 744$ billion, including depreciation of $\$ 205$ billion. The net depreciation BTD of $\$ 80$ billion (\$205 billion less \$125 billion) was half of the total BTDs in 1998.

Plesko (2002) also finds that BTDs are concentrated among the largest firms. Firms with assets exceeding \$250 million accounted for 96.9\% of BTDs in 1998, a higher percentage than they represented of the nation's assets, book profits and taxable income. Interestingly, of the $\$ 66.5$ billion increase in

\footnotetext{
${ }^{25}$ Before 1993, goodwill was never deductible for tax purposes. Since then, goodwill is occasionally deductible for tax purposes.
} 
BTDs from 1996-1998, two-thirds was from loss companies, i.e., those with negative NIBT and negative taxable income. ${ }^{26}$

Several papers note the change in BTDs over the last decade. Using Compustat and tax return data from 1991-1998 for 1,579 companies, Mills et al. (2002) show that NIBT exceeded taxable income throughout the 1990s and that the disparity widened over time. The gap was greatest for financial firms and multinationals. Off-balance sheet structured transactions or special purpose entities accounted for part of the difference. Consistent with Plesko (2002), Mills et al. (2002) find that the BTDs are concentrated among the largest firms. In 1998, the largest 20\% of firms accounted for almost all the BTDs, with the 15 largest companies responsible for almost one-third of the total. Noting that by 1998 more than half of the spread between taxable and book income could not be explained by understandable differences (e.g., depreciation), Desai (2003) conjectures that the widening gap is driven by the growth in corporate tax shelters. However, Poterba et al. (2009)'s analysis suggests that this conclusion should be interpreted cautiously. They find that 73\% of the book-tax gap from 1993 to 2004 was attributable to temporary differences, and these differences grew during their sample period. We believe that a fruitful area for future research would be to study permanent differences more directly (rather than all BTDs as in Desai (2003) to see if their trend and magnitude could plausibly explain the pattern and magnitude of tax sheltering activity.

Seidman (2008) attempts to explain the factors that create the divergence between book and tax. Analyzing hand-collected firm-level information about specific book-tax differences for the Fortune 50 companies from 1995 to 2004, she reports that general business conditions, earnings management, and changes in the financial accounting rules explain $55 \%$ of the variation in book-tax differences.

Interestingly, she finds that changes in GAAP mitigated the book-tax difference, i.e., the disparity would have been even larger if the accounting rules had not changed (in particular, rules related to the accounting treatment of goodwill). Seidman (2008) concludes that tax sheltering explains less than half

\footnotetext{
${ }^{26}$ The reason that loss companies would be the primary source of BTDs is that these firms have recognized their losses on their income statements, but have not yet realized the benefit from net operating loss carryforwards on their tax returns.
} 
of the variation in book-tax differences. As mentioned above, future research into this area should consider separating permanent differences from temporary differences.

Figure 3 updates the book-tax gap through 2008. Measuring book income as pretax income adjusted for minority interests and estimating taxable income as federal and foreign tax expense divided by the maximum statutory rate, we compute the economy-wide book-tax gap from 1993 to 2008. Book income exceeds estimated taxable income in all years, except 2001 and 2008. In those two recessionary years, a precipitous drop in book income reverses the book-tax gap, leaving book income substantially less than estimated taxable income. Over the 16 years, aggregate book income is $94 \%$ of aggregate estimated taxable income. However, if the two recessionary years are excluded, aggregated book income rises to $108 \%$ of aggregate taxable income. We infer from these findings that overall economic activity is an important predictor of the book-tax gap and that generalizations about the direction of the book-tax gap depends critically on whether the period of investigation is one of economic expansion or contraction.

Examining confidential tax return data, Plesko (2004) notes that before 2001 firms were recognizing more book revenue than taxable income (although firms also were recognizing more book expenses than tax deductions). In 2001, the revenue difference evaporated due to the substantial corporate losses and book expenses far exceeded tax deductions. We find a similarly abrupt disappearance of book profits in 2008, while estimated taxable income remains relatively steady during both recessions. One possible explanation for the divergent paths for book and taxable income during recessions would be a spike in impairments, which would reduce book income, but not taxable income. We find that impairments account for about half of the reversal in both 2001 and 2008. However, the pattern of book income exceeding taxable income, except during recessions while book income plunges, remains even after adjusting for impairments.

To summarize, both financial statements and corporate income tax returns provide information useful for estimating BTDs. Key findings are that DTLs exceed DTAs, with depreciation being the largest source of temporary differences. BTDs are concentrated among the largest companies and they are concentrated in two industries, namely the financial and information industries. The gap between book 
income and taxable income widened throughout the 1990s, reversed in 2001, then widened again, only to reverse again with the 2008 recession. ${ }^{27}$ Finally, the determinants of BTDs undoubtedly include tax planning, earnings management behavior, changes in financial accounting rules, changes in firm-level sales and the level of property, plant and equipment in a given firm. However, the similarly sharp reversals in the book-tax gap in both 2001 and 2008 lead us to conclude that much of the gap is a function of the business cycle.

\section{Tax Contingency}

As discussed in section 2, the income tax expense includes future tax payments arising from revenue recognized in the current period. Those future taxes include an estimate of the taxes expected to arise from audits of the current year's tax returns. If the taxing authorities successfully challenge the firm, then the company will pay taxes in future years that are related to activity in the current period. To accrue an expense on the income statement in the year of the activity for these possible future tax payments, firms establish liabilities on the balance sheet, known as tax contingencies, which are estimates of the additional taxes that might have to be paid in the future.

Although this uncertain tax contingency account (commonly referred to as the "cushion”) is included among the other liabilities on the balance sheet, historically it has rarely been reported as a separate line item or even disclosed. Thus, the cushion has been largely unobservable to researchers (impeding scholarly work), the taxing authorities (potentially impeding their ability to detect firms that consider their tax positions potentially unsustainable under audit), or other users of the financial statements (potentially enhancing its usefulness for managing earnings).

Since 2007, a new financial reporting standard (FIN 48) has required firms to disclose the balance of the tax contingency in their financial statement footnotes. These disclosures substantially expand our understanding of the process by which firms impound the uncertainty of tax plans in their income tax

\footnotetext{
${ }^{27}$ Correlation through time or across firms with a given year (or both) can inflate $t$-statistics. As we discuss in Section 11, book-tax differences are highly correlated across firms within a given year. In Section 11 we discuss how to deal with this issue econometrically so as to mitigate potential problems with inflated $t$-statistics.
} 
expense calculation. The new disclosure has spurred several studies about the use of the cushion to manage earnings, and we anticipate FIN 48 disclosures will attract considerable scholarly attention over the next few years.

FASB's adoption of FIN 48 was controversial. Many believed that these disclosures would hurt companies because the IRS could use them to both identify firms with significant uncertain tax positions as well as use the disclosures to more effectively challenge the firms’ aggressive tax positions. ${ }^{28}$ However, the first studies in this area do not support these concerns. Frischmann et al. (2008) conduct short-window event studies around key dates leading up to and including the passage of FIN 48. They find no evidence that tax-aggressive firms (which they classify as those with large BTDs or low cash taxes paid) experience significantly negative abnormal returns, except around the release of the exposure draft. Mills et al. (2009) model FIN 48's impact on the strategic interaction between companies and the taxing authorities and show that the mandatory disclosure of a firm's tax contingency does not necessarily put the firm at a disadvantage. Their conclusions rest critically under several simplifying assumptions (the most critical of which is that all firms truthfully report their FIN 48 liabilities). Even so, their paper can be viewed as highlighting the conditions that would be required for FIN 48 to be unambiguously deleterious from the corporate perspective.

One possible reason that FIN 48 may not have had the negative impact that some anticipated (e.g., may not have provided the IRS a road map for auditing purposes) is that the FIN 48 information is of limited usefulness to the IRS. Although other users of the financial statements may value the FIN 48 disclosures, the IRS may already have better information about a company’s tax position than FIN 48 disclosures provide. In fact, Frischmann et al. (2008) document results consistent with the market’s knowing that the IRS already had superior cushion information. This may be particularly true for the largest firms, which are for the most part under constant IRS audit and review.

\footnotetext{
${ }^{28}$ Consistent with the IRS' believing that the disclosures would aid in identifying firms that had underpaid their taxes, in 2007 (the year of FIN 48's adoption) IRS official Robert Adams said that FIN 48 disclosures were the “centerpiece of our revenue agent training this year” (Messier, 2007).
} 
Although the market did not seem to view the FIN 48 requirements negatively, corporate managers may have. Blouin et al. (forthcoming) examine the behavior of firms between the enactment and the adoption of FIN 48. Specifically, they examine the number of settlements made with the IRS between enactment and adoption, as well as the number and amount of reserves that were reduced during this period. They find that firms with higher IRS deficiencies were more likely to settle during the period between enactment and adoption. In addition, they find that firms reduced their reserves more during this period than they did prior to enactment. Thus, these results provide evidence that corporate management may have been worried about increased IRS scrutiny of the FIN 48 disclosures.

Several studies provide descriptive evidence of the magnitude of the contingency account, the change in the contingency account around the adoption of FIN 48, and the quality of the disclosures in terms of completeness and clarity. Blouin et al. (2007) and Dunbar et al. (2007) evaluate the new contingency disclosures mandated under FIN 48. Examining 100 of the largest companies with at least five analysts, Blouin et al. (2007) find that the aggregate contingency balance as of December 31, 2006 (the last disclosure before FIN 48 became effective) was 1.8\% of assets. Examining 348 S\&P 500 firms, Dunbar et al. (2007) find a similar average contingency balance of 1.5\% of assets. Blouin et al. (2007) also report that more firms changed their contingency in 2006 than in 2005. Most of those changes were decreases, consistent with companies having overstated their contingency balance in the past and reversing them before FIN 48 disclosures became publicly observable by investors; however, the mean change in 2006 was not statistically different from that in 2005. For comparison, they examined 100 of the smallest firms with at least five analysts and found no differences in the frequency or the magnitude of the changes in the contingency. While both of these studies provide interesting information, their sample sizes are quite small. Thus, results may not be broadly generalizable. ${ }^{29}$ Finally, there are two studies that examine the completeness and clarity of tax contingency disclosures. Gleason and Mills (2002) examine

\footnotetext{
${ }^{29}$ Alexander et al. (2009) (2009) (2009) (2009) examine the required disclosures made prior to the actual adoption of FIN 48. The SEC requires that firms provide information about the likely effects of accounting standards that are enacted, but not yet adopted. Thus, Alexander et al. (2009) (2009) (2009) (2009) examine the information provided by firms in 2006 about the future enactment of FIN 48. Interestingly, they find that fewer than one-fifth of companies provided an estimate of the effect of the adoption of FIN 48.
} 
the disclosures made before the enactment of FIN 48. They analyze the factors that cause firms to report and/or disclose their tax contingencies. Examining the 200 largest manufacturing firms on Compustat and included in the IRS's Coordinated Industry Cases (a confidential database with tax information about some of the largest, most frequently audited companies), the authors measure a company's expected loss upon audit as the product of its potential tax deficiency (from the IRS database) and its industry-specific average settlement rate. They find that only $27 \%$ of the firms disclose a contingency, and only $30 \%$ of those companies provide the level of information required by GAAP. As would be expected, the likelihood that the firm discloses a contingency increases with the magnitude of the tax deficiency and the amount of the contingency increases with the expected loss. ${ }^{30}$ Since the study preceded FIN 48, the authors do not have access to the actual contingency amount and therefore use a very rough estimate of the contingency (domestic current tax expense less the total tax liability). As a result, the paper's results should be interpreted with caution.

Robinson and Schmidt (2009) examine the disclosures that were reported after the adoption of FIN 48. They hypothesize and find that the quality of the disclosure is inversely related to the tax aggressiveness of the firm. Robinson and Schmidt (2009) measure quality in terms of both completeness and clarity. They measure tax aggressiveness using a principle component analysis on seven measures of tax aggressiveness used in prior studies. ${ }^{31}$ Their results are interesting and based on a larger sample (643 firms in the S\&P 1500) than used in prior FIN 48 disclosure-related research. However, one important caveat is that their analysis is only performed on the disclosures included in the $1^{\text {st }}$ quarter of 2007 (i.e., the first quarter after adoption of FIN 48). Thus, it is unclear whether these behavioral patterns will

\footnotetext{
${ }^{30}$ Gleason and Mills (2007) (2007) find that auditor-provided tax services are associated with higher quality reporting of the contingency account. Specifically, they find that corporations that purchase tax services from their auditor had more fully reserved contingency balances upon IRS audit.

${ }^{31}$ See Robinson and Schmidt (2009, p. 11) (2009, p. 11) for an interesting example of the many variations of compliant FIN 48 reporting.
} 
persist after firms and the market gain a deeper understanding of a new, and somewhat, complex standard. ${ }^{32}$

\section{AFIT Misconceptions}

This section addresses two common misconceptions related to AFIT. The first relates to how well the tax information in financial statements approximates actual tax return information. The second misconception relates to the extent to which the tax information in financial statements is useful for assessing a firm’s tax choices.

To shed light on the first issue, we review several studies that attempt to assess how well the tax information in financial statements approximates actual tax return information, e.g., the actual amount of taxes paid, taxable income, and loss and credit carryforwards. The literature identifies numerous reasons that book information could be a poor proxy for tax information and emphasizes that, under certain circumstances, the book numbers can lead to misleading and erroneous inferences, e.g., that a firm is paying substantial taxes when it is actually paying none. ${ }^{33}$ The extent to which the mismeasurement adversely affects research, markets, policy, and practice is not well understood.

Before we proceed, it is important to note that for many research questions the relevant tax measure is the tax information in the financial statements, not an estimate of actual taxes paid computed using the tax information in the financial statements. For example, suppose the research question is: Do

\footnotetext{
${ }^{32}$ Several studies address tax shelter/ tax avoidance issues in the context of FIN 48 . While we briefly mention them here, they are beyond the scope of this review. Lisowsky (2009b) (2009b) (2009b) develops a model of the likelihood of a firm engaging in tax sheltering behavior. The study finds that the uncertain tax liability is significantly related to the use of tax shelters. In a similar study, Wilson (2009) takes data from companies known to use tax sheltering to reduce their tax burden and develops a profile of the type of firm likely to use a tax shelter. He finds larger BTDs and more aggressive financial reporting practices among firms with the shelter profile. Song and Tucker (2008) find that certain variables (size, profitability, levels of research and development, growth, levels of general expenses, and levels of debt) that are typically associated with tax shelter activity are also associated with the tax contingency balance. The authors infer that the reported contingencies are indicators of tax sheltering activity. Gupta et al. (2009) (2009) provide evidence consistent with firms reducing their multistate tax avoidance in response to FIN 48 reporting requirements.

${ }^{33}$ For an example of firms reporting large income tax expense but not paying any taxes, see Graham et al. (2004) and Sullivan (2002), who provide evidence that many technology stocks in the late 1990s paid no (or very little) taxes because of huge employee stock options deductions, even though they reported substantial current income tax expenses.
} 
firms manage earnings through the income tax expense? The income tax expense from the financial statements, not an estimate of the actual taxes paid, is needed to answer this question. In fact, even if a researcher had access to the firm's tax returns, she would still use the income tax expense from the financial statements to answer this earnings management question. That said, to answer many questions, the researcher wants to estimate the actual taxes paid and therefore must rely on the financial statements. This section discusses the usefulness of the tax information in the books to provide such estimates.

Our discussion of the second issue (i.e., how useful is the tax information in the financial statements for evaluating the effectiveness of a firm's tax planning) centers on three limitations to assessing a firm's tax position based on the tax information in financial statements. Specifically, we discuss the failure of the tax information in the financial statements to report implicit taxes, non-tax costs, and discounted deferred tax accounts.

\section{a. How Well Does the Tax Information in Financial Statements Approximate Actual Tax Return Information?}

\section{i. Book-tax comparisons}

For many studies, the primary use of the tax information in the financial statements is to estimate the actual tax information on a tax return, usually the U.S. Federal tax return. ${ }^{34}$ Often, no other information is available to estimate the actual taxes. The purpose of this section is to identify the hazards of using tax information from the financial statements to estimate actual taxes on the tax return.

Hanlon (2003) thoroughly analyzes the difficulties in using the income tax expense on the income statement to infer actual tax information. ${ }^{35}$ The income tax expense on the income statement is dichotomized into current and deferred amounts. The deferred portion is the amount of expense that is attributable to temporary timing differences and, thus (at least conceptually) will result in future tax

\footnotetext{
${ }^{34}$ We recognize that firms file tax returns in many countries and other jurisdictions. However, throughout this paper, we will generally refer to the U.S. tax return as the tax return of interest and the U.S.'s Internal Revenue Service as the representative taxing authority.

${ }^{35}$ For a similar analysis of data from pre-SFAS No. 109 years, specifically 1979 to 1981, see Dworin (1985).
} 
payments. The remainder is the current income tax expense. Researchers sometimes use the current income tax expense on the income statement as a measure of the firm's confidential, and thus unobservable, current income tax liability on its tax return. As discussed above, a common approach to estimating taxable income as reported on the tax return is to gross up the current tax expense by the statutory tax rate. Hanlon (2003) identifies the following problems with this approach:

- Current tax expense rarely equals the actual taxes paid. Financial statements are usually filed months before the tax return is submitted. ${ }^{36}$ Thus, the tax information in the financial statements is only an estimate of the eventual numbers in the actual tax return. Even if the tax information in the financial statements perfectly anticipates the eventual numbers in the actual tax return, the current income tax expense in the financial statements will rarely equal the actual taxes paid. The reason is that the income tax expense must include an estimate of the taxes that will be paid under IRS audit, if detected. By definition, these potential future taxes are not reported in the tax return.

- The income tax expense reported separately on the income statement (and used to estimate taxable income) does not include all of the book income tax expense. Income from discontinued operations, extraordinary items, prior period adjustments, and other comprehensive income are not considered part of the ongoing activities of the firm; thus, they are reported separately in the income statement. Furthermore, these “below-the-line” items are reported net of any income taxes that they generate, a process called intraperiod tax allocation. Consequently, even though net-of-tax transactions affect actual taxes, the tax expenses related to them are excluded from the income tax expense that is commonly used to estimate actual taxes paid. ${ }^{37}$ The current income tax

\footnotetext{
${ }^{36}$ For example, a calendar-year end company must file its U.S. tax return by March 15. However, the filing date for the U.S. tax return can be and typically is extended six months to September 15. In contrast, large calendar-year firms must file their complete financial statements $(10-\mathrm{K})$ with the SEC by the end of February.

${ }^{37}$ Lisowsky (2009a) (2009a) (2009a) reports that the inability to observe the taxes imbedded in below-the-line items does not introduce substantial error into estimates of the U.S. tax liability. He regresses firms' actual U.S. tax liabilities, as reported on confidential tax returns, on various financial statement measures including a categorical variable that equals one if the absolute value of discontinued operations as a percentage of income from discontinued operations and extraordinary items exceeds $5 \%$. He finds that the estimated regression coefficient on the categorical variable is not significant, which he interprets as evidence that ignoring the taxes related to "belowthe-line" items is not particularly problematic in estimating actual taxes paid. It may be an overstatement, however, to infer from this analysis that below-the-line items are irrelevant in estimating taxes paid. Lisowsky (2009a)
} 
expense is reported after subtracting tax credits, which are not disclosed in the financial statements. Thus, using the statutory tax rate to gross up current income tax expense produces a measure that is less than actual taxable income. ${ }^{38}$

- The books and the tax returns often report information about different entities because the consolidation rules differ for book and tax. Two of the key differences are:

1. Books generally require consolidation of entities with common ownership of more than $50 \%$, while tax law only permits consolidation of firms with at least $80 \%$ common ownership.

2. Regardless of common ownership, foreign subsidiaries are never consolidated for tax purposes. GAAP makes no distinction between domestic and foreign subsidiaries.

This is not a complete review of the issues raised in Hanlon (2003). ${ }^{39}$ For brevity, we have only highlighted a few key insights, and we refer interested readers to her paper as well as Lisowsky (2009a) and Frank (2009) for further discussion of the difficulties in inferring U.S. tax liabilities from financial statement information. ${ }^{40}$ Nonetheless, this list provides a sense of the key issues.

Despite the many concerns that Hanlon (2003) raises, in some cases it is still possible that the book numbers may provide a reasonably good measure for estimating the taxes on the tax return. To assess how deleterious the book limitations are, we look to studies that compare the tax figures reported in the books with the actual tax information in the tax returns. Few such studies exist because access to confidential tax returns is difficult to obtain and limited to specific projects and researchers approved by the IRS. Furthermore, while access to corporate tax returns provides information that cannot be observed

(2009a) (2009a) ignores all below-the-line items except large discontinued operations, and only uses a categorical variables to identify those items. Thus, further analysis is warranted before dismissing below-the-line items when using financial statements to estimate the total tax liability.

${ }^{38}$ To prove, assume book and tax accounting are identical, the firm’s taxable income is $\$ 100$, its statutory tax rate is $30 \%$ and it has $\$ 10$ of credits. Then both its actual tax liability and its current income tax liability are $\$ 20$. If the $\$ 20$ is grossed up by the statutory tax rate of $30 \%$ then the estimated taxable income is \$67 or \$33 less than actual. ${ }^{39}$ One complex issue that we ignore is inferring the tax deductions from exercising employee stock options. See Hanlon and Shevlin (2002) for an excellent analysis of the problems associated with this estimation process.

${ }^{40}$ See McGill and Outslay (2002) for an excellent, detailed analysis of the difficulties in determining Enron's tax status from its financial statements, and see McGill and Outslay (2004) for a more general discussion of the difficulties of using financial statement to identify tax shelter activity. 
using publicly available data, these studies still face many of the Hanlon (2003) limitations. For example, if the consolidated firms in the tax return differ from the consolidated firms in the financial statements, then seemingly analogous measures, such as pre-tax book income and taxable income, are not comparable and must be adjusted, if possible. Nonetheless, studies with access to actual corporate tax returns provide valuable information about how closely the tax information in the financial statements approximates actual tax return information.

Using confidential IRS audit information for 219 firms from 1981 to 1995, Mills et al. (2003) assess the measurement error arising from using the net operating loss (NOL) measure on the books to identify firms that have NOL carryforwards on their tax returns. ${ }^{41}$ Their findings are encouraging; a firm with a book NOL carryforward and either a negative current income tax expense or a negative pretax book income is highly likely to have an NOL carryforward on its tax return.

Graham and Mills (2008) access tax return data and simulate corporate marginal tax rates using the method of Shevlin (1987) and Graham (1996) to account for dynamic features of the tax code. ${ }^{42}$ They simulate marginal tax rates (MTRs) based on the tax return information for 3,667 companies during 1998 to 2000. The authors perform a "horse race” by comparing these tax return tax rates with MTRs based on financial statement data, using several different definitions as well as simulation techniques to calculate several different MTRs based on book information. The correlation between tax return-simulated and book-simulated MTRs is about 70\%, which is the strongest relation to the tax return MTR for any of the tax rates that are based on financial statement data. The authors conclude that simulated MTRs based on financial statement data are reasonable approximations of MTRs based on tax return data. Again, this is encouraging and implies that tax return effects can be reasonably approximated with financial statement data. In addition, they provide a summary table of the different tax rates that researchers should consider using depending on the research question that they face.

\footnotetext{
${ }^{41}$ Note that because book income does not necessarily approximate taxable income, a firm may have an NOL carryforward for tax purposes but not exist for book purposes or vice versa.

${ }^{42}$ See Blouin et al. (2008) (2008) and Graham and Kim (2009) (2009) for alternative methods of simulating future taxable income to use in the estimation of corporate marginal income tax rates.
} 
Plesko’s (2006) findings are less encouraging to researchers who look to the tax information in the financial statements to estimate actual taxes on the tax return. He compares financial statements and actual U.S. tax returns from 1994 to 2001 (37,853 firm-years) to determine whether financial reporting information allows a user to infer information about a firm's tax attributes. Using a modified Jones (1991) model, Plesko (2006) compares discretionary financial accounting accruals with discretionary tax accruals. He contends that if book and tax are identical in all regards, they will move together. To the extent they are unrelated, a change in one has little effect on the other. Finding limited correlation between discretionary financial reporting accruals and discretionary tax accruals, Plesko (2006) concludes that financial statement disclosures do not convey much information about a firm's tax attributes. To summarize, much is known about differences between book and tax accounting and the difficulties in inferring information about the tax return from the tax information in the financial statements. Unfortunately, we know less about whether using the best publicly available firm-level tax data, i.e., the financial statements, leads to minor mismeasurement or substantial errors in scholarship, practice, and policy. ${ }^{43}$ In the meantime, in light of the scarcity of alternative sources of firm-level tax information, researchers will often have no choice but to continue to rely on the tax information in the financial statements. The good news is that as Mills et al. (2003) and Graham and Mills (2008) show, AFIT may provide reasonably good estimates of the actual taxes paid. However, we encourage producers and consumers of research to consider the limitations of the tax information in the financial statements and to interpret scholarly findings with caution.

\section{ii. Other issues}

This section discusses three topics that are related to the use of the tax information in the financial statements. First, even though we just detailed several problems with using tax information in the financial statements to estimate actual taxes paid, as mentioned above, for most research questions in this literature these problems are irrelevant because the tax information in the books is the correct tax

\footnotetext{
${ }^{43}$ See Frank (2009) for a review of the literature assessing the level and impact of potential mismeasurement.
} 
information. For example, suppose the research question is: Do investors use the tax information in the financial statements? Or, how do analysts value corporate tax shelters? Since neither investors nor analysts can observe the actual tax returns, it is the tax information in the financial statements that the researcher needs to answer these questions. For these types of questions and many other typical AFIT questions, the tax information in the financial statements provides the correct data. No adjustments are needed to estimate actual taxes paid. In fact, how well the tax information in the financial statements estimates the actual taxes paid is tangential to these questions.

Second, note that even researchers with access to U.S. tax returns struggle to link a multinational firm's financial statements to its U.S. tax return. The reason is that the financial statements are designed to provide information about the entire enterprise, both domestic and foreign, while the tax returns are jurisdictionally based (for example, U.S. tax returns reflect U.S. taxes levied on U.S. activities). Furthermore, even if the financial statements dichotomize net income and tax expense into U.S. and foreign parts, the U.S. tax information in the financial statements does not necessarily purge the impact of multinational activities. For example, as we detail in Section 6, foreign profits may trigger U.S. taxes. In those cases, U.S. book income will not include the profits from foreign operations. However, U.S. tax expense will include the taxes on those foreign profits. Thus, the U.S. ETR may be overstated because the foreign profits are in the foreign grouping, but the U.S. tax expense on those foreign earnings is in the domestic grouping. ${ }^{44}$

Finally, as noted in Section 2, there is tax information in the statement of cash flows. The account is cash taxes paid and, on the surface, this would appear to be a superior measure of the actual

\footnotetext{
${ }^{44}$ We would welcome a study that gained access to non-U.S. tax returns and attempted to map the tax information in those returns to the tax information in the financial statements. Given that studies comparing U.S. tax returns and financial statements shed light on the extent to which financial statements are useful for estimating U.S. tax payments (e.g., Plesko (2002)), a study of non-U.S. tax returns would enable us to assess the usefulness of foreign tax information in the financial statements for estimating foreign tax payments. Understanding the usefulness of the foreign tax information would make a valuable contribution because the foreign tax provision is commonly used in studies of tax haven activity, transfer pricing, treaty shopping, and other international tax maneuvers and also in studies of the impact of deferral, foreign tax credit limitations, and the inability to offset one country's losses against another country's gains on business decisions. Finding that the foreign tax information in the financial statements reasonably matches the actual foreign tax payments would allay concerns that these studies of international tax choices employ a flawed (and potentially misleading) measure.
} 
taxes paid on that year's tax returns. Unfortunately, it includes all taxes paid to all jurisdictions during the current year, regardless of the year of the tax return, and is net of refunds. For example, suppose that in 2008, the IRS and a company settle an audit triggered by a 1998 tax shelter. The taxes (or refund) resulting from that settlement will appear in the cash taxes paid account in the 2008 statement of cash flows. Therefore, this measure does not capture the actual taxes paid on the current year's tax return. ${ }^{45}$ Moreover, as with the tax expense on the income statement, taxes on the statement of cash flows might contain data from foreign jurisdictions, which reduces its value for assessing U.S. tax return information.

That said, Dyreng et al. (2008) use cash taxes paid to measure the net taxes paid over a ten-year period. Mismeasurement associated with the timing of cash taxes paid is mitigated in this setting because the longer the period, the less likely it is that a large settlement in a single year would distort an approximation of the firm's actual taxes paid. This holds true for income tax expense, as well. While they make progress on the temporal issue, Dyreng et al. (2008) do not address the jurisdiction issue. Ideally, studies in this area would either address jurisdiction directly or at least confirm their results on subsamples of firms for which jurisdictional issues most likely are minor (e.g., a U.S.-only sample or a sample of firms with no foreign tax credits).

\section{b. How Useful is the Tax Information in the Financial Statements for Assessing the Effectiveness of a Firm's Tax Planning?}

This section discusses three reasons why AFIT rarely produces sufficient information to conduct a comprehensive analysis of the effectiveness of a firm's tax planning. In fact, even if financial statements were to provide perfect information about the content of the firm's tax return, they would still provide an incomplete picture of how well the firm manages its tax function. The reason is that AFIT

\footnotetext{
${ }^{45}$ The income tax expense also suffers from an imperfect match between the profits in one year and the taxes attributed to those profits in that year. The reason is the income tax expense includes an estimate of future taxes attributed to the current year's economic activity. At some point, the uncertainty about those future taxes will be resolved and that future year's income tax expense will be adjusted to reflect the differences between the eventual tax settlement and the tax reserves.
} 
does not report (and indeed is not intended to provide) information about implicit taxes and non-tax costs, and AFIT does not discount the deferred tax accounts.

First, the income tax expense in the financial statements is limited to explicit taxes. Since AFIT ignores implicit taxes (the reduced returns an investor earns on favorably taxed investments), it is difficult to assess the full cost (tax and non-tax) of a transaction based just on financial statement data. ${ }^{46}$ As proof, suppose a firm invests in tax-exempt municipal bonds. Because of the tax-exemption, the interest income from municipal bonds is less than the interest income from equally risky, fully taxable bonds (because investors bid up the price of the tax-exempt bonds because they are tax-advantageous). Suppose that after-tax book profits from investing in municipal bonds were identical to those from investing in taxable bonds. In this case, the tax expense and the ETR would be lower if the firm invested in municipal bonds than they would be if the firm was invested in fully taxable bonds since AFIT ignores implicit taxes. Furthermore, even if the firm's after-tax profits were lower because it invested in municipal bonds, the tax expense would remain lower and, under certain conditions, the ETR would also be lower. ${ }^{47}$ In other words, there are cases where the tax information in the financial statements can mask poor tax planning. In short, a naïve analysis of tax information in a firm's financial statements might conclude that the firm is well-managed from a tax perspective, when that is not the case.

Second, AFIT does not produce sufficient information to assess the non-tax costs of tax minimization (see Scholes et al. (2009) for a thorough discussion of tax and non-tax costs). For example, if a bank sells real estate that has depreciated in value, the realized loss will reduce its taxable income, but

\footnotetext{
${ }^{46}$ Implicit taxes are reflected in the reduced before-tax rates of return earned on tax-advantaged investments (see Scholes et al. (2009)). For example, the yield on a municipal bond, which is exempt from federal taxation, is less than a similarly risky, fully taxable corporate bond. This reduction in the return on the tax-advantaged municipal bond is an implicit tax. Implicit taxes arise throughout the economy when similar assets are taxed differently. Ignoring these implicit taxes can lead to erroneous inferences about the effectiveness of a tax plan. See Jennings et al. (2009) (2009) for a recent analysis of implicit taxes.

${ }^{47}$ After-tax returns will be larger if the implicit tax rate exceeds the explicit tax rate, but the ETR also may be larger. For example, assume the firm's tax expense is 100 and its pre-tax income is 500, leaving 400 of after-tax profits and an ETR of $20 \%$. If a firm invests in $\$ 1,000$ in municipal bonds paying 6\%, its tax expense will remain 100 and its pre-tax income will increase to 560. Its after-tax profits will now be 460, and its ETR will fall to $17.9 \%$. Conversely, if the firm invests $\$ 1,000$ in fully-taxable bonds paying $10 \%$ and its tax rate is $30 \%$, then the firm's income tax expense will rise to 130 and its pre-tax income will be 600 . Its after-tax profits will be 470 and its ETR will increase to over $21.7 \%$. In other words, by investing in fully taxable bonds, the firm has increased its after-tax profits, but also its ETR.
} 
it also will deplete its regulatory capital. It is possible that the costs associated with a reduction in regulatory capital could exceed any tax benefits from the realized loss. ${ }^{48}$ If so, the firm should hold the asset, pay higher taxes, and report more tax expense on the income statement. If a company were to follow this course of action, a naïve analysis of the information produced by AFIT might erroneously suggest that the firm's tax planning is ineffective.

Third, AFIT ignores the time value of money. Since tax deferral is a primary means of reducing the net present value of taxes, the (undiscounted) deferred tax accounts make it difficult for tax analysts to assess the timing of the firm's future tax payments. Section 7 discusses this issue in more detail.

To summarize, to the chagrin of tax researchers and other users of the financial statements who attempt to evaluate the effectiveness of a firm's tax plans, financial statements are not designed for ideal evaluation of a company's tax policy or even the full tax implications of a particular transaction.

Although the financial statements provide users with substantial and important information about a firm's tax situation, they do not provide all of the information that would be required to undertake a comprehensive review of the effectiveness of the firm's tax planning.

\section{Earnings Management}

The remainder of the paper examines existing AFIT research, identifies areas that warrant additional inquiry, and proposes extensions. We begin with the primary area of AFIT empirical research, the study of whether, how, and why companies use GAAP-based tax accounts to manage earnings. All but a handful of the studies in this area have focused on two specific tax accounts: the valuation allowance and the income tax contingency. These studies look for evidence that managers manipulate these accounts in a manner consistent with achieving certain financial reporting objectives. ${ }^{49}$ In general,

\footnotetext{
${ }^{48}$ See Scholes et al. (1990), Beatty et al. (1995), and Collins et al. (1995) for evidence that banks forgo tax reductions in cases where these reductions would adversely affect their regulatory positions.

${ }^{49}$ Note that when managers manipulate balance sheet accounts, an income statement account is affected by the same amount. In the context of AFIT research, the affected income statement account is the income tax expense account.
} 
the evidence suggests that managers use these accounts to meet (or beat) analysts’ forecasts, but not to meet (or beat) prior earnings or to smooth earnings.

\section{a. Studies of Earnings Management Using the Valuation Allowance}

As discussed above, when managers believe that some or all of the future tax benefits of a deferred tax asset (DTA) will never be realized, they establish a valuation allowance account as an offset against the deferred tax asset account. Before exploring whether firms manipulate these accounts to manage earnings, two early papers studied how firms compute the VA. Behn et al. (1998) create proxies for the four sources of income that are supposed to be considered in estimating the VA. ${ }^{50}$ They determine that all four sources of income are statistically significant determinants of the VA balance (as a percentage of the DTA balance) in 1993, although the income sources explain less than half of the variation in the VA account, suggesting that other factors are also at work.

Another early study, by Miller and Skinner (1998), hypothesizes that firms with (1) greater expected future taxable income and (2) more DTLs (relative to DTAs) should be more likely to realize their DTAs and thus should have smaller VA balances. They also hypothesize that firms with larger carryforwards should be less likely to realize their DTAs and thus should have larger VA balances. Miller and Skinner (1998) find support for these hypotheses, which they test by determining the amount of DTLs the firm has relative to their DTAs, an association between future taxable income and the portion of the firms' DTAs that are attributable to loss and/or credit carryforwards because tax law places time limitations on the realization of these tax benefits. We note that Miller and Skinner (1998)'s support for the association between the VA and expected future taxable income is weak. They do find a very strong association between the VA and the amount of the DTA attributable to carryforwards, indicating that limitations of carryforwards are a primary determinant of the valuation allowance.

\footnotetext{
${ }^{50}$ Recall from Section 4 that GAAP lists four possible sources of income that managers should consider when they estimate how much of the DTA will not be recovered: (1) future reversals of existing taxable temporary differences, (2) future taxable income, (3) taxable income in carryback periods, and (4) the existence of tax-planning strategies (FASB, 1992).
} 
A recent study by the Federal Reserve Board concludes that there is substantial variation in the practice of establishing valuation allowances (Lindo, 2009). Surprised by the lack of increases in banks' valuation allowances during the recent financial crisis, the Federal Reserve Board reviewed the December 31, 2008 audit working papers for 15 banks with DTAs. The sample banks varied by asset size, coverage ratios, and financial strength and were audited by 10 different firms. The Board found that most banks were not establishing a VA if positive taxable income was anticipated during the next two to six years. At the extreme, two banks took the position that no VA was required if positive taxable income was expected within 10 years; notably, one of those banks failed soon thereafter. The study also documented a wide range of approaches to estimating future taxable income.

This considerable subjectivity in the determination of the VA suggests that it may be an attractive account for managing earnings. ${ }^{51}$ Since changes in the VA account typically flow through the income tax expense, manipulation of the VA account could be an effective means of earnings management. On the other hand, to the extent managers wish to camouflage their earnings management, other accounts may dominate the VA because firms must report the amount of the VA in the footnotes to their financial statements. In other words, the visibility of the VA may diminish its usefulness in earnings management. Research in this area examines a variety of possible earning management objectives including reporting smooth earnings, taking big baths, creating “cookie jar” reserves, and meeting various earnings targets. Largely, these studies provide little evidence that the valuation allowance is used to manage earnings with one exception: firms appear to use the VA to meet or beat analysts' forecasts.

Both Visvanathan (1998) and Miller and Skinner (1998) test the hypothesis that the change in the valuation allowance account is associated with managers' incentives to smooth earnings. ${ }^{52}$ Both studies regress the change in the VA on the change in income. ${ }^{53}$ They suggest that if managers use the VA to smooth earnings then the coefficient on the change in earnings should be positive because a positive

\footnotetext{
${ }^{51}$ See Khalaf (1993) for a brief discussion of the subjectivity of the VA account.

${ }^{52}$ Besides testing for earnings smoothing behavior, Miller and Skinner (1998) predict that highly levered firms are less likely to book a large VA because they have incentives to increase income. However, the authors find no support for this hypothesis.

${ }^{53}$ Visvanathan (1998) computes change in income excluding the effects of the change in the VA.
} 
(negative) change in earnings would result in an increase (decrease) in the VA. Neither study finds results consistent with the smoothing hypothesis; thus, this evidence is not supportive of firms' using the VA to smooth earnings.

That said, there are several reasons why readers should be cautious in accepting these conclusions. ${ }^{54}$ First, both sample sizes are small. Second, the samples include a narrow set of firms so it is not clear whether the results are generalizable. Third, both samples cover only the two or three years immediately following the effective date of SFAS No. 109. Specifically, Visvanathan (1998) examines 105 (182) observations in 1993 (1994) from firms in the S\&P 500 that had changes in their VA account. Attempting to focus on firms with large deferred tax asset balances, Miller and Skinner (1998) study 200 observations of firms that took large other post-employment benefit charges upon the adoption of SFAS No. 106. In addition,, the actual tests for smoothing (based on the coefficient on the change in earnings) are potentially problematic because more than one year of data is needed to construct a powerful test of smoothing. Earnings smoothing is inherently a time series phenomenon. A powerful test of smoothing would use many years (or quarters) of earnings data to examine the firm-specific pattern of earnings.

Three studies (Bauman et al. (2001), Christensen et al. (2008), and Frank and Rego (2006)) address the research question of whether firms use the VA to increase the magnitude of a big bath. ${ }^{55}$ Examining a limited sample of 62 firms, Bauman et al. (2001) find that the association between the income effect of the change in the VA and the amount of the loss (excluding the VA income effect) is consistent with a big bath story. That is, firms appear to overstate the VA when they face large losses from other operations. However, they cannot rule out a very likely alternative explanation, namely that firms with big losses are less likely to realize their DTAs and thus should increase their VA. Christensen et al. (2008) take a different approach. In an attempt to identify big-bath firms, they examine a sample of firms that reported large write-offs from 1996 through 1998. They compute unexpected VA (scaled by DTA) using VA determinants identified by Behn et al. (1998) and Miller and Skinner (1998). They then

\footnotetext{
${ }^{54}$ Miller and Skinner (1998, p. 232) acknowledge that their tests of earnings management are weak.

${ }^{55}$ The term "big bath" refers to a scenario where the firm accelerates as many expenses as possible into the current year (and defers as much revenue as possible), with the goal of enhancing future profitability.
} 
compare the unexpected VA balances for their sample with the unexpected VA balances for a control sample of firms without large write-offs, matched on industry and size. If the unexpected VA balances for their sample are larger than those for the control sample, they infer that firms are using the VA account to increase the magnitude of the big bath. Results are mixed. Thus, it is unclear whether the firms believed to be big-bath firms used the VA to decrease their income even more in the write-off year. Besides the problem of the alternative explanation of the results in Bauman et al. (2001), the analyses in both Bauman et al. (2001) and Christensen et al. (2008) are largely univariate, further limiting the conclusions that can be drawn.

Frank and Rego (2006) provide a thorough and well-executed study that provides strong evidence that companies do not use the VA to enhance a big bath. (We discuss Frank and Rego (2006) in more depth below.) After joint evaluation of Bauman et al. (2001), Christensen et al. (2008), and Frank and Rego (2006), we conclude that the extant literature provides no conclusive evidence that mangers utilize the VA account to enhance the magnitude of a big bath.

Schrand and Wong (2003) investigate whether firms use the VA account to create hidden reserves. They examine whether banks (which tend to have large DTAs) created reserves when they initially set up their VA accounts at the adoption of SFAS No. 109. They reason that in future years the bank could remove the reserves, reducing the VA account and increasing book earnings in the process. In their tests, the authors regress the VA on disincentives for earnings management, as measured by inadequacy of a bank's regulatory capital. If bank capital adequacy is low, the authors posit that banks are less likely to decrease current income by increasing the VA (which would thereby create hidden reserves). The authors find little evidence that banks established hidden reserves. While the study is definitive with respect to banks, its generalizability is limited.

Finally, three studies examine whether managers use the VA to meet (or beat) various earnings targets. Frank and Rego (2006), Schrand and Wong (2003) and Bauman et al. (2001) test whether firms use the VA to meet (or beat) prior earnings and analysts’ forecasts. Frank and Rego (2006) and Bauman et al. (2001) also test whether firms use the VA to avoid reporting a loss. 
Schrand and Wong (2003) find that banks use changes in the VA account to meet both prior earnings targets and analysts' forecast targets, though the latter result is weaker. In contrast, Bauman et al. (2001), in their study of 62 Fortune 500 firms that reported a change in VA during 1995-1997, find no evidence that managers use the VA to meet positive earnings or prior earnings. However, they do find some evidence that managers use the VA to meet analysts' forecasts.

Frank and Rego (2006) examine 2,243 firm-years from 1993 through 2002 to test for earnings management in the form of meeting earnings targets. They first regress the VA on previously identified determinants of the VA account. The residual is their measure of the unexpected (or discretionary) change in VA. They then regress the unexpected VA change on three measures of the amount by which the adjusted earnings of the firm (i.e., the earnings excluding the income effect of the discretionary change in the VA) miss the first target, positive earnings. They repeat the process for three measures of prior earnings and analysts' forecasts. This results in nine independent variables (3 measures for each of 3 targets). For each target, they include three categorical variables that indicate adjusted earnings are: (1) below the target by a large amount, (2) below the target by a small amount; or (3) above the target by a large amount.

Frank and Rego’s (2006) predictions assume that firms will overstate the VA if pre-managed earnings are higher than the target and understate the VA if pre-managed earnings are lower than the target. For example, if the firm uses the VA account to provide a small boost to earnings to meet the target, then the coefficients on the indicator variables that measure whether the adjusted earnings are slightly below the target will be negative since firms will be decreasing the VA in order to increase earnings. Based on these tests, Frank and Rego (2006) find no evidence that the VA is used to avoid losses or to meet earnings targets based on prior earnings. They do, however, find strong evidence that managers use the VA to meet (or beat) analysts' forecasts. Given the comprehensive nature of the Frank and Rego (2006) study, we conclude that managers do not use the VA to avoid losses or to meet prior earnings targets but that they do use the VA account to manage towards analysts' forecasts. Banks, 
however, may be different, given Schrand and Wong’s (2003) finding that banks manage towards prior earnings.

To summarize, the VA-earnings management studies provide somewhat mixed evidence as to whether managers use the VA account to manipulate earnings. There is no evidence consistent with smoothing behavior; however, recall that there is room for sample composition and other empirical improvements in this area. While there is mixed evidence that firms use the VA to increase their losses in a big bath, the most comprehensive study, Frank and Rego (2006) concludes that the VA is not used in this manner. Similarly, there is limited evidence that managers use the VA to avoid losses and meet prior earnings. Meeting or beating analysts' forecasts is the only setting where there is consistent evidence that nonfinancial managers use the VA to manage earnings. ${ }^{56}$ Finally, we note that these overall findings are consistent with Raedy and Wilson (2009) who find that managers use earnings discretion to achieve analysts' forecast targets (as opposed to other forms of earnings management) when the firms' primary stakeholders are equity investors (as is the case in the United States).

\section{b. Studies of Earnings Management Using the Tax Contingency Account}

Scholars also study the uncertain tax contingency account for evidence of earnings management. As discussed in section 5, the "cushion" is booked when a company takes an uncertain tax position on its tax return. The contingency balance is an estimate of how much the company will ultimately remit to the government related to the aggressive tax position taken. Since this estimate is subjective, it could allow for considerable manipulation.

\footnotetext{
${ }^{56}$ The papers in this section address the use of the tax accounts to manage earnings. A related literature, which is beyond the scope of this paper, explores the usefulness of the tax accounts to detect earnings management. Some examples include Phillips et al. (2003), who test whether the use of the deferred tax expense balance can help identify earnings management behavior incremental to using various existing accrual models to identify earnings management. They find that it can. Phillips et al. (2004) follow by examining which of the components of deferred tax expense are incrementally useful in identifying earnings management behavior. Building on these two papers, Joos et al. (2005) (2005) add that consideration of the level and change of deferred taxes can indicate both the conditions under which earnings management is more likely (when book income is smaller than taxable income) and the strategies that managers use to achieve certain earnings targets.
} 
Gupta and Laux (2008) use footnote disclosures from 2003 to 2005 (before FIN 48) to test whether companies reduced their tax cushion to meet or beat prior earnings and analysts' forecasts. ${ }^{57}$ From a random sample of 100 companies in the Fortune 500, they identify firm-quarters during which reversals in the tax contingency were reported. (Note that a reversal of the tax contingency results in an increase in income). They regress the amount of the cushion reversal on the amount by which earnings (adjusted for the amount of the cushion reversal) are less than the earnings target. The authors infer that firms manage the contingency account to beat analysts’ forecasts.

A strength of this paper is that it uses pre-FIN 48 data. Since the passage of FIN 48 (and thus the requirement that firms disclose their contingency balances) could cause a change in behavior, this is a useful analysis. A limitation of the paper is that before FIN 48 firms self-selected into disclosing the contingency. In an attempt to address this endogeneity, the authors utilize a two-stage analysis, with the first stage modeling the decision to disclose.

To our knowledge, no paper directly tests whether the contingency account is used to manage earnings post-FIN 48. However, some indirect evidence about earnings management can be gleaned from Blouin et al. (forthcoming). As discussed above, Blouin et al. (forthcoming) examine the number of settlements made with the IRS during the period between enactment and adoption of FIN 48, as well as the number and amount of reserves that were reduced during this period. When firms adopted FIN 48 (as of January 1, 2007 for calendar year-end firms), these companies had to adjust their contingency in accordance with the new rules under FIN 48 and they had to adjust their beginning shareholder's equity by the same amount. However, if firms adjusted their contingency in 2006 before FIN 48 became effective, then changes in the contingency balance flowed through income with a decrease (increase) in

\footnotetext{
${ }^{57}$ Blouin and Tuna (2007) (2007) also attempt to test for earnings management of the contingency before FIN 48. The problem that they faced, and a key reason why scholars had shied away from studying this interesting question, is that before FIN 48, the cushion disclosure was not required. Thus, it had to be estimated, and any error in the estimate could potentially render the study's findings meaningless. Blouin and Tuna (2007) (2007) measure the cushion as the difference between the current tax expense and the current tax liability with adjustments for stock options deductions. As evidence that they measure the cushion with error, for a small subsample of firms that disclosed their contingency balance, they find the correlation between the disclosed amount and the cushion amount that they estimated is only $40 \%$.
} 
the contingency increasing (decreasing) earnings. Thus, firms facing a decrease in their cushion had an earnings-based incentive to decrease the contingency in 2006. If they had waited until 2007, the adjustment would have flowed directly to their opening equity balance without affecting net income. Blouin et al. (forthcoming) find limited evidence that IRS settlements were associated with earnings management behavior. A logit analysis of the probability of settlement finds marginal evidence that a firm would have settled in the period between enactment and adoption, if the analysts' forecasts would have been missed without a reduction in tax expense. They find no evidence that they reduce the reserve account to meet analysts’ forecasts.

Testing for earnings management through the contingency account is not the primary purpose of Blouin et al. (forthcoming) and thus it is unfair to criticize their paper for its shortcomings in shedding light on earnings management. However, in the spirit of learning from their work, note that Blouin et al. (forthcoming) suffers from at least three weaknesses. First, the earnings management tests are somewhat weak. In particular, the measures used to capture the incentive to manage earnings (primarily a dummy variable that equals 1 if the firm would have missed the analysts' forecasts without a reduction in the tax expense) do not consider whether the reduction in the reserve balance actually allowed the firm to meet the forecast. The reason for this omission is that the actual decrease in the reserve account is not always included in the disclosures. Second, the sample size is only 100 firms, limiting the study's generalizability. Third, this is a study that is primarily about possible opportunistic behavior at adoption of the standard, rather than ongoing earnings management behavior, where the latter is of more ongoing interest. In summary, we know little about the use of the tax contingency to manage earnings on an ongoing basis and, in particular, whether this behavior occurs since the effective date of FIN 48. 


\section{c. Studies of Earnings Management Using the Discretion in Reporting the U.S. Tax Expense on Foreign Profits}

Another AFIT opportunity to manage earnings involves the reporting of U.S. taxes on foreign profits. APB No. 23 (Accounting Principals Board, 1972) permits managers to choose between permanent or temporary treatment if the U.S. tax rate exceeds the local tax rate for the foreign subsidiary. ${ }^{58}$ To elaborate, foreign subsidiaries of U.S. companies pay income tax in the jurisdictions where they operate. Their parent companies generally do not pay any U.S. taxes on these foreign earnings until the profits are repatriated to the parent as dividends. If the profits are never repatriated, then U.S. taxes are never paid. ${ }^{59}$

GAAP permits corporations to record the residual U.S. taxes in two ways. The first creates a temporary difference, leaving the ETR unaffected. Specifically, a firm estimates the U.S. tax that will be required at repatriation and accrues that income tax expense when it records the foreign earnings that will eventually trigger those U.S. taxes. This matching treatment creates a temporary difference (i.e., a DTL is recorded). A consequence of this option is reduced current after-tax book income. However, in the year that the dividend is repatriated to the parent and the U.S. taxes are paid, after-tax book income is unaffected.

A second option, if the firm does not expect to repatriate the profits in the foreseeable future, is to defer the expense until it decides to repatriate the funds. When a company makes this choice, the foreign profits are termed permanently reinvested. This deferral reduces the ETR because if the firm never repatriates, then it never pays the U.S. taxes. In contrast to the first option (i.e., booking the expense on the residual U.S. tax liability), this option boosts after-tax book earnings when the foreign profits are earned (because it assumes that repatriation and the accrual of eventual U.S. taxes will never occur).

\footnotetext{
${ }^{58}$ For further discussion of APB No. 23 and its implications for corporate behavior, see Collins et al. (2001), Krull (2004), Shackelford et al. (2009) (2009), Blouin and Krull (2009), Dharmapala et al. (2009) (2009), Graham et al. (2009) (2009), Schultz and Fogarty (2009), and Wunder (2009).

${ }^{59}$ Even upon repatriation, no U.S. taxes would be required if foreign tax credits offset any U.S. taxes due upon repatriation. Since foreign tax credits and other details about U.S. taxation of foreign profits are complex and beyond the scope of this paper, we assume for this discussion that at least some U.S. taxes are due at repatriation.
} 
However, the downside of this choice is that the after-tax book income falls by the amount of the estimated U.S. residual tax in the period if expectations change and the firm eventually repatriates the foreign profits.

Wunder (2009) shows that the amount of permanently reinvested foreign earnings (PRE) has grown rapidly in recent years. She finds that, as of year-end 2008, 273 firms in the Fortune 500 reported some amount of PRE. The total PRE for her companies is \$1.02 trillion, led by General Electric at \$75 billion. The 2008 total far exceeds Albring et al.’s (2005) estimate of \$381 million of PRE in 2002 for 296 Standard \& Poor’s 500 firms. Wunder’s (2009) average of \$3.74 billion per firm is over seven times the $\$ 485$ million mean reported by Krull (2004) is her study of Compustat firms in the 1990s.

The growth in PRE is particularly noteworthy because a large amount of PRE was eliminated through the large repatriations during the tax holiday provided by the American Jobs Creation Act of 2004. ${ }^{60}$ On the other hand, since PRE was one of the factors that determined the amount of foreign earnings that was subject to the favorable holiday rates in the 2004 Act, managers may be classifying as PRE as much foreign profits as possible so that their total PRE is as large as possible in the future. In other words, if managers believe that tax rates will be temporarily lowered in the future and PRE will be a factor in determining the amount of dividends that can enjoy the low rate, they have an incentive to overstate PRE now.

Examining the 50 largest U.S. companies, based on 2008 market capitalization, we find that their aggregate PRE in 2008 was $\$ 610$ billion. The mean, median and standard deviation of PRE as a percentage of market capitalization is $15 \%$, and the maximum is Pfizer's ratio $=$ of $67 \%$. PRE exceeds one-third of market capitalization for three other pharmaceuticals (Merck, Bristol-Myers-Squibb, and Eli Lilly) and General Electric.

To our knowledge, Krull (2004) is the only empirical study that examines whether firms manage earnings by exploiting the GAAP discretion in reporting permanently reinvested foreign earnings. Krull

\footnotetext{
${ }^{60}$ The American Jobs Creation Act of 2004 provided a one-time U.S. tax rate of 5.25\% on dividends from foreign subsidiaries (see Blouin and Krull (2009), for more details). An IRS study of actual corporate tax returns estimates that the legislation led to the repatriation of $\$ 362$ billion of foreign earnings (Redmiles, 2008).
} 
advances four reasons why firms may manage earnings by exploiting the discretion in recording residual taxes paid to the IRS. First, the computation of the permanently reinvested portion of foreign earnings forces managers to exercise considerable judgment. Second, changes in the permanently reinvested account have no cash flow implications. Third, investors may have difficulty detecting earnings management via this account because there is limited public information about a firm’s foreign operations. ${ }^{61}$ Fourth, the amount of unrepatriated foreign earnings (potentially subject to earnings management) is large. Consistent with her predictions that firms manage earnings by using their discretion in recording residual taxes, Krull (2004) shows that year-to-year changes in the amounts reported as permanently reinvested foreign earnings from 1993 to 1999 are positively related to the difference between analysts’ forecasts and pre-managed earnings.

Krull's (2004) conclusions rest critically on assuming that the tax information in the financial statements reveals the actual tax position of the firm, which is problematic as discussed in section 6. Her tests rely on the assumption that those companies whose foreign ETR (current foreign tax expense to foreign profits over the last five years) is less than the U.S. statutory rate are the only firms' managing earnings through the permanently reinvested foreign earnings account. This is a reasonable assumption because other firms could offset any residual U.S. taxes with excess foreign tax credits. However, it is not clear whether the tax footnotes provide enough information to identify the firms that will face repatriation taxes. As an example of the potential inadequacy of the data, the foreign ETR aggregates all foreign taxes and profits in the current year, whether from dividend-paying subsidiaries or other entities; however, the foreign tax credits are based on past and current taxes paid by the subsidiary remitting dividends and computed in the year of repatriation. In short, Krull (2004) is an example of research that relies crucially on AFIT to provide information about the actual taxes of the firm; whether the tax information in the financial statements is adequate for this task is unclear.

\footnotetext{
${ }^{61}$ This difficulty in detecting earnings management does not exist in all countries. The disclosure requirements in some countries (especially, European countries) provide substantial information about a firm's foreign operations.
} 
Collins et al. (2001) test whether the market can see through this APB No. 23 earnings management option. They examine the tax footnotes of the financial statements for firms that have classified at least some of their foreign profits as permanently reinvested. They find that the market values the permanently reinvested foreign earnings net of tax, i.e., as though the firm will eventually repatriate the profits and pay any residual U.S. taxes. ${ }^{62}$ Since it appears that the market can undo this type of earnings management, this suggests that either managers are unaware of the market's ability to seethrough this management technique or managers use this earnings management option to achieve nonequity market goals.

Collins et al. (2001) potentially suffers from self-selection. Under SFAS No. 109, firms are not required to disclose a residual tax if it is "not practicable" to determine the amount, a position that $26 \%$ of their sample takes. Since Collins et al. (2001) cannot observe the unrecognized residual taxes for these firms, they cannot reject the proposition that these firms are successfully managing their earnings through this APB 23 reporting option. Collins et al. (2001) also is subject to other design problems because it employs a price level regression model. As discussed in Barth et al. (2001), several studies identify a host of econometric concerns with price level regression models including measurement error, coefficient bias, inefficient standard errors, and cross-sectional differences in valuation parameters. While this same literature provides solutions to many of these problems, Collins et al. (2001) generally do not make use of these techniques. Thus, their analysis could produce misleading implications.

To summarize, presently only a very limited amount of research addresses whether and why managers exploit the discretion under APB 23 to manage earnings. The inference drawn from Krull (2004) is similar to those inferences drawn from the other AFIT earnings management studies, i.e., firms are more likely to defer recognition of the residual taxes if deferral better enables them to meet analysts' forecasts.

\footnotetext{
${ }^{62}$ De Waegenaere and Sansing (2008) analyze the role of the deferred tax liability in relation to the amount of permanently reinvested foreign earnings. They find that the valuation effects depend on whether the foreign earnings are invested in operating assets (which the authors argue would have no effect on firm value) or financial assets. If financial assets, the authors argue that there is some effect on firm value, but the book value sometimes overstates the effect of the liability on firm value.
} 


\section{d. Other Studies}

The papers discussed above study specific tax accounts in search of evidence of earnings

management. Another approach is to investigate settings where earnings management is suspected and

then look for patterns in the tax expense consistent with earnings management, without specifying the

balance sheet account that is being manipulated. Although knowing the specific balance sheet account

through which manipulation is occurring is important, the evidence about whether firms manage earnings

through the tax accounts is sufficiently wanting that we find merit in any documentation of AFIT earnings

management.

An example of this approach is Dhaliwal et al. (2004). They reason that since the income tax expense is usually the final account determined in the financial statement preparation process, it provides an important "last chance" to manage earnings. Dhaliwal et al. (2004) examine data from 1986 to 1999 to determine whether companies use the income tax expense account to meet analysts' forecasts in the fourth quarter. They find a negative association between the difference in the fourth quarter and the third quarter ETRs and the amount by which the firm would have missed its earnings forecast at the end of the year if earnings had not been managed. ${ }^{63}$ Their findings are consistent with managers manipulating tax expense down (thus, increasing net income and decreasing the ETR) when the pre-managed earnings would fall short of the forecasted earnings. ${ }^{64}$ Dhaliwal et al. (2004) do not attempt to identify the specific balance sheet account through which earnings management occurs. ${ }^{65}$

\footnotetext{
${ }^{63}$ The pre-managed fourth quarter earnings is computed as actual pretax income * ( 1 - third quarter ETR).

${ }^{64}$ Comprix et al. (2009) (2009) find that first quarter ETRs are on average the highest of the year and that ETRs decline monotonically through the year. The authors interpret this as being consistent with building slack in the ETR estimate that can be used to manage (increase) earnings later in the year. Bauman and Shaw (2005) find that on average changes in interim ETRs help predict an opposite signed movement in next quarter earnings during their 1994 to 2001 sample; however, they find the perplexing result that small increases in ETRs lead to large increases in next quarter earnings, while large increases in ETRs lead to lower next quarter earnings.

${ }^{65}$ Two studies test for changes in earnings management following passage of Sarbanes-Oxley. Cook et al. (2008) extend Dhaliwal et al. (2004), testing whether this usefulness of the tax accounts to achieve "last chance" earnings management changed with the Sarbanes-Oxley Act of 2002. They find that the earnings management discovered in Dhaliwal et al. (2004) is greater in firms that pay higher tax-related fees to their auditors and that this result did not change after Sarbanes-Oxley was enacted. They also find that among firms that pay no tax-related fees to their auditors, those that would miss their earnings forecasts utilize this form of earnings management more than for those
} 
Gleason and Mills (2008) conclude that the market mostly sees through the manipulation documented in Dhaliwal et al. (2004). They measure the market reaction to the unexpected earnings of firms that beat the analysts’ forecasts without manipulating their tax expense. Gleason and Mills (2008) then measure the market reaction to the unexpected earnings of firms that beat the analysts' forecasts by manipulating their tax expense. Comparing the two measures and controlling for abnormal accruals, they interpret a weaker market reaction to the manipulated unexpected earnings as evidence that the market sees through managerial manipulation of the tax expense account. Nonetheless, it is puzzling why managers manage tax expense to meet analyst forecasts at all, if the market sees through almost all of the manipulation.

Gordon and Joos (2004) identify another setting where the tax expense may be a prime candidate for earnings management. The U.K. once employed a partial method of accounting for deferred taxes. Under the partial method, the financial statements only recognize deferred tax balances that are expected to reverse in the foreseeable future. Thus, managers have some discretion in choosing which deferred taxes to record. By not recording DTLs (DTAs), a company can increase (decrease) income and equity. Gordon and Joos (2004) find that managers of British firms opportunistically used their discretion to manage their leverage (through increasing equity) but not to smooth earnings. While it is useful and interesting to know that firms did manipulate the tax accounts under the U.K.'s former accounting rules, it is not clear whether these results generalize to the less flexible AFIT rules under U.S. GAAP and IFRS.

\section{e. Summary}

In general, evidence indicates that the tax accounts are used to meet or beat analysts' forecasts, but they are not used for other forms of earnings management. Specifically, the general studies of earnings management, which do not look at specific balance sheet accounts, indicate that managers do use

that would not miss their forecasts. This result does not hold after the Sarbanes-Oxley Act. Gleason et al. (2007) (2007) also examine changes around the Sarbanes-Oxley Act. After studying cross-firm changes in earnings management following passage of Sarbanes-Oxley, they conclude that its mandated internal control reforms successfully reduced tax-accrual earnings management. 
the tax accounts to meet or beat analysts' forecasts. Likewise, studies of the VA, the tax contingency, and the discretion in reporting foreign profits, indicate that these tax accounts are used primarily to meet or beat analysts' forecasts. However, there does not seem to be much evidence that managers use the tax accounts to smooth earnings, increase a big bath, avoid losses, or meet/beat prior earnings.

In summary:

- Multiple studies report that managers manage the valuation allowance account to meet analysts' forecasts, but do not appear to use it for other forms of earnings management.

- At least one study reports that firms:

o Manage the tax contingency account to meet analysts' forecasts and prior earnings targets but not to smooth earnings;

o With over-reserved contingency balances did reduce the contingency balance in 2006 (immediately before FIN 48), thereby increasing earnings;

o Choose an amount of permanently reinvested foreign earnings to meet analysts’ forecasts;

o Manipulate tax expense downwards in the fourth quarter to meet analysts' forecasts.

\section{f. Future Research in Earnings Management}

Given that earnings management is alleged to be rampant among the tax accounts but the empirical evidence is hardly overwhelming, we see many avenues for additional study in this area. We close this section by highlighting some questions that remain unresolved:

- Does the lack of consensus about whether managers use the tax accounts to meet or beat prior earnings stem from which measure of prior earnings is being used as the benchmark? Both Bauman et al. (2001) and Frank and Rego (2006) use prior year earnings as the benchmark and find no result consistent with this type of earnings management in the VA account. However, Schrand and Wong (2003) find that the valuation allowance is used as hypothesized when they define the prior earnings benchmark as the three-year historical average. In addition, Gupta and 
Laux (2008) find that tax cushion reversals are used to meet or beat prior earnings when they define prior earnings as earnings from the same quarter, one year previous. Graham et al. (2005) report, for example, that while $85.1 \%$ of surveyed executives indicated that EPS from the same quarter in the prior year is an important benchmark, only $54.2 \%$ responded that the previous quarter EPS was an important benchmark.

- Why do managers not exploit the subjectivity in the tax accounts to facilitate big baths?

- The pre-FIN 48 earnings management studies related to the tax contingency had to be conducted using estimates of the contingency. Now that superior information about the contingency is available, the use of the tax contingency to manage earnings should be revisited.

- Have the increased disclosures that are required under FIN 48 affected the earnings management behavior of firms? In particular, has it decreased the use of the tax expense account to manage earnings? If so, are firms now using other income statement accounts instead of the tax expense line item, or has total earnings management decreased?

- What role does the tax expense line item play in earnings management, given its location on the income statement? Analysts and investors may be more interested in earnings reported above tax expense in the income statement, e.g., operating income (Robinson, forthcoming), EBITDA (Dyreng, 2009), or other accounts (Lipe, 1986). If so, even though the tax accounts enjoy relatively high levels of subjectivity and opaqueness and may be the last accounts closed (Dhaliwal et al. (2004); Gleason et al. (2007))—characteristics that would make them attractive for managing earnings—-managers would find them less effective for managing earnings than accounts reported higher on the income statement. ${ }^{66}$ Can analysts and the market see through earnings management of the tax accounts?

- Given the discretion permitted under APB No. 23, surprisingly few papers analyze this option to defer recognition of the residual U.S. tax on foreign earnings. Graham et al. (2009) present

\footnotetext{
${ }^{66}$ Consistent with a pre-tax account focus, Nelson et al.'s (2003) survey of auditors finds that only a few of the actual earnings management schemes detected by auditors involve the income tax expense account.
} 
evidence that managers value the ability to defer the recognition of the residual U.S. taxes statistically as much as they value the ability to defer the actual cash payments. Furthermore, this earnings management option likely will become more popular as foreign earnings become an increasingly large proportion of U.S. firms’ profits and as long as U.S. tax rates exceed those of most of its trading partners. Together, these developments lead us to encourage further study in this area.

- Krull (2004) analyzes firms from 1993 to 1999. She acknowledges that annual changes in the permanently reinvested foreign earnings account might “...raise suspicion with auditors...” Sarbanes-Oxley, FIN 48 and other regulatory changes have altered the practice of auditing. We would be interested to know whether firms still manipulate the permanently reinvested foreign earnings amount to manage earnings in the current auditing environment.

- $\quad$ Besides earnings management, the option under APB No. 23 to lower the ETR provides researchers with an opportunity to study the importance that managers place on the ETR.

- Gleason and Mills (2008) report that the market sees through the management of the tax accounts. If so, why do firms manage the tax accounts to meet earnings forecasts? Do managers believe they can fool the market? If not, why are managers manipulating the tax accounts (and likely other accounts) to meet analysts’ forecasts, rather than other targets, which might be used in contracting?

\section{The Pricing of Tax Information Reported in the Financial Statements}

The earliest AFIT studies assessed whether the market uses tax information to set prices. The pricing of tax information continues to be an active area of research. This section reviews the marketrelated literature and highlights important unresolved issues. In general, the evidence is consistent with the market impounding financial statement information about taxes. 


\section{a. Deferred Tax Accounts}

\section{i. Empirical Studies}

Several early papers at least tangentially address the pricing of deferred tax accounts. Beaver and Dukes (1972) determine that a measure of earnings that includes tax-related deferrals has a higher association with market returns than does a measure of earnings that excludes these deferrals. Rayburn (1986) finds that the tax accrual provides information to the market that is incremental to cash flow information. Similarly, Chaney and Jeter (1994) find that the deferred tax component of earnings provides information to the market incremental to that provided by income computed without the deferred tax component.

Recent research focuses on two approaches to determine whether the market prices the deferred tax accounts. The first approach used by Amir et al. (1997), Amir and Sougiannis (1999), Ayers (1998), and Dhaliwal et al. (2000), is a levels approach. These studies include some measure of the level of market equity as the dependent variable and measures of the deferred tax accounts (along with other balance sheet variables) as explanatory variables. Amir et al. (1997) provides perhaps the most comprehensive analysis of this issue. They test whether the market prices components of the deferred tax accounts differently depending on when they are likely to reverse. Using hand-collected data for a subsample of the Fortune 500 from 1992 to 1994, they regress market price on seven components of the deferred tax balance: (1) depreciation and amortization, (2) losses, credits and carryforwards, (3) restructuring charges, (4) environmental charges, (5) employee benefits, (6) valuation allowance, and (7) all others. They report that the components are priced as though the market discounts the value of the deferred tax account based on its likelihood of and length of time until settlement. For example, the market assigns the highest value to the deferred tax balances arising from restructuring charges, consistent with the deferred tax balances associated with restructuring charges reversing more quickly than other timing differences, such as depreciation. They also find that the VA coefficient is only significant in one of the three years they study, consistent with the market assigning a lower value to the VA because of its high level of subjectivity. 
Amir and Sougiannis (1999) focus on the DTAs that arise from loss and credit carryforwards. They study how analysts (investors) use the DTAs from carryforwards in determining their forecasts (setting prices). In general, they find that both the market and analysts view earnings as less persistent for firms with carryforwards, although the market evidence is somewhat mixed. Both the market and analysts consider firms that have reported a VA to have even less persistent earnings and they both value the carryforward piece of the DTA as a true economic asset. Tests of whether the market prices the VA are inconclusive, but the evidence suggests that analysts do not behave as if the VA is a reduction in the deferred tax asset. Finally, the authors report that analysts' accuracy is unaffected by the existence of DTAs attributable to carryforwards. ${ }^{67}$

Ayers (1998) also performs a levels regression with market value of equity as the dependent variable and the DTA, DTL and VA balances included as explanatory variables. ${ }^{68}$ He finds the coefficients are negative for the DTL and VA balances and are positive for the DTA balances. This is consistent with the market separately using the information in the DTAs, the DTLs, and the creation of the VA in a manner that is consistent with tax obligations reducing firm value. However, the fact that

\footnotetext{
${ }^{67}$ Amir and Sougiannis (1999), Amir et al. (1997) and Ayers (1998) regress stock prices on various accounting variables. They report estimated regression coefficients greater than 1.0 for deferred tax assets and the valuation allowance, implying that the market-to-book ratios for these accounts exceed one. This finding is surprising because the failure to discount the deferred tax accounts would be expected to cause the book value to exceed the market value. De Waegenaere et al. (2003) advance an explanation for these empirical findings. Modeling the valuation effects of firms with tax loss carryforwards, they compare the book value of the deferred tax asset (net of its valuation allowance) associated with a net operating loss carryover with the effect of the carryover on firm value. They argue that the book value could be higher or lower than the economic value because firm value reflects the discounted mean value, while GAAP records the undiscounted median value (The authors interpret the GAAP rule that the valuation allowance is recorded when the probability is $50 \%$ or higher that a tax benefit will not be realized to mean that firms report the $50^{\text {th }}$ percentile value, i.e., the median, net DTA amount.) If taxable income is positively skewed (so that the mean exceeds the median), then the market value should exceed the book value. ${ }^{68}$ Ayers (1998) also examines whether the tax accounts are more value-relevant under SFAS 109 (adopted by FASB in 1992) than APB No. 11. The new AFIT pronouncement required firms to separate their DTAs from their DTLs in their footnote disclosures. In addition, the pronouncement established the VA. Ayers (1998) compares the value relevance of the deferred tax accounts reported under APB No. 11 with those reported under SFAS No. 109. He finds that the deferred tax accounts under SFAS No. 109 are priced incrementally to the deferred tax accounts that were reported under the old regime.
} 
Ayers (1998) finds the VA balance to be associated with market equity values is counter to the evidence in Amir et al. (1997). ${ }^{69}$

Finally, unlike the previously discussed studies, which assess whether the market values the deferred tax accounts that appear on the balance sheet, Dhaliwal et al. (2000) test whether the market prices off-balance sheet DTLs. The off-balance sheet DTL that they study arises from the LIFO conformity rule, which states that firms must use LIFO for book purposes if they use it for tax purposes. The authors contend that even if a firm reports its financial statements using LIFO, investors may value the firm's inventory using FIFO (assuming FIFO is more relevant). This is possible because required disclosures permit investors to adjust from LIFO to FIFO. If the market makes this inventory-increasing off-balance sheet adjustment in an inflationary environment (under inflation, FIFO produces higher inventory costs than does LIFO), then the market also may impute an off-balance sheet increase to their valuation of the DTL. Regressing the firm's market value on an estimate of the off-balance sheet DTL, Dhaliwal et al. (2000) find that the market does price these off-balance sheet DTLs.

To summarize, the "levels" analyses provide consistent evidence that the market prices the deferred tax accounts, with the exception of the VA. The evidence on the VA is mixed. However, there are at least two important issues to consider. First, all three of the studies that examine the on-balance sheet deferred tax accounts use data from 1992, 1993 and 1994, which was when SFAS No. 109 was enacted. ${ }^{70}$ The generalizability of these studies is in question both because the sample sizes are small and because, during the years examined, the market likely was still learning how to impound these complex footnote disclosures. Second, as detailed in section 7, because these papers employ price level regression models, they potentially face substantial econometric shortcomings that may undermine their findings.

\footnotetext{
${ }^{69}$ Kumar and Visvanathan (2003) contend that, although a change in the VA is embedded in earnings, the VA might be incrementally informative because decisions about the VA involve judgments about the amount, timing, and sources of future taxable income. Consistent with this argument, they report that the market does find changes in the VA account to be incrementally informative. However, it is unclear whether their findings can be generalized because they limit their sample to those firms whose changes in the VA account are disclosed to the media. ${ }^{70}$ SFAS No. 109 was required for fiscal years beginning after December 15, 1992. Some firms adopted it a year early.
} 
The second approach for determining whether the market prices the deferred tax accounts is to examine the change in their pricing around the change of corporate tax rates. For example, Givoly and Hayn (1992) use the 1986 reduction in the corporate tax rate from $46 \%$ to $34 \%$ to test the pricing of DTLs during the APB No. 11 era. Since the 1986 legislation reduced future cash outlays, it should have increased the value of the firms. Furthermore, if the market viewed DTLs as "real” liabilities (i.e., taxes to be paid in the future), then the change in the firm's stock price should have been correlated with the amount of a firm’s DTLs (since those future tax payments would be less after the reduction in the corporate tax rate). Givoly and Hayn (1992) find that the market does price DTLs as liabilities.

Specifically, the abnormal returns of the firms in their sample are positively associated with the amount of DTL, consistent with the market anticipating that the DTLs would reverse when the tax rates fell. They also find that the market reaction is smaller for firms that were less likely to realize their DTL and also smaller for firms that had a longer expected period until reversal. One potential problem with this study is that it does not include a measure of unexpected earnings as an explanatory variable. Thus, coefficients could be biased if unexpected earnings are correlated with the change in the deferred tax accounts due to the tax rate change.

Unlike APB No. 11 (Accounting Principles Board, 1967), when the corporate statutory tax rate changes under SFAS No. 109, the deferred tax balances must be recomputed using the new corporate statutory tax rate in the year of the tax law change, and income is adjusted accordingly in that period. For example, under APB No. 11, the deferred tax balances were not altered when the statutory corporate tax rate fell from $46 \%$ to $34 \%$ in 1986 . If SFAS No. 109 had applied in 1986, the DTLs (DTAs) would have been revalued under the new lower rate and the change would have increased (decreased) current income.

In 1993, corporate statutory tax rates increased from 34\% to 35\%, increasing DTLs (DTAs) and decreasing (increasing) current period income. Chen and Schoderbek (2000) test whether analysts (investors) impounded this higher rate change into their forecasts (prices) before firms released their earnings. They find no evidence that analysts or investors accounted for this information, even though analysts and the market should have been able to estimate the expected adjustment based on the firms' 
current balance in their deferred tax accounts. Their results could be interpreted as being consistent with an inefficiency on the part of analysts and the market. ${ }^{71}$ Alternatively, since the statutory rate change in 1993 was only one percentage point, their tests may not have had adequate power to detect a response. In addition, the sample size of 158 is quite small, limiting the generalizability of the inferences.

In summary, much of the AFIT pricing literature examines the extent to which the market values the deferred tax accounts. With the possible exception of the VA account, the studies consistently show that the market impounds information from the deferred tax accounts into prices. The studies also show that the pricing of the tax account components varies in predictable ways with the likelihood of settlement and the length of time until reversal. However, it should be noted that most of these results are based on price level type regressions and thus should be interpreted with caution.

\section{ii. Theoretical Studies}

Three theoretical papers grapple with the valuation of deferred tax accounts. The primary finding is that under certain circumstances the deferred tax accounts should not be discounted to reflect the length of time until the reversal. This implication stands in contrast to Givoly and Hayn (1992) and Amir et al. (1997) who present empirical evidence that the timing of the reversal matters. Sansing (1998), the first of these theoretical papers, evaluates whether DTLs should have any valuation effects given that DTLs are not discounted and may never reverse. He demonstrates that the value of the DTL component related to depreciation is a specific fraction of the reported DTL component, thus providing theoretical support for the notion that DTLs should be valued at their full book value. ${ }^{72}$

Guenther and Sansing (2000) extend Sansing (1998). They demonstrate that if (a) the assets and liabilities that support the deferred tax accounts are reported at their present values, and (b) the tax deductions are taken on a cash basis, then the DTLs and DTAs should be valued at their reported

\footnotetext{
${ }^{71}$ Chen and Schoderbek (2000) find that this mispricing was more severe for firms with an income-increasing adjustment and for firms that did not disclose the adjustment in their earnings release. They do not find that the severity of the mispricing varies with the level of institutional holdings.

${ }^{72}$ The fraction is the tax depreciation rate divided by the sum of the tax depreciation rate and the cost of capital.
} 
amounts. If those two conditions do not hold, then the DTLs and DTAs should be valued less than their reported amounts. The authors also show that the anticipated reversal of the deferred tax accounts should not affect their value.

Guenther and Sansing (2004) focus on the relevance of the reversal. Evaluating the DTL that arises from BTDs in depreciation, they show that the value of the DTL is not a function of the expected time to reversal. Their explanation is that the timing of reversal can only affect valuation if it has cash flow implications. Since the rate of reversal is a function of book depreciation and has no cash flow implications, it should not have valuation implications.

As mentioned above, these findings stand in contrast to the empirical results that the timing of the reversal matters. A key difference appears to be whether the book-tax difference carries cash flow implications (e.g., warranty expense) or whether it has no cash flow implications (e.g., depreciation). If the BTD does not involve cash flow, reversal appears irrelevant. Would the theory's non-reversal conclusions hold if the book-tax difference carried cash flow implications? What conditions, if any, could the models relax to reach the same conclusions as the empirical papers?

\section{b. Tax Contingency}

Three papers address the market pricing of the unrecognized tax benefits (i.e., the tax contingency). Both Frischmann et al. (2008) and Robinson and Schmidt (2009) examine the market reaction to the release of the contingency balance in the 10-Q. Frischmann et al. (2008) regress the 3-day abnormal return (computed around the release of the 10-Q) on the unrecognized tax benefit balance reported in the footnotes (as required by FIN 48) and unexpected earnings. They find that the contingency balance is positively associated with the abnormal return, consistent with the market viewing tax planning positively. Robinson and Schmidt (2009) expand on this finding, testing whether this positive relationship varies with the quality of the disclosures. They find that the association is less positive for firms with high quality disclosures, indicating perhaps that investors are more concerned with the proprietary costs of disclosure than they are with increased transparency. 
While these results are interesting, there are a number of potential problems. First, they only examine the market reaction during the $1^{\text {st }}$ quarter of 2007 (i.e. the first quarter firms provided FIN 48 disclosures). It is unclear whether these results hold in subsequent periods after the market has had time to process the implications of this complex standard. Second, since the returns are computed around the release of the 10-Q, the market could be reacting to other information, much of which could be correlated with the contingency balance. Third, both papers use the contingency balance, rather than the unexpected contingency balance, which is more relevant when considering market reactions. The implicit assumption that the market would assume a balance of zero, so the entire realized balance is unexpected, limits our ability to interpret the results.

Blouin et al. (2009) is somewhat different because it uses a price-level regression to assess the market's valuation of the contingency balance during 2006 to 2008. The authors regress the market value of equity on the contingency balance along with various other balance sheet accounts. Consistent with Frischmann et al. (2008) and Robinson and Schmidt (2009), they find that market value is positively associated with the contingency balance. They also find that this is due primarily to the unrecognized tax benefit that relates to permanent differences (which affect earnings), as opposed to temporary differences (which only affect the timing of the tax payment).

Again, the results of the study are interesting. However, there are at least two concerns with the study. First, as a levels study, it faces the econometric problems enumerated above, most of which the authors do not address. Second, the authors use data that include observations from 2006, which is prior to the FIN 48 disclosure requirements. The authors break the sample into pre- and post-FIN 48 and find a positive coefficient on the contingency balance in both periods. However, it is unclear how the market obtains the information in 2006 given that it is not disclosed in the financial statements. This raises the possibility that an unmeasured effect might cause the significant relations both before and after FIN 48 was enacted.

In summary, the market seems to view the contingency account positively, consistent with a positive perception of tax planning activities. However, potential problems with extant research suggest 
caution in interpreting the results and also provide an opportunity for future research to address the suspect issues.

\section{c. Information Content of Estimated Taxable Income}

This section reviews a growing literature that investigates whether the tax information in the financial statements provides the market with information content incremental to that in book income. As discussed above, market participants cannot observe actual taxable income because tax returns are confidential filings with the taxing authorities. Nonetheless, researchers can attempt to estimate taxable income using the tax information in the financial statements. ${ }^{73}$ The standard taxable income estimate that researchers use to assess whether market participants find the tax information in the financial statements to have incremental content is current income tax expense grossed up by the statutory corporate income tax rate. ${ }^{74}$ Most studies adjust this amount by the change in net operating loss carryforwards. ${ }^{75}$

We review two bodies of literature in this area. First, we look at the studies that attempt to assess the association between contemporaneous returns and estimated taxable income. This literature provides evidence on whether the market values information in estimated taxable income. However, it does not address whether the market prices this information fully and efficiently. For example, the market might react to one dollar of unexpected taxable income (as estimated using financial statement data), but it might do so in a manner that does not fully and instantaneously impound the information. Thus, the second set of studies examines the association between future returns and estimated taxable income. If the market correctly impounds all relevant information when estimated taxable income is released, these

\footnotetext{
${ }^{73}$ See the detailed discussion in Section 6 about the limitations involved with estimating taxable income using the tax information in the financial statements.

${ }^{74}$ Section 6 notes that the research question dictates whether the researcher would ideally use actual or estimated taxable income. This is an example of a setting where, even if they had access to the actual tax returns, researchers would focus on information available to market participants without regard to confidential tax returns. Thus, the inability to observe the actual tax returns is not a limitation in this area of study.

${ }^{75}$ Lipe (1986) examines the information content of various components of earnings, including income tax expense. He finds that income tax expense provides additional information to the market incremental to that of the other components. Looking at a more recent period, Thomas and Zhang (2009) (2009) find that the tax expense is positively priced by the market, unlike other expense components of income. They attribute this to the possibility that taxable income is a measure of economic profit.
} 
studies implicitly assume that there should not be an association with future returns. If a statistical relation between current taxable income and future returns is found, it is possible that the market did not fully value taxable income when it was released. Overall, these studies do not provide conclusive evidence about whether the relation between estimated current taxable income and future returns is evidence of market inefficiency, resolution of uncertainty that occurs as the future is realized, or some other cause.

\section{i. Association between contemporaneous returns and estimated taxable income}

To test whether estimated taxable income provides the market with information that is incrementally "useful” beyond book income, Hanlon et al. (2005) perform three tests. First, they test the incremental information content of estimated taxable income by regressing long-window contemporaneous returns on both the change in pre-tax book income and the change in estimated taxable income. They find that both measures explain returns. Although book income has a larger coefficient (and $t$-statistic), the coefficient on estimated taxable income is still statistically significant, consistent with estimated taxable income providing incremental information to the market. Second, they test the relevant information content by comparing the adjusted $\mathrm{R}^{2}$ from a regression of returns on the change in pre-tax book income to the adjusted $\mathrm{R}^{2}$ from a regression of returns on the change in estimated taxable income. They find that the adjusted $\mathrm{R}^{2}$ from the pre-tax book income is higher than the adjusted $\mathrm{R}^{2}$ from the taxable income regression, thus concluding that book income is more "useful” than taxable income. Finally, they test portfolio returns to assess the returns that can be earned with foreknowledge of the change in income. They find that knowledge of both the sign and magnitude of the change in pre-tax book income (estimated taxable income) results in returns of $27.4 \%$ (21.1\%). The analyses performed by Hanlon et al. (2005) are well done, and it is reassuring that they perform three different tests as well as a host of robustness analyses.

Ayers et al. (2009) extend Hanlon et al. (2005) by considering cross-firm differences in tax planning and earnings quality. They hypothesize that firms that engage in more tax planning will report a 
taxable income figure that is less representative of the firm's underlying economic activity. They also hypothesize that estimated taxable income will have relatively greater information content for firms that engage in higher levels of earnings management. They define high tax planning firms as those in the lowest quintile of accumulated effective tax rates (industry-adjusted) over a five-year window and low quality earnings firms as those in the highest quintile of absolute abnormal accruals. ${ }^{76}$ Their tests begin with long-window association tests between returns and both book income and estimated taxable income, where the returns and the income variables are measured contemporaneously. From these regressions, they compute a ratio where the numerator is the $\mathrm{R}^{2}$ from the estimated taxable income regression and the denominator is the $\mathrm{R}^{2}$ from the book income regression. They then compare the ratio for the two groups of test firms (i.e., high tax planners and the low earnings quality firms) with the ratio for all other firms. As predicted, they find that the information content of estimated taxable income (compared with the information content in book income) is lower for firms with high levels of tax planning and higher for firms with low levels of book earnings quality.

As discussed extensively in Raedy (2009), the second hypothesis (i.e., estimated taxable income will have greater information content for firms that engage in higher levels of earnings management) deserves further scrutiny. It assumes that managers only undertake earnings management where book and tax do not conform and that the market treats book income and taxable income as substitute measures of economic income, as opposed to alternative measures. Consistent with this potential conceptual problem with the second hypothesis, the results in Ayers et al. (2009) are fairly weak for that hypothesis. However, the first hypothesis (i.e., estimated taxable income will have lesser information content for firms that engage in higher levels of tax planning) is well conceived and the tests are implemented well. In addition, Raedy (2009) provides additional sensitivity tests for the first hypothesis (that the information content of estimated taxable income varies with the level of tax planning) and finds results consistent with those reported by Ayers et al. (2009). One potential problem with the analyses in Ayers et al. (2009) is that they do not consider the effect of tax planning and earnings management simultaneously. Thus, they

${ }^{76}$ Abnormal accruals are measured using the modified Jones model as in Dechow et al. (1995). 
do not control for the book (tax) manipulation when testing the information content of the taxable income for tax planners (earnings managers). ${ }^{77}$

Lev and Nissim (2004) also focus on how earnings quality (as measured by earnings growth) is affected by the magnitude of the book-tax differences. They posit that the ratio of estimated taxable income to book income (TI/BI) is a measure of earnings quality (and thus contains information incremental to that found in accruals and cash flows) for three reasons. First, discretionary accruals are included in book income but often excluded from taxable income, and since discretionary accruals must reverse in the future, they reduce earnings quality. Second, if firms time transactions to smooth taxable income, then estimated current-period taxable income should reflect management's assessment of future taxable income. It then follows that high current estimated taxable income signals that managers anticipate having high future estimated taxable income and, by inference, high future book income. Third, since firms usually recognize income (deductions) for tax purposes before (after) they recognize revenue (expenses) for book purposes, a high ratio of TI/BI should predict high (low) future book revenues (expenses).

To test whether TI/BI provides information content, Lev and Nissim (2004) regress earnings growth on TI/BI and controls. They find that earnings growth is positively associated with TI/BI, consistent with the book-tax difference providing a measure of earnings quality. They then explore whether the market prices this information about the quality of earnings contemporaneously by regressing the current $\mathrm{E} / \mathrm{P}$ ratio on the TI/BI measure and controls. Curiously, they find that the market seems to (at least partially) impound this information in the post-SFAS No. 109 period but not the period that precedes

\footnotetext{
${ }^{77}$ Both Raedy (2009) and Chen et al. (2007) (2007) address this issue by including both the tax planning and earnings management variables in a regression together. Both papers find that the information content of estimated taxable income is less for tax aggressive firms, consistent with the results in Ayers et al. (2009). However, results of the effect of earnings management on the information content of taxable income are inconsistent among the three papers.
} 
the enactment of the standard, which the authors attribute to investors’ more quickly and fully learning the implications of the tax information for future earnings. ${ }^{78}$

While Lev and Nissim (2004) is an interesting paper that is generally well done, there are a few potential problems in the study. First, the motivation is perhaps not as straightforward as suggested. The authors are, in essence, assuming that the only form of tax planning involves tax smoothing. This would not necessarily be the case; however, this focus most likely only biases against finding an association between TI/BI and future earnings growth. . Also, there are several problems inherent in their research design. First, there are many potential determinants of the book-tax difference. This study only controls for industry effects. Thus, the results could be attributable to something other than earnings quality driving the relevance of TI/BI. Second, their measure of TI/BI is, in essence, merely current tax expense scaled by net income. Thus, they may not be capturing book-tax differences at all. Third, they only use ranked values (ranging from 1 to 5) of TI/BI, thus losing a great deal of information, raising concerns about the robustness of the findings to a richer measure. Finally, see Section 11 for a discussion on how to deal with correlated residuals like those in Lev and Nissim (2004)'s specification.

Earnings quality also motivates Hanlon’s (2005) study of the potential information content of BTDs. She focuses on deferred tax timing differences and tests whether BTDs affect the persistence of earnings, cash flows and accruals. She hypothesizes that firms with the most extreme BTDs (whether positive or negative) will have less persistent book earnings and that the accrual portion of earnings will have less persistence for these firms. ${ }^{79}$ Hanlon (2005) tests whether extreme BTDs affect the market’s assessment of the persistence of earnings. She finds that firms with the most extreme BTDs experience less persistence in earnings, accruals, and cash flows, thus indicating that extreme book-tax differences

\footnotetext{
${ }^{78}$ This explanation is a bit unsatisfactory. It is unclear why the ability of the market to understand the implications of the tax information would be related to the enactment of SFAS No. 109. While it may actually just be the results of a time trend in the market's ability to interpret data, the authors do not provide any analysis of this.

${ }^{79}$ Persistence is measured by the coefficient on a one-period lagged value of earnings (or the accrual portion of earnings), when the dependent variable is current period earnings.
} 
are associated with lower earnings quality. ${ }^{80}$ Building on this, she then finds that for firms with extremely negative BTDs (book income is less than estimated taxable income), the market correctly estimates the persistence of earnings and cash flows, but overestimates the persistence of accruals. For firms with the most extreme positive BTDs (book income is greater than estimated taxable income), the market actually underestimates the degree of persistence of earnings and cash flows, but correctly estimates the persistence of accruals. ${ }^{81}$

There are a few issues to consider when interpreting the results in Hanlon (2005). First, the study only examines earnings persistence, ignoring other measures of earnings quality, such as accruals quality, predictability, timeliness, and conservatism, to name a few. Second, any one-time accrual could cause the association documented with persistence and yet have nothing to do with earnings quality per se. Hanlon (2005) addresses this issue by excluding special items and rerunning the analysis. However, given that the results weaken in this sensitivity analysis and that all one-time accruals are not contained only within special items, the results should be interpreted with caution. Third, given Hanlon et al.'s (2005) finding that estimated taxable income for loss firms does not exhibit incremental explanatory power over book income, the results in Hanlon (2005) may be sensitive to its exclusion of loss firms. ${ }^{82}$ Fourth, her finding that, in addition to earnings, cash flows exhibit less persistence when the firm has extreme book-tax differences raises concerns that the changes in earnings quality arise for reasons other than BTDs. Finally, the mixed results of the market tests are puzzling and difficult to reconcile.

Schmidt (2006) also investigates the persistence of tax information, focusing on the tax change component of earnings (i.e., the change in earnings attributable to a change in the ETR). His work

\footnotetext{
${ }^{80}$ In their extension of Hanlon (2005), Blaylock et al. (2009) (2009) find that when aggressive tax reporting creates extremely positive BTDs (book income is greater than estimated taxable income), earnings and accruals persistence is greater than when the extremely positive BTDs arise for other reasons. Conversely, when upward earnings management creates extremely positive BTDs, earnings and accruals persistence is lower than when the extremely positive BTDs arise for other reasons.

${ }^{81}$ Jackson (2009) (2009) follows up on Hanlon (2005) and Lev and Nissim (2004) by attempting to sort out why large book-tax differences are associated with information about future firm performance. He finds that temporary (permanent) book-tax differences are associated with future changes in pretax earnings (tax expense).

${ }^{82}$ Thomas and Zhang (2009) (2009) show that results in these types of analyses are quite sensitive to the exclusion of loss firms.
} 
extends earlier studies that as a group were inconclusive and inconsistent about the persistence related to ETR changes (e.g., Lipe (1986), Lev and Thiagarajan (1993), Abarbanell and Bushee (1997) and (1998), and Bryant-Kutcher et al. (2007)). Schmidt (2006) finds that the tax change component of earnings in the first fiscal quarter is not transitory and hence may have predictive value. In fact, it rivals the ability of other (non-tax) components of earnings to forecast next year's earnings. However, Schmidt finds that revisions to the ETR in subsequent quarters are transitory and hence have less information content. The transitory nature of later quarters is consistent with Dhaliwal et al.’s (2004) finding that firms use the income tax expense account to meet analysts' forecasts in the fourth quarter. In addition, he finds that the market tends to underweight the persistence of the tax change component of earnings. Schmidt (2006) is well executed, though it is unclear whether the results are sensitive to the exclusion of loss firms.

In summary, the papers that test whether contemporaneous taxable income (as estimated with financial statement data) has incremental information content reach similar conclusions. All conclude that estimated taxable income has information content incremental to that in book income. Furthermore, cross-sectional tests show that the relative contribution of estimated taxable income decreases when firms engage in aggressive tax planning. There are conflicting results in the literature with respect to whether the incremental information content of estimated taxable income is higher (Ayers et al. (2009)) or lower (Chen et al. (2007)) for firms that have higher levels of earnings management. The literature also indicates that firms with extreme BTDs have less persistent earnings and accruals (and less persistence is interpreted as lower earnings quality). In addition, firms with large book-tax differences (low values of the TI/BI ratio) also have lower P/E ratios and lower future earnings growth. Finally, Schmidt finds that the earnings generated by a change in the ETR during the first quarter are informative in that they are positively associated with future earnings.

\section{ii. Association between future returns and estimated taxable income}

This section reviews three papers that examine the extent to which (and how quickly) market prices impound information about estimated taxable income. The earliest work was performed by Lev 
and Nissim (2004), who examine the explanatory power of TI/BI (the ratio of estimated taxable income to book income) for future returns. They find that TI/BI is positively correlated with one-year ahead stock returns, consistent with the market not immediately impounding all information about estimated taxable income into prices. The relation, however, is much weaker after SFAS No. 109, which, as discussed in the previous section, the authors attribute to investors' more quickly and fully learning the implications of the tax information for future earnings.

Thomas and Zhang (2007) control for book income in their analysis of the association between estimated taxable income and future market returns. They regress future stock returns on the surprise components for both taxable and book income (where surprise is defined as the current quarter's income less the income from four quarters before). They find that the estimated taxable income surprise is associated with stock returns up to six months in the future, consistent with the market not fully impounding the information in estimated taxable income when the financial statements are released.

Thomas and Zhang (2007) explore two reasons that this anomaly might exist: (1) The tax surprise contains information about future book income that is not included in current book income; (2) The tax surprise captures information that is not contained in future book income but is contained in other financial information that will be released in the future. They find support for both of these explanations. This study provides intriguing results and is competently executed. It is difficult to interpret the second result (i.e. that the tax surprise captures information that is released in the future) without better understanding the type of information that (1) is not included in future book income, (2) is not predicted by current book income, (3) is not included in future cash flow, but (4) is priced when future earnings are released.

Weber (2009) expands upon Lev and Nissim (2004) and Thomas and Zhang (2007) in several ways. First, he demonstrates that the association between future returns and book-tax differences only exists in firms with weaker information environments (as measured by analyst following). Second, he examines analysts' forecasts to assess whether they fully capture the information in estimated taxable income. Regressing analyst forecast errors on the ratio of estimated taxable income over book income, he 
finds that the forecast errors are significantly associated with this tax variable, which is consistent with analysts not fully utilizing the information in estimated taxable income. ${ }^{83}$ Specifically, he finds that forecasts are, on average, more optimistically biased when book-tax differences are large. He then tests whether this failure on the part of analysts explains the inability of the market to impound immediately and fully the information in current-period estimated taxable income. Regressing future returns on both the forecast error and the tax variable, he reports that the analysts' forecast error is significantly associated with future returns but the tax variable is not. He interprets these results as evidence that the failure of analysts to fully incorporate current-period tax information into their forecasts (at least partially) explains the failure of the market to fully and immediately impound tax information. While interesting, this hypothesis rests heavily on the implicit assumption that the market relies on analysts to interpret and report tax information.

To summarize this section, both unexpected estimated taxable income and the ratio of estimated taxable income to book income predict future returns. Lev and Nissim (2004) and Thomas and Zhang (2007) leave unanswered the question as to why tax information is not fully and immediately impounded into market prices (given that current tax information affects future stock returns). Weber (2009) attributes this result to the failure of analysts to utilize properly the information in estimated taxable income, which, while intriguing, implicitly assumes that analysts play an important informationprocessing role. Below we suggest possible extensions in this area of research.

\section{d. Summary}

The research reviewed in Section 8 provides robust evidence that markets use the tax accounts to set prices. Primary findings include:

- The market impounds information from the deferred tax accounts into prices.

\footnotetext{
${ }^{83}$ In a separate study, Chen et al. (2003) find evidence that they interpret as indicating that analysts do not fully understand certain AFIT provisions. A one-time deferred tax adjustment was required in association with the 1993 increase in corporate income tax rates from 34\% to 35\%. Given that this was a one-time adjustment, it should not have affected analysts' forecasts of the future - but it did, on average, implying that analysts incorrectly thought the adjustment would be recurring.
} 
- The market prices the tax account components at a discount, which reflects the length of time until expected reversal of the deferred tax component.

- Taxable income, estimated using tax information in the financial statements, provides information to the market incremental to the information in book income.

- In cross-sectional tests, the relative contribution of estimated taxable income decreases to the extent that firms engage in aggressive tax planning.

- Firms with extreme BTDs have less persistent earnings and accruals.

- Firms with large BTDs (low values of the TI/BI ratio) have lower P/E ratios and lower future earnings growth.

- Unexpected estimated taxable income and the ratio of estimated taxable income to book income predict future returns, a finding that Weber (2009) attributes to the failure of analysts to utilize properly the information in estimated taxable income.

\section{e. Future Research about the Pricing of Tax Information Reported in the Financial Statements}

The findings in this section raise interesting questions and provide several avenues for additional work:

- Further work is needed to test and reconcile the theoretical predictions and the empirical findings about the valuation of DTLs and whether they should be discounted. DTLs are not discounted under SFAS No. 109, and Guenther and Sansing (2004) show that, under certain assumptions, the value of the DTL is unrelated to the time until reversal. On the other hand, empirical evidence indicates that the market discounts DTLs. Policymakers, among others, would benefit from resolution of this apparent conflict between the theory and the empirical evidence.

- Additional work is warranted to determine whether the market prices the valuation allowance account. Ayers (1998) reports that the VA is priced as a reduction in assets, while Amir and 
Sougiannis (1999) and Amir et al. (1997) report that it is not. Reconciliation of these conflicting findings and exploration of the circumstances under which the VA proves to be value relevant could prove interesting. A substantial issue with respect to these studies is that most of them conduct some form of a price level analysis, and thus are subject to a variety of econometric issues. This literature, to date, has done very little to resolve these problems.

- Additional work is warranted to determine whether the incremental information content of estimated taxable income is higher (Ayers et al. (2009)) or lower (Chen et al. (2007)) for firms that appear to extensively manage earnings.

- Resolution of the informativeness of temporary timing differences to the market is needed. Hanlon (2005) finds that temporary differences affect earnings persistence while Lev and Nissim (2004) report that they have no explanatory power for current E/P and future earnings growth. It could be useful to disaggregate the BTDs and determine which are relevant for both current and future returns and why they are.

- Given that taxable income is estimated for these studies by grossing up the current income tax expense reported in the income statement, it is not clear whether the observed pricing behavior relates to the market's attempts to actually price taxable income or whether the market is merely pricing a component of the income statement. Further analysis is needed to assess what exactly the market is pricing.

- We look forward to research about the information content of taxes netted against below-the-lines items. Do the markets respond to them the same as to other taxes? To our knowledge, no one has explored how the market evaluates these items.

- As a whole, the tax (and non-tax) accounting literature has not adequately explained why and how tax information affects future stock returns. In other words, why is the market slow to impound current period tax information? 
- It is interesting to note that this literature deals only with the use of the tax information by equity market participants. However, as discussed by Holthausen and Watts (2001), there are many other users of the financial statements (e.g. public debt market participants, private creditors, customers, employees, and regulatory bodies.) It could be interesting to examine the extent to which and the accuracy with which tax information in the financial statements is used by other groups.

- Finally, the measurement of standard errors could be improved in many of these studies. Future research based on robust standard errors may reverse or temper some of the extant conclusions. Section 11 explores this issue in more detail.

\section{Book-Tax Conformity}

\section{a. Background}

As discussed above, for many transactions book and tax treatments are the same or similar. For those transactions, financial accounting considerations can constrain tax management, and tax considerations can constrain financial reporting management, so that ultimately a firm has to balance tax and financial reporting choices. If book and tax do not conform, then the tension (e.g., between higher earnings and lower taxable income) does not exist, or at least is reduced. With lack of conformity, managers can potentially produce favorable outcomes for book purposes without increasing their tax liability or reduce their taxes without adversely affecting their financial reports. In some cases when book and tax do not conform, managers can achieve both favorable financial reports and lower taxes.

Since non-conformity appears to increase the opportunities for earnings and tax management, some tax scholars and policymakers have called for expanded conformity (also called alignment) of book and tax treatment as a constraint on earnings management and tax avoidance. ${ }^{84}$ Among other benefits,

\footnotetext{
${ }^{84}$ Freedman (2008) notes that, while conformity is being advocated in the U.S. as a means of improving book and tax reporting, the conformity debate in the EU has centered on the appropriateness of IFRS for establishing the tax base and particularly the potential for harmonizing the EU tax base (see discussions in Schön (2004) and (2005)
} 
proponents of conformity argue that aligning book and tax treatment will reduce earnings overstatement and taxable income understatement. ${ }^{85}$

Conformity proponents recommend that tax accounting adopt the same rules as financial accounting as often as possible, so that the tax liability approaches the product of the tax rate and pre-tax GAAP profits. For example, in July 2009, Senators Carl Levin and John McCain introduced Senate Bill 1491 (Ending Excessive Corporate Deductions for Stock Options Act). They propose setting the tax deduction for stock options equal to the book expense for stock options. Currently, firms can deduct the excess of the stock's market value over the strike at exercise. For book purposes, the expense is determined at grant using an option pricing method. If tax were conformed to book, then the tax deduction in the current period would shift from the ex-post tax realization to the ex-ante book estimate, eliminating the current difference between the financial accounting expense and the tax deduction.

McClelland and Mills (2007) summarize many of the costs and benefits of taxing book income, besides reining in earnings and tax manipulation. ${ }^{86}$ First, eliminating the need for tax accounting would enable firms to maintain a single set of books, thereby reducing record keeping, tax compliance, tax planning, and tax administration costs. Second, for decades financial accounting has been refining measures of income. Conformity would allow the tax system to better exploit this investment. Third, conformity would eliminate cross-firm differences in effective tax rates and the need for the complexity of deferred tax accounts.

(2005) and Freedman (2004), among others). Although the debate is generating important attention on both sides of the Atlantic, we focus on the American issues swirling around increased alignment.

${ }^{85}$ For example, Badertscher et al. (2009) examine a set of firms that restated earnings. They differentiate between firms that engage in conforming earnings management activities versus those that engage in nonconforming earnings management. Conforming (nonconforming) earnings management involves management that does (does not) have current income tax consequences. They find that nonconforming earnings management is more prevalent than conforming earnings management. Thus, the authors suggest that since firms can currently find ways to manage book earnings upward without affecting taxable income, imposing book-tax conformity could discourage earnings management. Mills and Newberry (2001) examine a sample of public and private firms and find that public firms have larger book-tax difference than do private firms. This finding is consistent with book income being more useful for investors in public firms than for investors in private firms, who likely are insiders.

${ }^{86}$ For other discussions of the pros and cons of increased alignment, see Desai (2005), Neubig (2006), Lenter et al. (2003), Hanlon and Shevlin (2005), and Schön (2005) (2005), among others. 
A fourth possible benefit in McClelland and Mills (2007) is that by taxing book profits, the same amount of tax revenue could be collected with a lower, and thus less distortive, corporate tax rate. This purported benefit assumes that firms would not reoptimize to reduce book income in a conformed system. It also assumes that book income exceeds taxable income. As discussed above, the findings in Figure 3 raise doubts about this second assumption. Figure 3 shows that book income usually exceeds estimated taxable income. However, dramatic declines in book profits in 2001 and 2008, both recessionary years, resulted in aggregate book income (summed from 1993 to 2008) actually being less than aggregate estimated taxable income. Thus, the revenue benefits of conformity appear to vanish when economic downturns are taken into consideration.

However, there is an effect, not mentioned in the extant literature, including McClelland and Mills (2007), that could lead to a reduction in corporate tax rates. All else equal, if book income is more volatile than taxable income, then expected corporate tax revenues will increase if book profits are taxed because of the convexity of the tax schedule (see Graham and Smith (1999)). The findings in Figure 3 are consistent with book income being more volatile than taxable income. The coefficient of variation for book income is 0.48 , more than double the coefficient of variation for estimated taxable income of 0.23. Consequently, this convexity effect would appear to enable a reduction in corporate tax rates, while still holding overall tax revenues constant.

On the cost side, McClelland and Mills (2007) argue that there are several detriments to taxing book profits. First, eliminating the need for separate tax accounting for U.S. federal tax purposes would not necessarily eliminate the need for tax accounting. Firms would still need tax accounting for state and foreign jurisdictions and regulators. Second, if firms were taxed on book profits, they would have an incentive to understate their earnings. Such earnings understatement could diminish the usefulness of the financial statements for the capital markets. ${ }^{87}$ Third, transition from the current system to a conformed

\footnotetext{
${ }^{87}$ One possible way that firms could circumvent the adverse effects of reporting reduced earnings would be to use alternative means of communicating information to the markets, e.g., issuing pro-forma statements that would not use the same accounting as tax returns.
} 
system would be non-trivial, particularly for multinationals and with respect to coordination with trading partners. $^{88}$

Fourth, the goals and implementation of financial reporting differ from those of tax accounting in important ways. For example, financial reporting requires more judgment. Introducing more judgment into the tax system would undermine the certainty needed to administer a tax system. Likewise, requiring firms to accelerate losses and defer gains (consistent with conservatism in financial accounting) runs counter to the principle of gain acceleration and loss deferral in the current tax system (which is designed to limit the loss of tax revenue from the government's perspective).

\section{b. Empirical Tests}

Rather than elaborating further on the pros and cons of conformity, we now turn to empirical work that attempts to inform policymakers about the benefits and costs of taxing book profits.

Unfortunately, we find little work that is of direct usefulness in the policy arena, where the debate is most heated. There are at least two reasons for the paucity of work in this area. First, many accounting scholars believe that the costs of conformity far outweigh its benefits and that its passage is highly unlikely. Consequently, few accounting researchers have engaged in the debate despite the competitive advantages of accounting researchers in this arena. Second, the ideal research design for purposes of informing the policy community would observe the changes in financial reporting and tax planning following mandated conformity. Unfortunately, researchers rarely have the opportunity to observe behavior before and after conformity.

Probably the most active area of related research investigates an indirect implication of alignment, i.e., whether the market would suffer a loss of information if book and tax were conformed. The potential loss of information in the financial statements arises because no BTDs would exist if book and tax accounting were identical. Because we discussed many of these papers in Section 8.c. (e.g., Lev

\footnotetext{
${ }^{88}$ See Hanlon and Maydew (2009) for a detailed analysis of the difficulties in applying book-tax alignment to multinationals. Problems include differences in the consolidation of foreign subsidiaries, integration with other governments' tax systems, and the determination of the source (jurisdictional location) of income.
} 
and Nissim (2004), Hanlon et al. (2005), Schmidt (2006), Thomas and Zhang (2007), and Weber (2009), among others), we do not review them here. Although most of these papers do not explicitly discuss conformity, they speak to the implications of conformity when they test whether estimates of taxable income drawn from the financial statements have incremental content, even after controlling for book income. For example, Hanlon et al. (2005) infer from their findings that the financial statements would suffer a substantial decrease in information content if conformity were implemented. Specifically, they estimate an information loss of 50\% if book income were conformed and based on tax rules. Largely, these studies conclude that conformity would lead to a loss of information to market participants. The reason is that the tax accounts in financial statements, which they find informative, would no longer be necessary under conformity.

For the remainder of this section, we focus on a handful of empirical studies motivated largely by conformity. One setting in which before and after behavior is observed following a mandate to tax book profits ended with investigators disagreeing about the conclusions to be drawn. A provision in the Tax Reform Act of 1986 required a firm to include some of the excess of book profits over taxable income in its alternative minimum taxable income. Gramlich (1991), Boynton et al. (1992), Dhaliwal and Wang (1992), Manzon (1992), and Wang (1994) report that companies shifted income from 1987 (when the law became effective) to 1986 (before the effective date). However, Choi et al. (2001) question their findings on methodological grounds, concluding that sample partition procedures, difficulty in identifying treatment and control firms, the choice of scaling variables, and procedures to estimate discretionary accruals are so problematic in these studies that the literature provides little evidence that the AMT affected book earnings. ${ }^{89}$ Consequently, this setting, which appeared to provide an excellent opportunity for estimating the impact of linking book profits to taxable income, failed to advance our understanding of the impact of taxing book profits. Given the disappointing outcome of this series of papers, we cannot recommend further exploration of this AMT provision until there is a resolution of the methodological problems that plagued these inquiries.

\footnotetext{
${ }^{89}$ For completeness, see Dhaliwal's (2001) response to their concerns.
} 
Guenther et al. (1997) and Hanlon et al. (2008) examine another setting where book-tax conformity was mandated. Using a time-series design, both take advantage of the fact that the Tax Reform Act of 1986 required a small set of firms to change from the cash to the accrual basis of accounting for tax purposes, thus increasing book-tax conformity for these firms. Guenther et al. (1997) find that following the imposed increase in conformity, firms chose to defer book income in order to reduce their tax payments. Hanlon et al. (2008) build on their study to test whether the information content of earnings for the firms that were forced to switch methods decreased after the legislation became effective. They find that it did, indicating that in this case book-tax conformity resulted in a loss of value-relevant information. An implication of their study is that book-tax conformity would reduce the quality of book income because firms would opt, at least to some extent, to pay less taxes even at the expense of providing the markets with poorer information. The strength of these studies is they exploit a rare natural experiment. Unfortunately, only a few, mostly small companies were required to change from the cash method to the accrual method. Guenther et al. (1997) analyze only 66 firms that were forced to switch from cash to accrual and Hanlon et al. (2008) study only 56 firms. Consequently, it is unclear whether these findings generalize to the broader population.

Natural experiments are rare. Therefore, few extant studies provide direct evidence about the impact of mandated conformity on earnings management and tax avoidance. Nonetheless, a few papers have looked at ancillary implications of conformity. Each of these studies identifies a cost of conformity that policymakers appear to have ignored, but which are important considerations.

One example is Young and Guenther (2003), who attempt to test whether conformity might reduce international capital mobility. They test whether countries with greater disclosure of value-related accounting information have more international capital mobility. One of their measures of the value relevance of financial reporting is a categorical variable based on the degree of book-tax conformity. They classify 13 countries as high conformity (e.g., France, Germany, and Japan) and ten countries as low conformity (mostly countries that were under the British crown at some point, including the U.S., Hong 
Kong, and Singapore). They find that international capital mobility is inversely related to book-tax conformity, implying that aligning book and tax reduces international capital mobility.

Although Young and Guenther (2003) attempt to control for differences between countries, other than conformity, their conclusions rest critically on the assumption that the interpretation regarding conformity is not adversely affected by an omitted, correlated variable that potentially captures a more important fundamental difference between these sets of countries. In addition, since all countries have elements of conformity, but none is fully conformed, attempting to distinguish among countries based on a single categorical variable fails to capture the richness of the book-tax accounting relationship.

Moreover, some countries, e.g., Germany, may be highly aligned at the company-level, but less so at the consolidated level.

Another study potentially undermined by omitted correlated variables is Ali and Hwang (2000), who report that conformity adversely affects the value relevance of earnings and cash flows. Employing a cross-sectional research design and studying 16 countries, they find that high book-tax conformity is associated with low value relevance of earnings and cash flows. ${ }^{90}$ Their findings should be interpreted with caution for two reasons. First, with only 16 countries, Ali and Hwang (2000) are unable to untangle the effects of conformity from other country-level differences. This is particularly problematic because they document that a country's book-tax alignment is correlated with whether its financial system is bankoriented or market-oriented, whether its financial accounting standards are set privately or by the government, and its level of spending on external auditing services. Second, they too use a categorical variable to assess the level of conformity in a country. While we applaud both Young and Guenther's (2003) and Ali and Hwang's (2000) aspirations to tackle important issues and recognize that they face data limitations that are common in cross-country analyses, advances in this area require more powerful settings and measures.

\footnotetext{
${ }^{90}$ Ali and Hwang (2000) also examine the effect that three additional country-specific variables have on value relevance. These other variables fall outside the purview of our current discussion.
} 
Atwood et al. (forthcoming) develop a continuous measure of book-tax conformity that can vary across years. Reasoning that the correlation between taxable income and book income should be greater in high-conformity countries, they measure a country’s book-tax divergence as the portion of current income tax expense that is not explained by book income and dividends. They end up with country-year conformity measure for 33 countries from 1992 to 2005. They then test whether the ability of current earnings to predict both future earnings and future cash flows varies with a country's level of conformity. They find that current earnings are less useful for predicting future earnings and cash flows when booktax conformity is high.

Interestingly, the country-level conformity measures (averaged over time) in Atwood et al.'s (forthcoming) Table 1 do not line up with the dichotomizations used in the prior literature. For example, 15 countries are included in both Ali and Hwang (2000) and Atwood et al. (forthcoming). Ali and Hwang (2000) classify seven as low conformity countries and eight as high conformity. Since Atwood et al.’s (forthcoming) scores are inversely related to conformity, we would expect the seven low-conformity countries to have scores less than those for the eight high-conformity countries. We find that the opposite is true, although the differences are not statistically significant. Specifically, the mean (median) conformity score for the low-conformity countries is 11.1 (11) compared with 10.4 (10) for the high conformity countries.

Notably, Atwood et al. (forthcoming) classify only two countries, Canada and South Africa, as having less conformity than Germany, which is usually put forth as a very high-conformity country. In their footnote 22, Atwood et al. (forthcoming) defend their classification of Germany because they evaluate firms based on their consolidated financial statements, which are not required by German law to conform, while other studies focus on their separate company accounts, which are required to conform. Perhaps similar explanations exist for other surprising differences in the Atwood et al. (forthcoming) measures and conventional thinking. However, at a minimum, Atwood et al. (forthcoming) raises serious concerns about all of the conformity studies, including theirs, that attempt to measure the level of 
conformity in countries. A consensus is badly needed about the general ranking of conformity across countries before the literature can move forward.

\section{c. Summary}

Book-tax conformity has emerged as a possible means of mitigating the adverse effects of both earnings management and tax underpayment. Scholars struggle to construct strong empirical tests that can provide policymakers with some sense of the changes that would occur in response to conformity because conformity changes are rare. To date, most empirical studies have attempted to assess the impact of conformity indirectly, although a few have identified settings where conformity has been implemented. Inferences, to date, are:

- The tax accounts provide incremental information to the equity markets. Thus, the elimination of the book-tax differences would reduce the flow of information to the markets.

- In the rare natural experiments where conformity has been imposed, the evidence is mixed about whether firms have altered the information reported on their financial statements in order to reduce their tax liability.

- Strong inferences are difficult to draw from any of these studies of whether firms behave differently depending on the level of conformity in their country. These studies struggle with omitted variables at the country-level that are potentially correlated with conformity. They also lack consensus about how to measure conformity.

\section{d. Future Research about Book-tax Conformity}

- Given the important policy implications of conformity, we look forward to additional empirical tests of the extent to which more alignment might reduce earnings and tax management as well as those that shed light on other implications of conformity. Additional estimates of the savings in compliance costs, possible reductions in tax rates, and transition costs are needed. Since 
accountants tend to emphasize the importance of high quality accounting information for the markets, they may dismiss the benefits of alignment and reject conformity out-of-hand. While we share their strong reservations about conformity, going forward we encourage accountants, economists, lawyers, and others to take a balanced approach to evaluating the potential costs and benefits of increased book-tax alignment.

- The low-to-high conformity scores produced by Atwood et al. (forthcoming) raise doubts about the prior measures of the level of conformity across countries. We look forward to the development of consensus measure of conformity, preferably continuous and varying across time, which is necessary to advance the important study of conformity.

\section{Unresolved Issues}

Throughout the paper, we have identified specific research questions and topics that merit additional inquiry. In this section, we highlight five general issues that deserve attention from the research community.

First, an overarching theoretical framework is needed to guide future empirical AFIT research. Shackelford and Shevlin (2001, pp. 377-378) termed AFIT research “a potentially understudied topic” and asserted that "Collaboration between tax and financial accounting researchers could address how firms coordinate reducing tax payments and managing book effective tax rates.” Since this call for research, nearly 50 empirical AFIT studies have been conducted, and work in this area is continuing. Much of it is interesting and important. However, looking forward, if no framework is developed, we envision diminishing returns as the empirical papers document increasingly minute AFIT factoids without really advancing our broad understanding of the role that AFIT plays in business, tax, and financial reporting decisions.

An important issue that an AFIT framework must consider addressing is the coordination of tax considerations with the standard agency problems that underlie much of financial accounting and economics. For example, tax information is reported confidentially to the taxing authorities and publicly 
through the financial statements. Understanding how these dual reports affect tax, book, and other decisions might provide some guidance for empirical AFIT studies. One recent theoretical paper that attempts to grapple with this coordination is Shackelford et al. (2009), who jointly evaluate taxation and financial reporting in a standard economic analysis of corporate behavior. They focus on the trade-offs between tax, book and investment choices. ${ }^{91}$ Another is Edgerton (2009) who argues that because AFIT determines the reporting of tax information to public investors, the timing of cash tax payments is less salient than it would be if tax information were reported on a cash basis. As a result, AFIT both mitigates the distortion from corporate tax minimization and diminishes the effectiveness of tax policy for altering behavior. Similar studies are needed to develop a unified framework that could aid interpretation of the many varied, and sometimes seemingly contradictory, empirical findings.

Until then, the AFIT literature risks remaining a collection of empirical findings, each interesting in its own right, but failing to provide a coherent narrative. For example, despite numerous studies attempting to determine whether, why, and how the tax accounts are used to manage earnings, we can only report in this review that the evidence is mixed. The new disclosures under FIN 48 will doubtlessly generate additional studies of earnings management through the tax contingency, and we believe that these studies are much more likely to reach clear and deep conclusions if conducted under an overarching framework, one that can guide tests of earnings management using the tax accounts.

Perhaps this is a common weakness of an emerging field, and certainly this criticism applies to areas of accounting research other than AFIT research, e.g., despite years of studying earnings management outside the tax accounts, there remain many unanswered questions. However, there are encouraging exceptions that might provide useful direction for developing a better mapping of empirical findings and theoretical models. Three come to mind. One, modern finance theory (beginning with

\footnotetext{
${ }^{91}$ Shackelford et al.'s (2009) (2009) key finding is that, to the extent that managers value flexibility in their tax and financial reporting choices, they are more likely to make non-tax, non-book decisions that provide discretion. A weakness of their study is that they do not formally model the role of information in determining the demand for financial reporting. Instead, they employ a reduced-form model and assume that managers may value accounting earnings, conditional on firm's cash flows.
} 
studies such as Modigliani and Miller (1958)) continues to provide a paradigm for evaluating empirical findings in finance. Two, positive accounting theory (Watts \& Zimmerman, 1986) revolutionized thinking about the role of accounting in contracting, leading to extensive empirical study in financial accounting. Three, the "Scholes-Wolfson” framework (Scholes \& Wolfson, 1992) has provided the structure for many tax studies in accounting, finance and economics over the last two decades. Similar structure would aid AFIT empirical research immensely.

Second, scholars need to reconcile seemingly inconsistent views about the tax information in the financial statements. On the one hand, the findings from some of the earnings management papers covered in section 7 (e.g., Frank and Rego (2006), Schrand and Wong (2003), and Krull (2004)) imply that at least in some situations (e.g., to meet analysts' forecasts), managers believe that the tax accounts can influence at least some users of financial statements. In addition, section 8 discusses other studies (e.g., Lev and Nissim (2004), Hanlon (2005), and Thomas and Zhang (2007)), which show that the markets appear to treat the tax items in the financial statements as if they contain information that is incremental to the information in book income in terms of explaining future earnings and share prices. On the other hand, anecdotal evidence from accountants, auditors, and tax specialists suggests that practitioners doubt that much can be learned about a firm’s actual taxes by perusing its financial statements. ${ }^{92}$ They assert that the tax information in the financial statements is inadequate and too obfuscatory to convey much information, in part because firms do not want to aid the taxing authorities in their audits.

We find it puzzling that the tax information in the financial statements can simultaneously communicate so little about a firm's actual taxes (as asserted by practitioners) and still influence analysts, explain future earnings, and predict share prices, among other things (as found in the empirical studies

\footnotetext{
${ }^{92}$ See anecdotes in McGill and Outslay (2002), among others. One purported reason for making the tax information somewhat opaque is to limit information to the taxing authorities. While this might explain the financial reporting choices of some smaller companies, the extent to which the IRS relies heavily on the public tax disclosures of large companies (given that they conduct continual tax return audits) is unclear. In fact, findings from some of the early FIN 48 studies, e.g., Frischmann et al. (2008), are consistent with added disclosure (in this case, FIN 48) providing little information to IRS auditors.
} 
discussed above). We look forward to research that resolves this conundrum. One possible explanation is that analysts and the capital markets are not interested in the firm's actual taxes. Instead, market participants may find something useful in the tax information that is unrelated to the actual taxes paid. For example, Thomas and Zhang's (2009) finding that returns are increasing in the tax expense, especially the current portion, suggests that the tax information provides another assessment of a firm's profitability. If so, researchers need to identify the non-tax information that is apparently communicated solely or more effectively through the tax accounts.

Third, disaggregating the book-tax differences may aid in resolving this and other puzzles. Some studies indicate that aggregated BTDs are associated with market pricing, aggressive tax planning, and earnings management, among other things (e.g., Desai 2003 and Hanlon et al. 2005). These studies use aggregated BTDs because the few separately disclosed BTDs in the financial statements are not readily available in computer readable form. Since some BTDs presumably convey little information to the users of the financial statements (e.g., differences in depreciation), this implies that other BTDs must provide important information that cannot be found elsewhere.

We are interested in research that disaggregates book tax differences and discovers the specific BTDs that are informative and why they are informative. We see at least two barriers to such inquiry. First, to our knowledge, no theory exists to guide researchers in their search for the more informative BTDs. In fact, it is difficult to imagine the types of BTDs that might be informative. Second, data collection likely will be costly. For example, to gather disaggregated BTDs, Poterba et al. (2009) and Seidman (2008) hand-collect data. Notwithstanding these barriers, BTD disaggregation could both advance scholarship and aid in policy questions concerning book-tax conformity.

Fourth, the pricing of the tax accounts raises questions about whether the market is inefficient or whether there is an important pricing factor that is not well understood. There is ample evidence that the market prices the tax information in the financial statements. At the same time, there also is evidence that current period tax information is associated with future prices. The challenge for future studies is to 
discern whether the long-run return effects are driven by market inefficiencies or a form of efficient pricing not currently understood. ${ }^{93}$

Finally, the U.S. is moving toward a convergence of current GAAP and IFRS, if not full adoption of IFRS. While there may be several researchable implications of this transition, it is currently unclear what the end result will be once we are through the transition. For example, this may result in opportunities to examine the issues surrounding book-tax conformity. The IRS (and Congress) will need to decide how they will handle the tax implications of IFRS adoption. Depending upon what they decide, there may well then exist a setting where the degree of book-tax conformity changes in the U.S.

In addition, there will likely be changes to the AFIT rules, either as a result of convergence of IAS 12 and SFAS No. 109 or as a result of full adoption of IFRS. Currently, the IASB has issued an exposure draft to revise IAS 12 and are anticipating the issuance of a final standard late in 2010 . While there are currently a number of differences between SFAS No. 109 and the revised IAS 12, it is uncertain which of these differences will remain upon the issuance of a final document. Thus, although it seems likely that there might be some changes in the AFIT rules if the U.S. adopts IFRS, it would be premature to chart a course for future research in this area. ${ }^{94}$

While the exact AFIT rules under IFRS are currently in transition, it is generally true that the international financial standards are more principle-based then the U.S. standards. Thus, there might exist an opportunity to reexamine the implications on the earnings management behavior of firms and the implications on market pricing under a set of standards that, in principle, allow for more judgmental decision making on the part of management.

\footnotetext{
${ }^{93}$ We recognize that the pricing of tax accounts is not the only area that raises this puzzle. Similar issues exist with post-earnings announcement drift, for example.

${ }^{94}$ There are still a number of differences in SFAS No. 109 and the revised IAS 12. For example, while the exposure draft now includes requirements for the reporting and measuring of tax contingencies, it is a one-step process under IFRS and the contingency is measured using a probability-weighted average as opposed to the FIN 48 requirement that bases the amount of the benefit to be recognized on the largest amount of tax benefit that is greater than $50 \%$ likely of being realized upon ultimate settlement.
} 


\section{Econometric Issues}

We close by focusing on problems involving econometric techniques and statistical inference that frequent the AFIT literature. ${ }^{95}$ The central issue is that AFIT researchers have often relied on ordinary least squares (OLS) methods to estimate parameters and calculate standard errors, implicitly assuming identically and independently distributed (i.i.d.) errors. This assumption is violated when residuals are correlated through time or across firms. ${ }^{96}$ With such correlation in residuals, there are effectively fewer “independent observations” than assumed by OLS, and therefore the t-statistics are often inflated. Once one adjusts for this correlation (i.e., clustering) in residuals, estimates of standard errors usually grow and, therefore, statistical significance as measured by corrected t-stats usually shrinks. Note that for clustering to affect a standard error, both the independent variable and the residual (or loosely speaking, the dependent variable) must be correlated across firms or through time. (This is because a standard error is associated with an estimated coefficient that itself measures the covariation between $\mathrm{X}$ and $\mathrm{Y}$.) Thus, accounting for the correlation in residuals addresses the lack of independence problem. We keep our discussion intuitive, to help researchers think through the basic issues and corrections. Readers interested in more details are encouraged to read Petersen (2009), Thompson (forthcoming), or Gow et al. (forthcoming).

We start by examining an empirical model that contains a measure of book tax differences as a right-hand-side variable. Recall from Figure 3 that book tax differences move dramatically in aggregate, depending on the state of the economy. Therefore, a specification including BTD is likely to contain residuals that are not particularly correlated for a given firm through time--but likely will contain (positive) cross-sectional correlations in the sense that many firms move together in a given year. ${ }^{97}$ In

\footnotetext{
${ }^{95}$ The issues discussed in this section are also commonly encountered broadly in empirical work in the fields of accounting, finance and economics, and they are by no means peculiar to AFIT studies.

${ }^{96}$ In this section, we focus on the independence assumption of residuals when we discuss clustering standard errors, and only briefly mention the impact of violations of the identical distributional assumption (i.e., heteroskedasticity) when we examine empirical examples.

${ }^{97}$ Consistent with such correlation patterns, in an untabulated analysis we find that the serial correlation in book tax differences, calculated separately for each individual firm and then averaged, is about 0.03 . At the same time, there is high cross-sectional correlation because aggregate book tax differences move dramatically from positive to
} 
such a setting, when we cluster standard errors by time (i.e., across firms in a given year) we expect a large effect on standard errors. The relatively small serial correlation for the typical firm implies that clustering standard errors by firm will not have much impact.

To illustrate these points, we estimate a model roughly similar to Heltzer (2008). Heltzer (2008) investigates the relation between book tax differences and accounting conservatism. In her specification, she includes indicator variables based on book tax differences on the right-hand side. Our goal is not to exactly mimic Heltzer (2008) but rather to illustrate general econometric points. Therefore, in our specification in equation (1) we include two straight-forward book tax difference variables, though the point we make here is the same if we copy her specification exactly. Specifically, we estimate the following regression for a panel of Compustat firms from 1983 to 2007:

$$
E / P_{i, t}=\alpha+\operatorname{Ret}_{i, t}+\operatorname{LPBTD}_{i, t}+L N B T D_{i, t}+\varepsilon_{i, t}
$$

where $\mathrm{E} / \mathrm{P}_{\mathrm{i}, \mathrm{t}}$ is the earnings-to-price ratio adjusted for the market's $\mathrm{E} / \mathrm{P}$ ratio, Ret $_{\mathrm{i}, \mathrm{t}}$ is the 12 -month cumulative stock return in excess of the CRSP market return and is aligned with the contemporaneous fiscal year-end. $\operatorname{LPBTD}_{i, t}$ (large positive book tax difference) is an indicator which is equal to 1 if the firm-year’s book-tax difference scaled by average assets falls in the top quintile of the 2-digit SIC industry, and $L N B T D_{i, t}$ (large negative book tax difference) is an indicator which is equal to 1 if the firmyear's book-tax difference scaled by average assets falls in the bottom quintile of the 2-digit SIC industry for firm $\mathrm{i}$ in time $\mathrm{t}$.

As can be seen in Table 2, the estimated coefficient on the large positive BTD is 0.957 in the OLS specification, with an estimated standard error of 0.189 and a $t$-statistic of 5.07 . When we correct by clustering standard errors by time in column 4 , the standard error nearly doubles, and the $t$-statistic falls almost in half. (Note that the estimated coefficient does not change. The analysis is simply to correct the standard errors and does not affect the coefficients.) In contrast, as conjectured (because serial correlation is low), clustering standard errors by firm (i.e., for a given firm through time; see column 3) has little

negative (the latter during economic downturns), apparently affecting the cross-section of firms similarly at any point in time (see Figure 3 for aggregate patterns). 
effect on standard errors or $t$-statistics. The effects are even starker for the variable that measures large negative book tax differences. The time-clustered standard error increases by a factor of five, with a similar effect on the estimated $t$-statistic. For LNBTD, there are some firm-clustering effects but as before not as large as for time-clustering.

Two other points are worth making. First, what would happen if one were to blindly correct for both time- and firm-clustering? We can see from Table 2 that the estimated coefficient is again the same, and the estimated standard errors in this case are similar to those for just time clustering (because in this case, time clustering is the correction that matters). That is, there is not much to gain (or in this case lose) in correcting for both potential issues. ${ }^{98} 99$ In general, however, we believe it makes sense to anticipate which correction(s) is (are) more likely to be needed so as to properly model the situation at hand. The second point is that when time-clustering is the primary issue, the traditional Fama-MacBeth method of correcting standard errors works well (very well for the book-tax difference variables in Table 2but not as well for the return variable). The Fama-MacBeth approach addresses cross-sectional correlation because it first estimates one cross-sectional equation per year. In a second stage, Fama-MacBeth then estimates the coefficients and standard errors based on the time series of these first stage estimates - but the standard errors from the first stage, and any cross-sectional clustering effects in first stage residuals, are not used and thus do not affect the second-stage outcome. If there is little firm-specific serial persistence of residuals, like for the book-tax difference variables in this example, the standard errors from this second step exhibit little bias due to autocorrelation effects, and Fama-MacBeth effectively produces standard error estimates close to the true standard errors.

Table 3 shows another example in which the earnings-to-price $(\mathrm{E} / \mathrm{P})$ ratio is a dependent variable. The empirical model is similar to that in Lev and Nissim (2004) who examine the ability of tax-based

\footnotetext{
${ }^{98}$ However, a "small” number of clusters could lead to large variances in standard error estimates (note that the standard errors that one uses are estimates of the "true" standard errors). Therefore, clustering standard errors in both dimensions (i.e., firm and time) is not always optimal. See the discussion at end of this section.

${ }^{99}$ Though not the focus of the example in Table 2, note that because returns (Ret) are correlated both through time and across firms, t-statistics fall when residuals are clustered by firm (column 3), by time (column 4), or both (column 6). Also note that, as discussed next, Fama-MacBeth (column 5) only addresses time clustering, and therefore does fully address the column (1) inflated t-statistic on the return variable.
} 
fundamentals to predict the $\mathrm{E} / \mathrm{P}$ ratio. Specifically we estimate the following regression for a panel of Compustat firms from 1980 to 2008:

$$
E / P_{i, t}=\alpha+\text { LNTA }_{i, t}+\text { Leverage }_{i, t}+\operatorname{Div}_{i, t}+\operatorname{Tax}_{i, t}+\varepsilon_{i, t}
$$

where $E / P_{i, t}$ is the earnings-to-price ratio, $L N T A_{i, t}$ is the log of total assets, Leverage $_{i, t}$ is book leverage, $\operatorname{Div}_{i, t}$ is common dividend divided by net income, and $\operatorname{Tax}_{i, t}$ is the ratio of taxable income $\times(1-$ top statutory federal tax rate) and net income for firm i in time t.

Since the models in Lev and Nissim (2004) and Heltzer (2008) have very similar dependent variables (i.e., E/P), we expect that the standard errors would be affected by time-clustering but not as much by firm-clustering for this specification. Indeed, Table 3 shows that implications of standard errors correction for Lev and Nissim (2004) are similar to Heltzer (2008). Across independent variables, standard errors increase by a factor of three to five when we cluster by time while they increase only by a factor of about two when we cluster by firm. In particular, the coefficient on LNTA appears highly significant for the OLS standard errors ( $\mathrm{t}$-stat $=-11.08$ ) but is barely significant (t-stat $=-1.79$ ) when the standard errors are corrected for clustering in the time dimension.

We conclude these examples by noting that Heltzer (2008) and Lev and Nissim (2004) use the Fama-MacBeth approach, so the potential statistical issues in the data are largely addressed. We will not do so here so as to avoid picking on particular papers, but many papers do not correct standard errors in a similar setting. It is our hope that future research into AFIT (as well as accounting, finance, and economics more generally) will properly address standard error issues, perhaps reevaluating the conclusions or earlier research along the way.

Another potential case for which clustering standard errors by time is recommended occurs when one uses permanently reinvested foreign earnings (“PRE”) as a dependent variable. Suppose that a large number of firms fail to meet an earnings target in an economic downturn. Then, many of these firms may respond to the bad year by increasing PRE to meet the earnings target. Similarly, many firms would decrease PRE in good years. Therefore, we expect that economy-wide shocks to earnings would lead 
PRE for many firms to move together; therefore, clustering standard errors by time is important for correct inference when permanently reinvested foreign earnings is a left-hand-side variable.

We now turn to an example involving the valuation allowance as a left-hand-side variable. The VA allowance contains substantial serial correlation and modest correlation in the cross-section. ${ }^{100}$ We use an empirical specification similar to that of Miller and Skinner (1998), who examine the determinants of the valuation allowance for deferred tax assets. Specifically, we estimate the panel regression in the following equation from 1993 to 2007:

$$
V A_{i, t}=\alpha+A V G R O A_{i, t}+\text { Leverage }_{i, t}+T L C F_{i, t}+\varepsilon_{i, t}
$$

where $\mathrm{VA}_{\mathrm{i}, \mathrm{t}}$ is the valuation allowance divided by total assets ${ }^{101}, \mathrm{AVGROA}_{\mathrm{i}, \mathrm{t}}$ is the average of return on assets (EBIT / beginning-year total assets) for current and previous years, Leverage $\mathrm{e}_{\mathrm{i}, \mathrm{t}}$ is book leverage defined as short- and long-term debt divided by total assets, and $\mathrm{TLCF}_{\mathrm{i}, \mathrm{t}}$ is net operating loss carryforward divided by total assets for firm $\mathrm{i}$ in time $\mathrm{t}$.

Table 4 presents the effects of correcting standard errors for clustering by firm, time, or both, when the dependent variable is the valuation allowance. The first column shows the OLS coefficient and standard error estimates based on the assumption of i.i.d. residuals. In this specification, the coefficient on tax-loss carryforward is -0.342 and the standard error estimate is 0.008 with a very large $t$-statistic of 41.60. When we cluster standard errors by firm in the third column, the standard error estimate more than quadruples to 0.039 and thus the $t$-statistic becomes -8.72 . Similarly, standard errors estimates for average ROA and book leverage also increase by a factor of three to five when we cluster standard errors by firm. In contrast, when we cluster standard errors by time (or equivalently use the Fama-MacBeth procedure), the estimates of standard errors only double for all coefficients. This result suggests that firm effects are more important than time effects in this setting because residuals and regressors are more highly correlated within rather than across firms. As a result, contrary to the examples of Heltzer (2008)

\footnotetext{
${ }^{100}$ Consistent with a persistent firm effect, we find that the valuation allowance has a mean within-firm autocorrelation of 0.46 .

${ }^{101}$ We thank Jeri Seidman and Jim Poterba for providing these valuation allowance data.
} 
and Lev and Nissim (2004), using the Fama-MacBeth procedure (or similarly, clustering by time) does not adequately correct residuals that are clustered by firm in this example. ${ }^{102} 103$

Note that if firm effects are permanent, standard errors can be corrected for firm-level clustering by including firm fixed effects in the specification. However, if the firm effects are not fixed (that is, not permanent), then this approach will not completely address firm-level clustering of residuals. Moreover, even when firm fixed effects do completely address standard error issues, the estimated coefficients of independent variables generally differ from OLS coefficients because the former are not based on total variation (i.e., firm-level variation is excluded). Analogously, time fixed effects can be used to address time-clustering with the same caveats.

As mentioned above, clustering standard errors affects inferences when independent variable(s) and the residual (or loosely, the dependent variable) are both correlated across firms (or through time). For example, if an independent variable is serially uncorrelated, clustering standard errors by firm would not change standard error estimates even when a dependent variable alone is highly serially correlated. Also, although clustering standard errors by firm or time increases the standard error estimates and thereby decreases the significance of coefficients in the examples above, there are cases in which correcting for clustering actually reduces standard errors. This could happen if an independent variable has a negative correlation through time (or across firms) while the dependent variable has a positive correlation through time (or across firms), or vice versa.

We conclude this section by noting that using more robust standard errors (e.g., double clustering by firm and time rather than clustering in one dimension only) is not always best. In general, more robust standard errors tend to be less biased but have higher variances because estimates of clustered standard

\footnotetext{
${ }^{102}$ In principle, to address firm clustering, one could follow a "transposed Fama-MacBeth” strategy of first performing a single time series regression for each firm, and then averaging these first stage estimated coefficients across firms. Such an approach in principle would side-step serial correlation for any given firm. However, for small sample reasons, we would not recommend such an approach unless a very long time series (large T) is available. ${ }^{103}$ While it is not a focus of this section, the example in Table 4 illustrates that heteroskedasticity in the errors can introduce bias to estimates of standard errors. For instance, standard errors more than double for AVGROA and TLCF when we use the heteroskedasticity-robust standard errors (White, 1980) compared to the OLS standard errors. Also, note that the clustering techniques discussed in this section correct for heteroskedasticity.
} 
errors are based on sample averages across clusters (e.g., firm or time). When the number of clusters is small, the estimates of clustered standard errors become noisier due to small samples. ${ }^{104}$ Therefore, researchers should begin by using economic reasoning about the existence of cross-sectional or serial correlation in variables of interest, and then choose methods for correcting standard errors, rather than blindly using the most elaborate standard error corrections.

\section{Closing Remarks}

To our knowledge, this is the first paper that attempts to provide a comprehensive structure for understanding and evaluating recent research about the tax information in financial statements. Historically largely overlooked by both financial accounting and tax researchers, no area of tax research in accounting is currently attracting more scholarly attention than is accounting for income taxes. Applying skills developed in and questions imported from mainstream financial accounting research, the empirical studies have concentrated on the role of the tax accounts in earnings management and the extent to which the market prices the tax information that is contained in the financial statements.

AFIT studies have been conducted primarily by accounting scholars with expertise in both financial accounting and taxation, a sufficiently rare combination that has served as a barrier to researching this complex area of financial reporting. We hope that this review will encourage, expedite, and guide further AFIT study. We also hope that this paper will expose scholars from finance, economics, law, and other fields to the ongoing AFIT work, interest them in both producing and consuming its knowledge, and guide them toward questions of interest. We conclude our review with a summary of our findings.

The first half of the paper explains the tax accounts and the rules that govern them, discusses permanent and temporary differences, and provides descriptive information about the tax disclosures. It

\footnotetext{
${ }^{104}$ See Thompson (forthcoming) for more a detailed discussion of the trade-off between the bias and variance in clustered standard errors estimates. He argues that one would like at least 25 observations in a given direction to minimize the impact of false rejections that can occur in small samples. Thus, Thompson concludes that fewer than 25 clusters in both dimensions would be considered too few to apply double-clustering techniques.
} 
also notes the inadequacy of the tax information in the financial statements for estimating actual tax return information and assessing the effectiveness of the firm's tax planning.

The second half of the paper begins with a review of earnings management using the tax accounts. We find mixed evidence about earnings management. Managers appear to use the valuation allowance and the uncertain tax contingency to meet or beat analysts' forecasts, but not to meet or beat prior earnings, smooth earnings, increase a big bath, or avoid losses. This result is a bit puzzling, and we suggest some avenues for future research to address these inconsistencies. Studies of the new disclosures under FIN 48 are emerging, and they may provide fresh insights about the use of the tax contingency account to manage earnings.

Next, we address the pricing of the tax accounts. With the possible exception of the VA account, the studies consistently show that the market impounds information from the deferred tax accounts into prices. Furthermore, the pricing of the tax account components varies in predictable ways with the length of time until reversal. In addition, taxable income (estimated from the financial statement tax accounts) provides information to the market incremental to that in book income. Unexpected estimated taxable income and the ratio of estimated taxable income to book income predict future returns. Finally, large BTDs are associated with less persistent earnings and accruals, lower P/E ratios, and lower future earnings growth. Further understanding of BTDs may require disaggregating them to determine which differences are driving the results.

We discuss a topic of increasing interest in the tax policy community, namely the alignment of book and tax accounting. Proponents see book-tax conformity as a means of constraining both earnings manipulation and tax evasion, among other advantages. Those opposed to conformity point to the different goals of financial accounting and tax compliance and question whether conformity would impede manipulation of book or tax accounts. The limited empirical evidence suggests that conformity would reduce the information that financial reports provide to the capital markets, but additional studies are needed to fully discern the costs and benefits of increased book-tax alignment. 
In the final two sections of the paper, we identify issues that deserve close scrutiny going forward. First, empirical AFIT research is suffering from a lack of theoretical guidance. As a group, the empirical studies reviewed in this paper lack focus, which impedes interpretation of extant findings and identification of the next frontiers. Second, some findings suggest that market participants greatly value the tax information in the financial statements. This stands in stark contrast to a widely held view among many practitioners that tax disclosures are of little value. Further study is needed to explain how reportedly poor quality disclosures convey such important information.

Third, numerous studies point to book-tax differences as evidence of aggressive earnings management and/or aggressive tax planning and find that the market responds to cross-sectional differences in BTDs. However, almost all of these studies use aggregated BTDs. Some BTDs are presumably evidence of neither earnings management nor tax planning (e.g., differences in depreciation). Thus, disaggregating BTDs into their specific accounts could enable us to identify those BTDs that are related to earnings management, tax planning, or other factors, such as growth and business cyclicality.

Fourth, the extant literature is mostly silent about whether certain market reactions, in particular long run return effects, are evidence of market inefficiency or limits to arbitrage or some other market imperfection. We hope that future research can help to resolve these puzzling effects related to the pricing of tax information. Fifth, the coming adoption of IFRS in the U.S. will affect the tax information in the financial statements and provide further research opportunities.

Finally, the paper closes with a discussion of econometric weaknesses that permeate some AFIT research. Few of the papers reviewed herein take advantage of state-of-the-art econometric techniques that are available to properly calculate standard errors when residuals are correlated cross-sectionally or through time, or both. Presently standard errors in much AFIT research are calculated as if all observations are independent. Therefore, the statistical significance likely is overstated for many findings in the literature. Going forward, empirical AFIT research should give careful attention to clustered standard errors and cross-correlation patterns in the residuals. 
In conclusion, AFIT research has blossomed in the last few years, vastly expanding our knowledge about the use of the tax information in the financial statements. Assuming that a framework develops to better interpret extant empirical findings and guide future study, we see many questions that still need resolution. We have detailed many suggestions for additional research throughout the paper and look forward to further discovery of knowledge and understanding about the tax accounts in the financial statements. 


\section{References}

Abarbanell, J., \& Bushee, B. (1998). Abnormal returns to a fundamental analysis strategy. The Accounting Review , 73, 19-45.

Abarbanell, J., \& Bushee, B. (1997). Fundamental analysis, future earnings, and stock prices. Journal of Accounting Research , 35, 1-24.

Accounting Principals Board. (1972). Opinion No. 23, Accounting for Income Taxes - Special Areas. Stamford: APB.

Accounting Principles Board. (1967). Opinion No. 11, Accounting for Income Taxes. Stamford: APB.

Albring, S., Dzuranin, A., \& Mills, L. (2005, August 5). Tax savings on repatriations of foreign earnings under the Jobs Act. Tax Notes , 655.

Alexander, R., Ettredge, M., Stone, M. S., \& Sun, L. (2009). No news is bad news: Determinants of the availability and usefulness of mandatory SAB74 disclosures. University of Kansas working paper.

Ali, A., \& Hwang, L. (2000). Country-specific factors related to financial reporting and the value relevance of accounting data. Journal of Accounting Research , 38, 1-21.

Amir, E., \& Sougiannis, T. (1999). Analysts' interpretation and investors' valuation of tax carryforwards. Contemporary Accounting Research , 16, 1-33.

Amir, E., Kirschenheiter, M., \& Willard, K. (1997). The valuation of deferred taxes.

Contemporary Accounting Research , 14, 597-622.

Atwood, T., Drake, M., \& Myers, L. (forthcoming). Book-tax conformity, earnings persistence

and the association between earnings and future cash flows. Journal of Accounting and

Economics .

Ayers, B. (1998). Deferred tax accounting under SFAS No. 109: an empirical investigation of its incremental value-relevance relative to APB No. 11. The Accounting Review , 73, 195-212. Ayers, B., Jiang, X., \& Laplante, S. (2009). Taxable income as a performance measure: the effects of tax planning and earnings quality. Contemporary Accounting Research , 26 (1), 15-54. Badertscher, B., Phillips, J., Pincus, M., \& Rego, S. (2009). Earnings mangement strategies: To confrom or not to conform. The Accounting Review , 84 (1), 63-97.

Barth, M., Beaver, B., \& Landsman, W. (2001). The relevance of the value relevance literature for financial accounting standard setting: another view. Journal of Accounting and Economics , 31, 77-104.

Bauman, C., Bauman, M., \& Halsey, R. (2001). Do firms use the deferred tax asset valuation allowance to manage earnings? Journal of the American Taxation Association , 23 (Supplement), 27-48.

Bauman, M., \& Shaw, K. (2005). Disclosure of managers' forecasts in interim financial statements: A study of effective tax rate changes. Journal of the American Taxation Association , 27, 57-82.

Beatty, A., Berger, P., \& Magliolo, J. (1995). Motives for forming research \& development financing organizations. Journal of Accounting and Economics , 19, 411-442.

Beaver, W., \& Dukes, R. (1972). Intraperiod tax allocation, earnings expectations, and the behavior of security prices. The Accounting Review , 47, 320-332. 
Behn, B., Eaton, T., \& Williams, J. (1998). The determinants of the deferred tax allowance account under SFAS No. 109. Accounting Horizons , 12, 63-78.

Blaylock, B., Shevlin, T., \& Wilson, R. (2009). Tax avoidance, large positive book-tax differences, and earnings persistence. University of Washington working paper.

Blouin, J., \& Krull, L. (2009). Bringing it home: A study of the incentives surrounding the repatriation of foreign earnings under the American Jobs Creation Act of 2004. Journal of Accounting Research , 47 (4), 1027-1059.

Blouin, J., \& Tuna, I. (2007). Tax contingencies: Cushioning the blow to earnings? University of Pennsylvania working paper.

Blouin, J., Core, J., \& Guay, W. (2008). Improved estimates of marginal tax rates: Why they are needed, approach, and implications. University of Pennsylvania working paper.

Blouin, J., Gleason, C., Mills, L., \& Sikes, S. (forthcoming). Pre-empting disclosure? Firms’ decisions prior to FIN 48. The Accounting Review.

Blouin, J., Gleason, C., Mills, L., \& Sikes, S. (2009). The implications of uncertain tax benefits for valuation. University of Pennsylvania working paper.

Blouin, J., Gleason, C., Mills, L., \& Sikes, S. (2007). What can we learn about uncertain tax benefits from FIN 48? National Tax Journal , 60 (3), 521-535.

Boynton, C., Dobbins, P., \& Plesko, G. (1992). Earnings management and the corporate alternative minimum tax. Journal of Accounting Research , 30 (Supplement), 131-153. Bryant-Kutcher, L., Guenther, D., \& Jones, D. (2007). Earnings persistence and the value of changes in firms' effective tax rates. University of Oregon working paper.

Chaney, P., \& Jeter, D. (1994). The effect of deferred taxes on security prices. Journal of Accounting, Auditing and Finance, 9, 91-116.

Chen, K., \& Schoderbek, M. (2000). The 1993 tax rate increase and deferred tax adjustments: a test of functional fixation. Journal of Accounting Research, 38, 23-44.

Chen, K., Danielson, M., \& Schoderbek, M. (2003). Analysts’ interpretation of transitory earnings components: Evidence from forecast revisions after disclosure of the 1993 deferred tax adjustment. Journal of Accounting, Auditing, and Finance , 18 (3), 333-353.

Chen, L., Dhaliwal, D., \& Trombley, M. (2007). The impact of earnings management and tax planning on the information content of earnings. University of Arizona working paper.

Choi, W., Gramlich, J., \& Thomas, J. (2001). Potential errors in detecting earnings management: Reexamining studies investigating the AMT of 1986. Contemporary Accounting Research , 18, 571-613.

Christensen, T., Paik, G., \& Stice, E. (2008). Creating a bigger bath using the deferred tax valuation allowance. Journal of Business Finance \& Accounting , 35 (5-6), 601-625.

Clinch, G., \& Shibano, T. (1996). Differential tax benefits and the pension reversion decision. Journal of Accounting and Economics , 21 (1), 69-106.

Collins, J., Geisler, G., \& Shackelford, D. (1997). The effect of taxes, regulation, earnings, and organizational form on life insurers' investment portfolio realizations. Journal of Accounting and Economics , 24 (3), 337-361.

Collins, J., Hand, J., \& Shackelford, D. (2001). Valuing Deferral: The Effect of Permanently Reinvested Foreign Earnings on Stock Prices. In J. James R. Hines (Ed.), International Taxation and Multinational Activity. Chicago: University of Chicago Press.

Collins, J., Shackelford, D., \& Wahlen, J. (1995). Bank differences in the coordination of regulatory capital, earnings, and taxes. Journal of Accounting Research , 33, 263-291. 
Comprix, J., Mills, L., \& Schmidt, A. (2009). Bias in quarterly estimates of annual effective tax rates and earnings management incentives. University of Texas working paper.

Cook, K., Huston, G., \& Omer, T. (2008). Earnings Management Through Effective Tax Rates: The Effects of Tax Planning Investment and the Sarbanes-Oxley Act of 2002. Contemporary Accounting Research , 25 (2), 447-471.

Crabtree, A., \& Maher, J. (2009). The influence of differences in taxable income and book income on the bond credit market. Journal of the American Taxation Association , 31 (1), 75-99. De Waegenaere, A., \& Sansing, R. (2008). Taxation of international income and accounting valuation. Contemporary Accounting Research , 25, 1045-1066.

De Waegenaere, A., Wielhouwer, J., \& Sansing, R. (2003). Valuation of a firm with a tax loss carryover. Journal of the American Taxation Association , 25 (Supplement), 65-82.

Dechow, P., Sloan, R., \& Sweeney, A. (1995). Detecting earnings management. The Accounting Review , 70, 193-225.

Desai, M. (2006, May 9). Reform alternatives for the corporate tax. Testimony before the US House of Representatives Committee on Ways and Means, Subcommittee on Select Revenue Measures, Corporate Tax Reform public hearing . Washington DC.

Desai, M. (2005). The degradation of reported corporate profits. Journal of Economic Perspectives , 19, 171-192.

Desai, M. (2003). The divergence between book income and tax income. (J. M. Poterba, Ed.) Tax Policy and the Economy, pp. 169-206.

Desai, M., \& Dharmapala, D. (2006). Corporate tax avoidance and high-powered incentives. Journal of Financial Economics , 79, 145-179.

Dhaliwal, D. (2001). Discussion of "Potential errors in detection of earnings management:

Reexamining studies investigating the AMT of 1986". Contemporary Accounting Research , 18, 615-623.

Dhaliwal, D., \& Wang, S. (1992). The effect of book income adjustment in the 1986 alternative minimum tax on corporate financial reporting. Journal of Accounting and Economics , 15, 7-26. Dhaliwal, D., Gleason, C., \& Mills, L. (2004). Last-chance earnings management: using the tax expense to meet analysts’ forecasts. Contemporary Accounting Research , 21, 431-459.

Dhaliwal, D., Huber, R., Lee, H., \& Pincus, M. (2008). Book-tax differences, uncertainty about fundamentals and information quality, and cost of capital. University of Arizona working paper. Dhaliwal, D., Trezevant, R., \& Wilkins, M. (2000). Tests of deferred tax explanation of the negative association between the LIFO reserve and firm value. Contemporary Accounting Research , 17, 41-59.

Dharmapala, D., Foley, C., \& Forbes, K. (2009). Watch what I do, not what I say: The unintended consequences of the Homeland Investment Act. NBER working paper 15023. Dunbar, A., Kolbasovsky, L., \& Phillips, J. (2007). FIN 48 Adoption Disclosures . Financial Reporting Watch .

Dworin, L. (1985). On estimating corporate tax liabilities from financial statements. Tax Notes , 29 (Special Report), 965.

Dyreng, S. (2009). The cost of private debt covenant violation. Duke University working paper. Dyreng, S., Hanlon, M., \& Maydew, E. (2008). Long-run corporate tax avoidance. The Accounting Review , 83, 61-82.

Edgerton, J. (2009). Investment, accounting and the salience of the corporate income tax. Federal Reserve Board working paper. 
Engel, E., Erickson, M., \& Maydew, E. (1999). Debt-equity hybrid securities. Journal of Accounting Research , 37, 249-274.

Financial Accounting Standards Board. (1984). Concept Statement No. 5, Recognition and Measurement in Financial Statements of Business Enterprises. Norwalk: FASB. Financial Accounting Standards Board. (2006). Financial Accounting Standards Board Interpretation No. 48, Accounting for Uncertainty in Income Taxes. Norwalk: FASB. Financial Accounting Standards Board. (1992). Statement of Financial Accounting Standards No. 109, Accounting for Income Taxes. . Norwalk: FASB.

Frank, M. M. (2009). Discussion of "Inferring U.S. tax liability from financial statement information". Journal of the American Taxation Association , 31 (1), 65-74.

Frank, M. M., \& Rego, S. (2006). Do managers use the valuation allowance account to manage earnings around certain earnings targets? Journal of the American Taxation Association , 28, 4365.

Freedman, J. (2004). Aligning taxable profits and accounting profits: Accounting standards, legislators and judges. eJournal Tax Research , 2 (1), 71-99.

Freedman, J. (2008). Financial and tax accounting: Transparency and truth. In W. Schon (Ed.), Tax and Corporate Governance (pp. 71-92). Springer Science.

Frischmann, P., Shevlin, T., \& Wilson, R. (2008). Economic consequences of increasing the conformity in accounting for uncertain tax benefits. Journal of Accounting and Economics , 46, 261-278.

Givoly, D., \& Hayn, C. (1992). The valuation of the deferred tax liability: evidence from the stock market. The Accounting Review , 67, 394-410.

Gleason, C., \& Mills, L. (2007). Do auditor-provided tax services improve the estimate of tax expense? University of Texas working paper.

Gleason, C., \& Mills, L. (2008). Evidence of differing market responses to beating analysts' targets through tax expense decreases. Review of Accounting Studies , 13, 295-318.

Gleason, C., \& Mills, L. (2002). Materiality and contingent tax liability reporting. The Accounting Review , 77, 317-342.

Gleason, C., Pincus, M., \& Rego, S. (2007). Material weaknesses in tax-related internal controls and earnings management. University of Texas working paper.

Gordon, E., \& Joos, P. (2004). Unrecognized deferred taxes: evidence from the U.K. The Accounting Review , 79, 97-124.

Gow, I., Ormazabal, G., \& Taylor, D. (forthcoming). Correcting for cross-sectional and timeseries dependence in accounting research. The Accounting Review .

Graham, J. (1996). Proxies for the corporate marginal tax rate. Journal of Financial Economics , 42, 187-221.

Graham, J. R., \& Kim, H. (2009). Simulating corporate marginal income tax rates and implications for corporate debt policy. Duke University working paper.

Graham, J. R., \& Smith, C. (1999). Tax incentives to hedge. Journal of Finance , 54, 2241-2262.

Graham, J. R., Hanlon, M., \& Shevlin, T. (2009). The effect of financial accounting on the location, reinvestment, and repatriation decisions of multinational companies. Duke University working paper.

Graham, J. R., Harvey, C., \& Rajgopal, S. (2005). The economic implications of corporate financial reporting. Journal of Accounting and Economics , 40, 3-73.

Graham, J. R., Lang, M., \& Shackelford, D. (2004). Employee stock options, corporate taxes and debt policy. Journal of Finance , VIX (4), 1585-1618. 
Graham, J. (2003). Taxes and corporate finance: A review. Review of Financial Studies , 16, 1074-1128.

Graham, J., \& Mills, L. (2008). Using tax return data to simulate corporate marginal tax rates. Journal of Accounting and Economics , 46, 366-380.

Gramlich, J. (1991). The effect of the alternative minimum tax book income adjustment on accrual decisions. The Journal of the American Taxation Association , 13, 36-56.

Guenther, D. (1994). Earnings Management in response to corporate tax rate changes: Evidence from the 1986 tax reform act. The Accounting Review , 69, 230-243.

Guenther, D., \& Sansing, R. (2004). The valuation relevance of reversing deferred tax liabilities. The Accounting Review , 79, 437-451.

Guenther, D., \& Sansing, R. (2000). Valuation of the firm in the presence of temporary book-tax differences: the role of deferred tax assets and liabilities. The Accounting Review , 75, 1-12.

Guenther, D., Maydew, E., \& Nutter, S. (1997). Financial reporting, tax costs, and book-tax conformity. Journal of Accounting and Economics , 23 (3), 225-248.

Gupta, S., \& Laux, R. (2008). Do firms use tax cushion reversals to meet earnings targets?

Arizona State University working paper.

Gupta, S., Mills, L., \& Towery, E. (2009). Did FIN 48 arrest the trend in multistate tax avoidance? Michigan State University working paper.

Hanlon, M. (2005). The persistence and pricing of earnings, accruals, and cash flows when firms have large book-tax differences. The Accounting Review , 80, 137-166.

Hanlon, M. (2003). What can we infer about a firm's taxable income from its financial statements? National Tax Journal , LVI, 831-863.

Hanlon, M., \& Heitzman, S. (2009). A review of tax research. MIT working paper.

Hanlon, M., \& Maydew, E. (2009). Book-tax conformity: Implications for multinational firms. National Tax Journal , 62, 127-153.

Hanlon, M., \& Shevlin, T. (2002). Accounting for tax benefits of employee stock options and implications for research. Accounting Horizons , 16, 1-16.

Hanlon, M., \& Shevlin, T. (2005). Book-tax conformity for corporate income: An introduction to the issues. Tax Policy and the Economy, 19, 101-134.

Hanlon, M., Laplante, S., \& Shevlin, T. (2005). Evidence for the possible information loss of conforming book income and taxable income. Journal of Law and Economics , XLVIII, 407-442. Hanlon, M., Maydew, E., \& Shevlin, T. (2008). An unintended consequence of book-tax conformity: A loss of earnings informativeness. Journal of Accounting and Economics , 46, 294311.

Heiman-Hoffman, V., \& Patton, J. (1994). An experimental investigation of deferred tax asset judgments under SFAS 109. Accounting Horizons , 8, 1-7.

Heltzer, W. (2008). Conservatism and book-tax differences. DePaul University working paper. Holthausen, R., \& Watts, R. (2001). The relevance of the value-relevance literature for financial accounting standard setting. Journal of Accounting and Economics , 31, 3-75.

Jackson, M. (2009). Book-tax differences and earnings growth. University of Oregon working paper.

Jennings, R., Mayew, W., \& Weaver, C. (2009). The Effect of TRA86 on the extent of implicit taxes at the corporate level. University of Texas at Austin working paper.

Jones, J. (1991). Earnings management during import relief investigations. Journal of Accounting Research , 29, 193-228. 
Joos, P., Pratt, J., \& Young, S. (2005). Using deferred taxes to detect earnings management: Further evidence. Indiana University working paper.

Junt, A., Moyer, S., \& Shevlin, T. (1996). Managing interacting accounting measures to meet multiple objectives: a study of LIFO firms. Journal of Accounting and Economics , 21 (3), 339374.

Keating, S., \& Zimmerman, J. (1999). Depreciation policy changes: tax, earnings management, and investment opportunity incentives. Journal of Accounting and Economics , 28, 359-389.

Khalaf, R. (1993, February 15). Read those footnotes! Forbes Magazine , 154.

Krull, L. (2004). Permanently reinvested foreign earnings, taxes, and earnings management. The Accounting Review , 79, 745-767.

Kumar, K., \& Visvanathan, G. (2003). The information content of the deferred tax valuation allowance. The Accounting Review , 78, 471-490.

Lenter, D., Shackelford, D., \& Slemrod, J. (2003). Public disclosure of corporate tax return information: Accounting, economics, and legal perspectives. National Tax Journal , LVI, 803830.

Lev, B., \& Nissim, D. (2004). Taxable income, future earnings, and equity values. The Accounting Review , 79, 1039-1074.

Lev, B., \& Thiagarajan, S. (1993). Fundamental information analysis. Journal of Accounting Research , 31, 190-215.

Lindo, A. (2009). Speech at the Regulatory Accounting Update session. AICPA 2009 National Conference on Banks \& Savings Institutions. Washington, DC.

Lipe, R. (1986). The information contained in the components of earnings. Journal of Accounting Research , 24 (Supplement), 37-64.

Lisowksky, P. (2009b). Seeking shelter: Empirically modeling tax shelters and examining their link to the contingent tax liability reserve. University of Illinois working paper.

Lisowsky, P. (2009a). Inferring U.S. tax liability from financial statement information. Journal of the American Taxation Association , 30 (1), 29-63.

Manzon, G. (1992). Earnings management of firms subject to the alternative minimum tax.

Journal of the American Taxation Association , 14, 88-111.

Manzon, G., \& Plesko, G. (2001). The relation between financial and tax reporting measures of income. Tax Law Review , 175-214.

Matsunaga, S., Shevlin, T., \& Shores, D. (1992). Disqualifying dispositions of incentive stock options: tax benefits versus financial reporting costs. Journal of Accounting Research , 30

(Supplement), 37-68.

Maydew, E. (1997). Tax-induced earnings managements by firms with net operating losses. Journal of Accounting Research , 35, 83-96.

McClelland, J., \& Mills, L. (2007). Weighing benefits and risks of taxing book income. Tax Notes , 114, 779-787.

McGill, G., \& Outslay, E. (2002). Did Enron pay taxes? Using accounting information to decipher tax status. Tax Notes , 96 (Special Report), 1125-1136.

McGill, G., \& Outslay, E. (2004). in translation: detecting tax shelter activity in financial statements. National Tax Journal , LVII, 739-756.

Messier, S. (2007, October 1). New tax rules for small business. The Tax Adviser .

Miller, G., \& Skinner, D. (1998). Determinants of the valuation allowance for deferred tax assets under SFAS No. 109. The Accounting Review , 73, 213-233. 
Mills, L. (1998). Book-tax differences and Internal Revenue Service adjustments. Journal of Accounting Research , 36 (2), 343-356.

Mills, L., \& Newberry, K. (2001). The influence of tax and nontax costs on book-tax reporting differences: Public and private firms. Journal of the American Taxation Association , 23, 1-17. Mills, L., Newberry, K., \& Novack, G. (2003). How well do Compustat NOL data identify firms with U.S. tax return loss carryovers? Journal of the American Taxation Association , 1-17. Mills, L., Newberry, K., \& Trautman, W. (2002). Trends in book-tax income and balance sheet differences. Tax Notes , 96 (Special Report), 1109-1124.

Mills, L., Robinson, L., \& Sansing, R. (2009). FIN 48 and tax compliance. Dartmouth University working paper.

Modigliani, F., \& Miller, M. (1958). The cost of capital, corporation finance and the theory of investment. American Economic Review , 48 (3), 261-297.

Nelson, M., Elliott, J., \& Tarpley, R. (2003). How are earning managed? Examples from auditors. Accounting Horizons, Supplement, 17-35.

Neubig, T. (2006). Where's the applause? Why most corporations prefer a lower rate. Tax Notes , 111, 483-486.

Petersen, M. (2009). Estimating standard errors in finance panel data sets: Comparing approaches. Review of Financial Studies , 22, 435-480.

Phillips, J., Pincus, M., \& Rego, S. (2003). Earnings management: new evidence based on deferred tax expense. The Accounting Review , 78, 491-521.

Phillips, J., Pincus, M., Rego, S., \& Wan, H. (2004). Decomposing changes in deferred tax assets and liabilities to isolate earnings management activities. Journal of the American Taxation Association , 26, 43-66.

Plesko, G. (2004). Corporate tax avoidance and the properties of corporate earnings. National Tax Journal , LVIII, 729-737.

Plesko, G. (2006). Estimates of the magnitude of financial and tax reporting conflicts. University of Connecticut working paper.

Plesko, G. (2002, Spring). Reconciling corporation book and tax net income, tax years 19961998. Statistics of Income Bulletin , pp. 111-132.

Poterba, J., Rao, N., \& Seidman, J. (2009). New evidence on the sources, importance, and potential consequences of temporary differences. University of Texas working paper.

Raedy, J. (2009). Discussion of "Taxable income as a performance measure: The effects of tax planning and earnings quality”. Contemporary Accounting Research , 26 (1), 55-63.

Raedy, J., \& Wilson, W. (2009). Stakeholder influence on earnings properties: International evidence. University of North Carolina working paper.

Rayburn, J. (1986). The association of operating cash flow and accruals with security returns. Journal of Accounting Research , 24 (Supplement), 112-133.

Redmiles, M. (2008). The one-time received dividend deduction. Statistics of Income Bulletin , 27, 103-117.

Robinson, L. (forthcoming). Do firms incur costs to avoid reducing pre-tax earnings? Evidence from the accounting for low-income housing tax credit. The Accounting Review .

Robinson, L., \& Schmidt, A. (2009). Firm and investor responses to uncertain tax benefit disclosure requirements. Dartmouth University working paper.

Robinson, L., Sikes, S., \& Weaver, C. (forthcoming). Performance measurement of corporate tax departments. The Accounting Review .

Sansing, R. (1998). the deferred tax liability. Journal of Accounting Research , 36, 357-363. 
Schmidt, A. (2006). The persistence, forecasting, and valuation implications of the tax change components of earnings. The Accounting Review , 81, 589-616.

Scholes, M., \& Wolfson, M. (1992). Taxes and Business Strategy: A Planning Approach. Englewood Cliffs: Prentice-Hall, Inc.

Scholes, M., Wilson, P., \& Wolfson, M. (1990). Tax planning, regulatory capital planning, and financial reporting strategy for commercial banks. The Review of Financial Studies , 3, 625-650.

Scholes, M., Wolfson, M., Erickson, M., Maydew, E., \& Shevlin, T. (2009). Taxes and Business Strategy: A Planning Approach (4th ed.). Upper Saddle River: Pearson Prentice Hall.

Schön, W. (2004). International accounting standards—A “starting point” for a common European tax base? European Taxation , 44 (10), 426-440.

Schön, W. (2005). Odd couple: A common future for financial and tax accounting? Tax Law Review , 58, 111-147.

Schrand, C., \& Wong, F. (2003). Earnings management using the valuation allowance for deferred tax assets under SFAS No. 109. Contemporary Accounting Research , 20, 579-611. Schultz, T., \& Fogarty, T. (2009). The fleeting nature of permanent reinvestment: Accounting for the undistributed earnings of foreign subsidiaries. Advances in Accounting, incorporating Advances in International Accounting , 25, 112-123.

Seidman, J. (2008). Interpreting fluctuations in the book-tax income gap as tax sheltering: Alternative explanations. University of Texas working paper.

Shackelford, D. (2006, May 9). Testimony before the US House of Representatives Committee on Ways and Means, Subcommittee on Select Revenue Measures, Corporate Tax Reform public hearing . Washington DC.

Shackelford, D., \& Shevlin, T. (2001). Empirical research in accounting. Journal of Accounting and Economics , 31, 321-387.

Shackelford, D., Slemrod, J., \& Sallee, J. (2009). Financial reporting, taxes, and real decisions: A unifying framework. University of North Carolina working paper.

Shevlin, T. (1987). Taxes and off-balance-sheet financing: research and development limited. The Accounting Review , 52 (3), 480-509.

Shevlin, T. (2007). The future of tax research: From an accounting professor's perspective. Journal of the American Taxation Association , 29 (2), 87-93.

Song, W., \& Tucker, A. (2008, January 23). Corporate tax reserves, firm value, and leverage. AFA 2009 San Francisco Meetings Paper .

Sullivan, M. (2002). Stock options take $\$ 50$ billion bite out of corporate taxes. Tax Notes , 13961401.

Thomas, J. (1988). Corporate taxes and defined benefit pension plans. Journal of Accounting and Economics , 10 (3), 199-237.

Thomas, J., \& Zhang, F. (2007). Tax income momentum. Yale University working paper.

Thomas, J., \& Zhang, F. (2009). Valuation of tax expense. Yale University working paper.

Thompson, S. (forthcoming). Simple formulas for standard errors that cluster by both firm and time. Journal of Financial Economics .

US Congress, S. C. (2003). Report On Fishtail, Bacchus, Sundance, and Slapshot: Four Enron transactions funded and facilitated by US financial institutions. 2: Permanent Subcomittee on Investigations.

Visvanathan, G. (1998). Deferred tax valuation allowances and earnings management. Journal of Financial Statement Analysis , 3, 6-15. 
Wang, S. (1994). The relationship between financial reporting practices and the 1986 alternative minimum tax. The Accounting Review , 69, 495-506.

Watts, R., \& Zimmerman, J. (1986). Positive Accounting Theory. Englewood Cliffs: PrenticeHall Inc.

Weber, D. (2009). Do analysts and investors fully appreciate the implications of book-tax differences for future earnings? Contemporary Accounting Research , 26 (4), 1175-1206.

Weisbach, D. (2002). Ten truths about tax shelters. Tax Law Review , 55, 215-253.

Whitaker, C. (2005). Bridging the book-tax accounting gap. The Yale Law Journal , 115, 680726.

White, H. (1980). A heteroskedasticity-consistent covariance matrix estimator and a direct test for heteroskedasticity. Econometrica , 48, 817-838.

Wilson, R. (2009). An examination of corporate tax shelter participants. The Accounting Review , 83 (4), 969-999.

Wunder, H. (2009, October 5). The scope and distribution of permanently reinvested earnings. Tax Notes , 89-99.

Young, D., \& Guenther, D. (2003). Financial reporting environments and international capital mobility. Journal of Accounting Research , 41, 553-579. 
Figure 1. Organization of the Paper

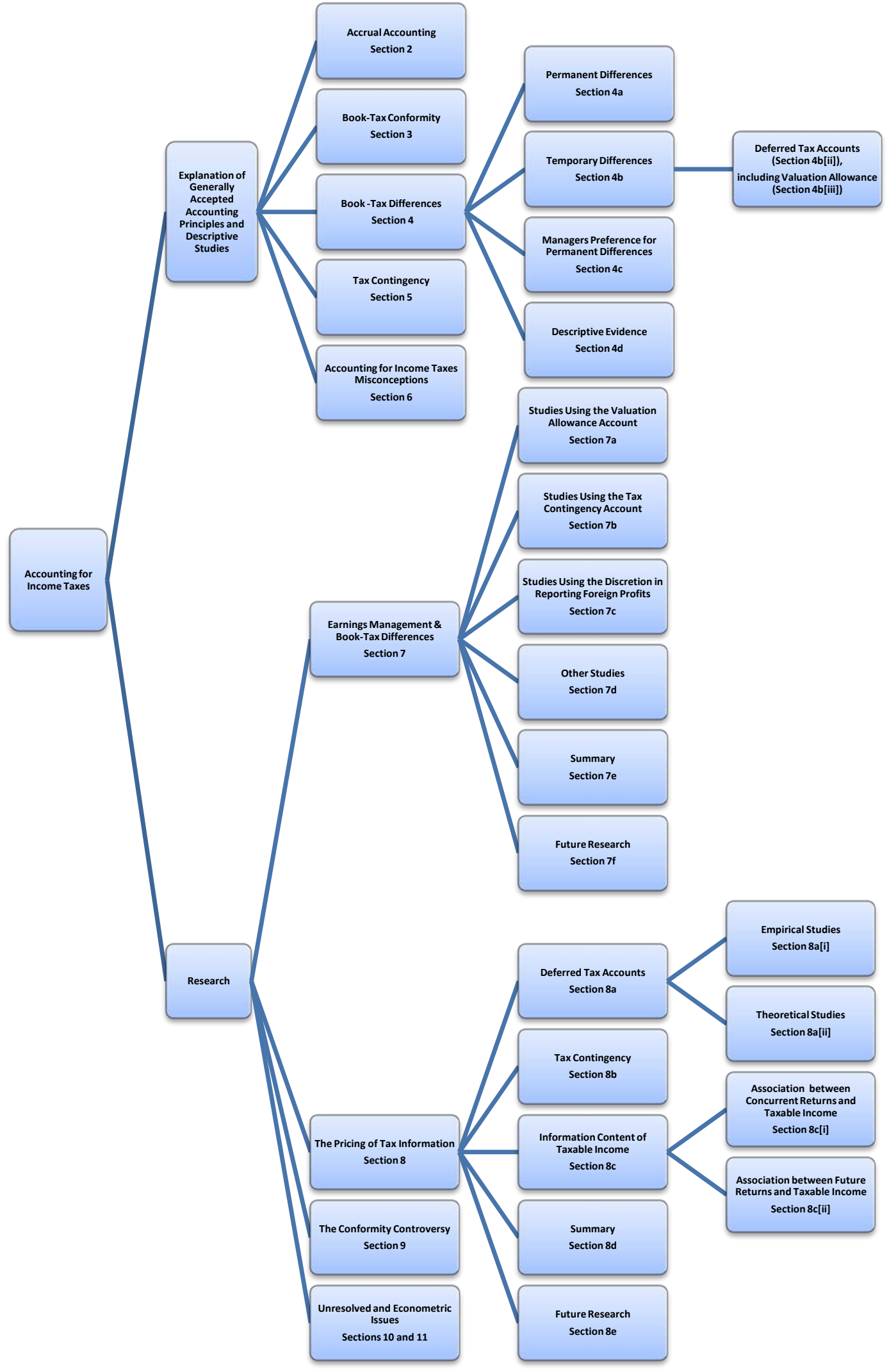


Figure 2. Example Income Statements and Balance Sheets

\begin{tabular}{|c|c|c|c|c|}
\hline & $\begin{array}{r}\text { Book-tax } \\
\text { Conformity } \\
\end{array}$ & $\begin{array}{r}\text { Permanent } \\
\text { Difference }\end{array}$ & $\begin{array}{c}\text { Temporary Difference - } \\
\text { Deferred Tax Liability }\end{array}$ & $\begin{array}{r}\text { Temporary } \\
\text { Difference - DTA } \\
\end{array}$ \\
\hline \multicolumn{5}{|l|}{ Simplified Income Statement } \\
\hline Sales Revenue & $\$ 500$ & $\$ 500$ & $\$ 500$ & $\$ 500$ \\
\hline Municipal Interest & & $\$ 40$ & & \\
\hline Installment Sales Revenue & & & $\$ 60$ & \\
\hline Warranty Expense & & & & $(\$ 110)$ \\
\hline Income before income taxes (NIBT) & $\$ 500$ & $\$ 540$ & $\$ 560$ & $\$ 390$ \\
\hline Income Tax Expense & $(\$ 175)$ & $(\$ 175)$ & $(\$ 196)$ & $(\$ 136.5)$ \\
\hline Net Income & $\$ 325$ & $\$ 365$ & $\$ 364$ & $\$ 253.5$ \\
\hline ETR & $35 \%$ & $32.4 \%$ & $35 \%$ & $35 \%$ \\
\hline \multicolumn{5}{|l|}{ Balance Sheet } \\
\hline \multicolumn{5}{|l|}{ Assets: } \\
\hline Cash & & $\$ 40$ & & \\
\hline Accounts Receivable & $\$ 500$ & $\$ 500$ & $\$ 500$ & $\$ 50$ \\
\hline Accounts Receivable - Installments & & & $\$ 60$ & \\
\hline Deferred Tax Asset & & & & $\$ 38.5$ \\
\hline TOTAL & $\$ 500$ & $\$ 540$ & $\$ 560$ & $\$ 538.5$ \\
\hline \multicolumn{5}{|l|}{ Liabilities and Owner's Equity: } \\
\hline Warranty Liability & & & & $\$ 110$ \\
\hline Income Taxes Payable & $\$ 175$ & $\$ 175$ & $\$ 175$ & $\$ 175$ \\
\hline Deferred Tax Liability & & & $\$ 21$ & \\
\hline Owners' Equity & $\$ 325$ & $\$ 365$ & $\$ 364$ & $\$ 253.5$ \\
\hline TOTAL & $\$ 500$ & $\$ 540$ & $\$ 560$ & $\$ 538.5$ \\
\hline
\end{tabular}




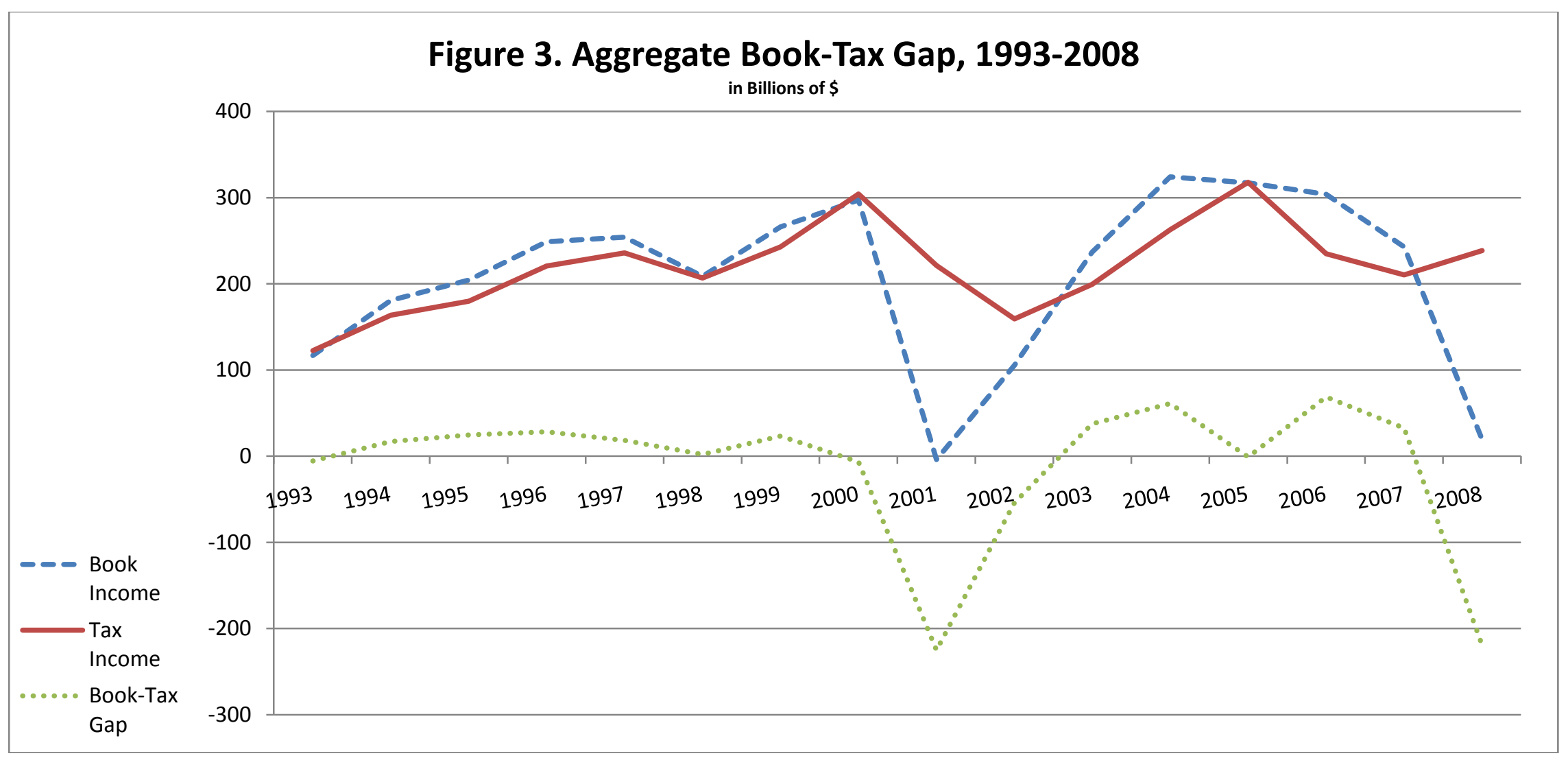

This figure shows the book-tax gap from 1993 through 2008. Book income is pretax income adjusted for minority interest. Taxable income is federal and foreign tax expense divided by the maximum statutory rate. The book-tax gap is book income less taxable income. 


\section{Table 1: Summary of Extant Literature}

\begin{tabular}{|c|c|c|c|c|}
\hline & Descriptive Studies & Earnings Management Studies & Pricing Studies & Conformity Studies \\
\hline $\begin{array}{l}\text { Book-tax } \\
\text { Differences } \\
\text { (BTDs) }\end{array}$ & $\begin{array}{l}\text { The majority of companies have net DTL } \\
\text { balances (as opposed to net DTA } \\
\text { balances). } \\
\text { - } \text { On average, VA balances are } \\
\text { approximately half of the DTA balances. } \\
\text { Book income typically exceeds taxable } \\
\text { income, on average. } 2001 \text { is the only } \\
\text { year for which the opposite is true. } \\
\text { BTDs are concentrated in the largest } \\
\text { firms. } \\
\text { BTDs are concentrated in the financial } \\
\text { and information industries. } \\
\text { Determinants of BTDs include tax } \\
\text { planning, change in sales, level of PPE, } \\
\text { earnings management behavior, general } \\
\text { business conditions, and changes in } \\
\text { financial accounting rules. }\end{array}$ & & & $\begin{array}{l}\text { - There is some evidence } \\
\text { that companies will } \\
\text { shift book income to } \\
\text { lower their taxes when } \\
\text { book-tax conformity is } \\
\text { imposed. } \\
\text { High conformity } \\
\text { countries experience } \\
\text { reduced international } \\
\text { capital mobility, less } \\
\text { value relevance for } \\
\text { earnings and cash } \\
\text { flows, and higher } \\
\text { correlation between } \\
\text { book and taxable } \\
\text { income. } \\
\text { Higher levels of book- } \\
\text { tax conformity are } \\
\text { associated with lower } \\
\text { value relevance of } \\
\text { earnings and cash } \\
\text { flows. } \\
\text { Higher levels of book- } \\
\text { tax conformity are } \\
\text { associated with a lower } \\
\text { level correlation } \\
\text { between current } \\
\text { earnings and both future } \\
\text { earnings and future cash } \\
\text { flows. }\end{array}$ \\
\hline $\begin{array}{l}\text { Deferred Tax } \\
\text { Accounts }\end{array}$ & & $\begin{array}{l}\text { Managers in the U.K. use } \\
\text { their discretion in reporting } \\
\text { deferred tax accounts to } \\
\text { manage their leverage, but } \\
\text { not to smooth earnings. }\end{array}$ & $\begin{array}{l}\text { The market prices the } \\
\text { deferred tax liability } \\
\text { and asset accounts. It } \\
\text { does so in a way that is } \\
\text { consistent with the } \\
\text { likelihood of and length } \\
\text { of time until settlement. }\end{array}$ & \\
\hline
\end{tabular}




\begin{tabular}{|c|c|c|c|c|}
\hline & & & $\begin{array}{l}\text { Theoretical studies } \\
\text { indicate that under } \\
\text { certain circumstances, } \\
\text { DTLs should be valued, } \\
\text { even though they are } \\
\text { not discounted and they } \\
\text { may never reverse. In } \\
\text { addition, the models } \\
\text { show that the valuation } \\
\text { of a DTL may not } \\
\text { depend on the time } \\
\text { until reversal, if the } \\
\text { BTD does not involve } \\
\text { cash flows. }\end{array}$ & \\
\hline $\begin{array}{l}\text { Valuation } \\
\text { Allowance }\end{array}$ & $\begin{array}{l}\text { Determinants of the VA balance include } \\
\text { the four sources of income listed in } \\
\text { FAS109 as well as the magnitude of } \\
\text { carryforwards. }\end{array}$ & $\begin{array}{l}\text { - Studies have generally } \\
\text { shown that mangers use the } \\
\text { VA account to meet } \\
\text { analysts' forecasts. } \\
\text { - Studies have consistently } \\
\text { found that firms do not use } \\
\text { the VA account to engage } \\
\text { in earnings smoothing } \\
\text { behavior. } \\
\text { - Studies have generally } \\
\text { indicated that managers do } \\
\text { not use the VA to take (or } \\
\text { increase) big baths. } \\
\text { There is mixed evidence as } \\
\text { to whether managers us the } \\
\text { VA to meet prior and zero } \\
\text { earnings targets. The bulk } \\
\text { of the evidence indicates } \\
\text { that the VA is not used for } \\
\text { these purposes. }\end{array}$ & $\begin{array}{l}\text { Evidence is mixed as to } \\
\text { whether the market } \\
\text { prices the VA account. }\end{array}$ & \\
\hline $\begin{array}{l}\text { Tax } \\
\text { Contingency }\end{array}$ & $\begin{array}{l}\text { Variables that are positively correlated } \\
\text { with the amount of the tax contingency } \\
\text { balance include the amount of the } \\
\text { expected loss, the likelihood of having a } \\
\text { tax shelter, firm value and the magnitude } \\
\text { of abnormal accruals. }\end{array}$ & $\begin{array}{l}\text { - The study performed before } \\
\text { FIN } 48 \text { indicate that the tax } \\
\text { contingency is used } \\
\text { primarily to meet analysts' } \\
\text { forecasts but is not used as } \\
\text { much to meet other }\end{array}$ & $\begin{array}{l}\text { The market seems to } \\
\text { view the tax } \\
\text { contingency account in } \\
\text { a positive fashion, } \\
\text { consistent with the } \\
\text { market rewarding tax }\end{array}$ & \\
\hline
\end{tabular}




\begin{tabular}{|c|c|c|c|}
\hline & $\begin{array}{l}\text { - According to FIN } 48 \text { disclosures the } \\
\text { contingency balance averages between } \\
1.5 \% \text { and } 1.8 \% \text { of assets. } \\
\text { - The quality of the FIN } 48 \text { disclosures is } \\
\text { inversely related to the tax } \\
\text { aggressiveness of the firm. }\end{array}$ & earnings targets. & $\begin{array}{l}\text { aggressive firms. } \\
\text { Tax aggressive firms } \\
\text { did not, in general, } \\
\text { experience negative } \\
\text { abnormal returns } \\
\text { around events related to } \\
\text { the passage of FIN } 48 \text {. }\end{array}$ \\
\hline $\begin{array}{l}\text { Foreign } \\
\text { Earnings }\end{array}$ & & $\begin{array}{l}\text { Managers use their } \\
\text { discretion in reporting } \\
\text { permanently reinvested } \\
\text { foreign earnings to meet } \\
\text { analysts’ forecasts. } \\
\end{array}$ & $\begin{array}{l}\text { The market values } \\
\text { permanently reinvested } \\
\text { foreign earnings net of } \\
\text { the U.S. taxes that will } \\
\text { be paid at repatriation. }\end{array}$ \\
\hline $\begin{array}{l}\text { Taxable } \\
\text { Income/Tax } \\
\text { Expense }\end{array}$ & $\begin{array}{l}\text { - Some book information appears to be } \\
\text { useful for assessing tax information, such } \\
\text { as book NOLs and simulated book } \\
\text { MTRs. } \\
\text { Some book information appears to be } \\
\text { less useful for assessing tax information. } \\
\text { In particular, there is little correlation } \\
\text { between discretionary tax accruals and } \\
\text { discretionary book accruals. }\end{array}$ & $\begin{array}{l}\text { Managers manipulate tax } \\
\text { expense to meet/beat } \\
\text { analysts' forecasts. In } \\
\text { addition, the market (at } \\
\text { least partially) sees through } \\
\text { this behavior. }\end{array}$ & $\begin{array}{l}\text { - Estimated taxable } \\
\text { income provides } \\
\text { information to the } \\
\text { market that is } \\
\text { incremental to book } \\
\text { income. This effect is } \\
\text { lower for firms that } \\
\text { engage in greater tax } \\
\text { planning. } \\
\text { The ratio of taxable } \\
\text { income to book income } \\
\text { is positively associated } \\
\text { with earnings growth, } \\
\text { current P/E, and future } \\
\text { returns. } \\
\text { Extreme book-tax } \\
\text { differences are } \\
\text { associated with less } \\
\text { persistent book } \\
\text { earnings. } \\
\text { Unexpected taxable } \\
\text { income is associated } \\
\text { with future returns. } \\
\text { Analysts' forecast } \\
\text { errors are positively } \\
\text { associated with the ratio } \\
\text { of taxable income to } \\
\text { book income, implying }\end{array}$ \\
\hline
\end{tabular}




\begin{tabular}{|l|l|l|l|l|}
\hline & & & $\begin{array}{l}\text { that potential market } \\
\text { inefficiencies identified } \\
\text { in the literature are } \\
\text { partially due to } \\
\text { analysts' inefficiency. }\end{array}$ \\
\hline
\end{tabular}


Table 2 - Clustering Standard Errors for Book-tax Difference

This table presents estimates of coefficients and standard errors based on ordinary least squares (OLS) regressions and the FamaMacBeth procedure for a model similar to Heltzer (2008). Columns 1 to 4 and 6 (column 5) show coefficient estimates based on OLS (Fama-MacBeth). OLS standard errors are corrected for heteroskedasticity (column 2), clustering by firm (column 3), clustering by time (column 4), or both firm and time (column 6). Clustering by firm addresses serial correlation for a given firm through time. Clustering by time addresses correlation across firms in a given time period. In addition to column (4), Fama-MacBeth (column 5) also addresses time clustering. The dependent variable, market-adjusted E/P, is the earnings-to-price ratio adjusted for the market's E/P ratio, Ret is the contemporaneous cumulative stock return in excess of the CRSP market return, LPBTD (large positive book tax difference) is an indicator which equals to 1 if the firm-year's book-tax difference scaled by average assets falls in the top quintile of the 2-digit SIC industry, and LPBTD is an indicator which equals to 1 if the firm-year's book-tax difference scaled by average assets falls in the bottom quintile of the 2-digit SIC industry.

\begin{tabular}{|c|c|c|c|c|c|c|c|}
\hline \multicolumn{2}{|c|}{$\begin{array}{l}\text { Dep Var: } \\
\text { Market-adj E/P }\end{array}$} & $\begin{array}{l}\text { OLS } \\
(1) \\
\end{array}$ & $\begin{array}{c}\text { OLS - White } \\
(2)\end{array}$ & $\begin{array}{c}\text { Cluster-Firm } \\
\text { (3) } \\
\end{array}$ & $\begin{array}{c}\text { Cluster-Time } \\
(4)\end{array}$ & $\begin{array}{c}\text { Fama-MacBeth } \\
(5)\end{array}$ & $\begin{array}{c}\text { Cluster-F\&T } \\
(6) \\
\end{array}$ \\
\hline \multirow[t]{3}{*}{ Ret } & Estimate & 8.948 & 8.948 & 8.948 & 8.948 & 10.246 & 8.948 \\
\hline & Standard error & 0.133 & 0.180 & 0.192 & 1.085 & 0.926 & 1.087 \\
\hline & t-stat & 67.31 & 49.66 & 46.63 & 8.25 & 11.06 & 8.23 \\
\hline \multirow[t]{3}{*}{ LPBTD } & Estimate & 0.957 & 0.957 & 0.957 & 0.957 & 0.917 & 0.957 \\
\hline & Standard error & 0.189 & 0.150 & 0.184 & 0.340 & 0.341 & 0.356 \\
\hline & t-stat & 5.07 & 6.36 & 5.20 & 2.82 & 2.69 & 2.69 \\
\hline \multirow[t]{3}{*}{ LNBTD } & Estimate & -23.092 & -23.092 & -23.092 & -23.092 & -22.362 & -23.092 \\
\hline & Standard error & 0.190 & 0.268 & 0.309 & 1.048 & 0.997 & 1.060 \\
\hline & t-stat & -121.58 & -86.32 & -74.72 & -22.03 & -22.42 & -21.79 \\
\hline \multicolumn{2}{|l|}{$\mathrm{N}$} & 77,162 & 77,162 & 77,162 & 77,162 & 77,162 & 77,162 \\
\hline \multicolumn{2}{|l|}{$\mathrm{R}^{2}$} & $23.1 \%$ & $23.1 \%$ & $23.1 \%$ & $23.1 \%$ & $23.0 \%$ & $23.1 \%$ \\
\hline
\end{tabular}


Table 3 - Clustering Standard Errors for Earnings-to-price Ratio

This table presents estimates of coefficients and standard errors based on ordinary least squares (OLS) regressions and the FamaMacBeth procedure for a model similar to Lev and Nissim (2004). Columns 1 to 4 and 6 (column 5) show coefficients estimates based on OLS (Fama-MacBeth). OLS standard errors are corrected for heteroskedasticity (column 2), clustering by firm (column 3), clustering by time (column 4), or both firm and time (column 6). Clustering by firm addresses serial correlation for a given firm through time. Clustering by time addresses correlation across firms in a given time period. In addition to column (4), Fama-MacBeth (column 5) also addresses time clustering. The dependent variable, E/P, is the earnings-to-price ratio, LNTA is the log of total assets, Leverage is book leverage, Div is common dividend divided by net income, and Tax is the ratio of taxable income $\times(1-$ top statutory federal tax rate) and net income.

\begin{tabular}{|c|c|c|c|c|c|c|c|}
\hline $\begin{array}{l}\text { Dep. Var = } \\
\text { E/P }\end{array}$ & & $\begin{array}{l}\text { OLS } \\
(1)\end{array}$ & $\begin{array}{c}\text { OLS - White } \\
\text { (2) }\end{array}$ & $\begin{array}{c}\text { Cluster-Firm } \\
\text { (3) }\end{array}$ & $\begin{array}{c}\text { Cluster-Time } \\
(4)\end{array}$ & $\begin{array}{c}\text { Fama-MacBeth } \\
\text { (5) }\end{array}$ & $\begin{array}{c}\text { Cluster-F\&T } \\
(6)\end{array}$ \\
\hline \multirow[t]{3}{*}{ LNTA } & Estimate & -0.118 & -0.118 & -0.118 & -0.118 & 0.039 & -0.118 \\
\hline & $\mathrm{SE}$ & 0.011 & 0.011 & 0.020 & 0.066 & 0.076 & 0.068 \\
\hline & t-stat. & -11.08 & -10.67 & -5.91 & -1.79 & 0.51 & -1.73 \\
\hline \multirow[t]{3}{*}{ Leverage } & Estimate & 4.509 & 4.509 & 4.509 & 4.509 & 4.082 & 4.509 \\
\hline & $\mathrm{SE}$ & 0.109 & 0.136 & 0.219 & 0.432 & 0.439 & 0.464 \\
\hline & t-stat. & 41.48 & 33.15 & 20.59 & 10.45 & 9.29 & 9.71 \\
\hline \multirow[t]{3}{*}{ Div } & Estimate & -0.975 & -0.975 & -0.975 & -0.975 & -1.077 & -0.975 \\
\hline & $\mathrm{SE}$ & 0.027 & 0.025 & 0.039 & 0.070 & 0.090 & 0.076 \\
\hline & t-stat. & -35.54 & -39.19 & -25.22 & -14.02 & -11.94 & -12.90 \\
\hline \multirow[t]{3}{*}{ Tax } & Estimate & -1.374 & -1.374 & -1.374 & -1.374 & -1.283 & -1.374 \\
\hline & $\mathrm{SE}$ & 0.039 & 0.037 & 0.052 & 0.200 & 0.211 & 0.203 \\
\hline & t-stat. & -34.85 & -37.57 & -26.42 & -6.87 & -6.08 & -6.75 \\
\hline $\mathrm{N}$ & & 105,968 & 105,968 & 105,968 & 105,968 & 105,968 & 105,968 \\
\hline $\mathrm{R}^{2}$ & & $4.0 \%$ & $4.0 \%$ & $4.0 \%$ & $4.0 \%$ & $3.8 \%$ & $4.0 \%$ \\
\hline
\end{tabular}


Table 4 - Clustering Standard Errors for Valuation Allowance

This table presents estimates of coefficients and standard errors based on ordinary least squares (OLS) regressions and the FamaMacBeth procedure for a model similar to Miller and Skinner (1998). Columns 1 to 4 and 6 (column 5) show coefficients estimates based on OLS (Fama-MacBeth). OLS standard errors are corrected for heteroskedasticity (column 2), clustering by firm (column 3), clustering by time (column 4), or both firm and time (column 6). Clustering by firm addresses serial correlation for a given firm through time. Clustering by time addresses correlation across firms in a given time period. In addition to column (4), Fama-MacBeth (column 5) also addresses time clustering. The dependent variable, VA, is the valuation allowance divided by total assets, AVGROA is the average of return on assets (EBIT / beginning-year total assets) for current and previous years, Leverage is book leverage defined as short- and long-term debt divided by total assets, and TLCF is net operating loss carryforward divided by total assets.

\begin{tabular}{|c|c|c|c|c|c|c|c|}
\hline \multicolumn{2}{|c|}{$\begin{array}{l}\text { Dep. Var: } \\
\text { Valuation Allowance / Assets }\end{array}$} & \multirow{2}{*}{$\begin{array}{c}\text { OLS } \\
(1) \\
0.245\end{array}$} & \multirow{2}{*}{$\begin{array}{c}\text { OLS - White } \\
(2) \\
0.245\end{array}$} & \multirow{2}{*}{$\begin{array}{c}\text { Cluster-Firm } \\
\text { (3) }\end{array}$} & \multirow{2}{*}{$\begin{array}{c}\begin{array}{c}\text { Cluster-Time } \\
(4)\end{array} \\
0.245\end{array}$} & \multirow{2}{*}{$\begin{array}{c}\text { Fama-MacBeth } \\
(5)\end{array}$} & \multirow{2}{*}{$\begin{array}{c}\begin{array}{c}\text { Cluster-F\&T } \\
(6)\end{array} \\
0.245\end{array}$} \\
\hline AVGROA & Estimate & & & & & & \\
\hline & Standard error & 0.010 & 0.025 & 0.045 & 0.022 & 0.020 & 0.044 \\
\hline & t-stat & 24.14 & 9.85 & 5.43 & 11.06 & 11.68 & 5.60 \\
\hline \multirow[t]{3}{*}{ Leverage } & Estimate & 0.030 & 0.030 & 0.030 & 0.030 & 0.026 & 0.030 \\
\hline & Standard error & 0.003 & 0.006 & 0.010 & 0.007 & 0.007 & 0.011 \\
\hline & t-stat & 8.75 & 4.87 & 2.96 & 4.17 & 3.93 & 2.78 \\
\hline \multirow[t]{3}{*}{ TLCF } & Estimate & -0.342 & -0.342 & -0.342 & -0.342 & -0.320 & -0.342 \\
\hline & Standard error & 0.008 & 0.022 & 0.039 & 0.018 & 0.026 & 0.037 \\
\hline & t-stat & -41.60 & -15.83 & -8.72 & -18.91 & -12.46 & -9.14 \\
\hline $\mathrm{N}$ & & 5,466 & 5,466 & 5,466 & 5,466 & 5,466 & 5,466 \\
\hline $\mathrm{R} 2$ & & $36.4 \%$ & $36.4 \%$ & $36.4 \%$ & $36.4 \%$ & $36.4 \%$ & $36.4 \%$ \\
\hline
\end{tabular}




\section{Appendix A: Organizational Chart with References}

Author(s) (year) [paper section]

\begin{tabular}{|c|c|c|c|c|}
\hline & Descriptive Studies and Other & Earnings Management Studies & Pricing Studies & Conformity Studies \\
\hline \multicolumn{5}{|l|}{ Book-tax Differences } \\
\hline & Desai (2003) [4d, 9] & & & $\begin{array}{l}\text { Ali and Hwang (2000) } \\
\text { [9b] }\end{array}$ \\
\hline & Manzon and Plesko (2001) [4d] & & & $\begin{array}{l}\text { Atwood et al. } \\
\text { (forthcoming) [9b] }\end{array}$ \\
\hline & Mills et al. (2002) [4d] & & & $\begin{array}{l}\text { Badertscher et al. (2009) } \\
\text { [9a] }\end{array}$ \\
\hline & Plesko (2002) [4d] & & & Desai (2005) [9] \\
\hline & Plesko (2004) [4c, 4d] & & & Hanlon et al. (2008) [9b] \\
\hline & Poterba et al. (2009) [4a, 4d, 9] & & & $\begin{array}{l}\text { Hanlon and Maydew } \\
\text { (2009) [9b] }\end{array}$ \\
\hline & Seidman (2008) [4a, 4d, 9] & & & $\begin{array}{l}\text { Hanlon and Shevlin } \\
\text { (2005) [9b] }\end{array}$ \\
\hline & & & & Lenter et al. (2003) [9a] \\
\hline & & & & $\begin{array}{l}\text { McClelland and Mills } \\
\text { (2007) [9a] }\end{array}$ \\
\hline & & & & $\begin{array}{l}\text { Mills and Newberry } \\
\text { (2001) [9a] }\end{array}$ \\
\hline & & & & Neubig (2006) [4c, 9] \\
\hline & & & & Schön (2005) [9a] \\
\hline & & & & $\begin{array}{l}\text { Young and Guenther } \\
\text { (2003) [9b] }\end{array}$ \\
\hline \multicolumn{5}{|l|}{ Deferred Tax Accounts } \\
\hline & & Gordon and Joos (2004) [7d] & Amir et al. (1997) [8a] & \\
\hline & & Joos et al. (2005) [7a] & Amir and Sougiannis (1999) [8c] & \\
\hline & & Phillips et al. (2003) [7a] & Ayers (1998) [8a] & \\
\hline & & Phillips et al. (2004) [7a] & Beaver and Dukes (1972) [8a]] & \\
\hline & & & Chaney and Jeter (1994) [8a] & \\
\hline & & & Chen and Schoderbek (2000) [8a] & \\
\hline & & & De Waegenaere et al. (2003) [8a] & \\
\hline & & & De Waegenaere and Sansing (2008) [7c] & \\
\hline & & & Dhaliwal et al. (2000) [8a] & \\
\hline & & & Givoly and Hayn (1992) [8a] & \\
\hline & & & Guenther and Sansing (2000) [8a] & \\
\hline & & & Guenther and Sansing (2004) [8a] & \\
\hline & & & Rayburn (1986) [8a] & \\
\hline & & & Sansing (1998) [8a] & \\
\hline \multicolumn{5}{|l|}{ Valuation Allowance } \\
\hline & Behn et al. (1998) [7a] & Bauman et al. (2001) [7a] & Kumar and Visvanathan (2003) [8a] & \\
\hline & $\begin{array}{l}\text { Heiman-Hoffman and Patton } \\
\text { (1994) [4biii] }\end{array}$ & Burgstahler et al. (2002) [6b] & & \\
\hline
\end{tabular}




\begin{tabular}{|c|c|c|c|c|}
\hline & Miller and Skinner (1998) [7a] & Christensen et al. (2008) [7a] & & \\
\hline & & Frank and Rego (2006) [7a] & & \\
\hline & & Miller and Skinner (1998) [7a] & & \\
\hline & & Schrand and Wong (2003) [7a] & & \\
\hline & & Visvanathan (1998) [6ba] & & \\
\hline \multicolumn{5}{|l|}{ Tax Contingency } \\
\hline & Alexander et al. (2009) (2009) [5] & Blouin et al. (2007) [5] & Blouin et al. (2009) [8b] & \\
\hline & Dunbar et al. (2007) [5] & Blouin et al. (forthcoming) [5, 7b] & Frischmann et al. (2008) [5, 8b] & \\
\hline & $\begin{array}{l}\text { Gleason and Mills (2002), (2007) } \\
\text { [5] }\end{array}$ & Blouin and Tuna (2007) [7b] & Robinson and Schmidt (2009) [5, 8b] & \\
\hline & Lisowsky (2009b) [6ci] & Gupta and Laux (2008) [7b] & & \\
\hline & Mills et al. (2009) [5] & Song and Tucker (2008) [6] & & \\
\hline & & Wilson (2009) [5] & & \\
\hline \multicolumn{5}{|l|}{ Foreign Earnings } \\
\hline & Albring et al. (2005) [7c] & Collins et al. (2001) [7c] & Collins et al. (2001) [7c] & \\
\hline & & Krull (2004) [7c] & & \\
\hline \multicolumn{5}{|l|}{ Taxable Income/Tax Expense } \\
\hline & Blouin et al. (2008) [6a] & Bauman and Shaw (2005) [7d] & Abarbanell and Bushee (1997) [8c] & \\
\hline & Dworin (1985) [6a] & Comprix et al. (2009) [7d] & Abarbanell and Bushee (1998) [8c] & \\
\hline & Dyreng et al. (2008) [6a] & Cook et al. (2008) [7d] & Ayers et al. (2009) [8c] & \\
\hline & Graham (1996) [6a] & Dhaliwal et al. (2004) [7d, 8c] & Blaylock et al. (2009) [8c] & \\
\hline & Graham and Mills (2008) [6a] & Gleason et al. (2007) [7d, 7f] & Bryant-Kutcher et al. (2007) [8c] & \\
\hline & Hanlon (2003) [6a] & Gleason and Mills (2008) [7d] & Chen et al. (2003) [8c] & \\
\hline & Hanlon and Shevlin (2002) [6a] & & Chen et al. (2007) [8c] & \\
\hline & Lisowsky (2009a) [6a] & & Hanlon (2005) [8c] & \\
\hline & McGill and Outslay (2002) [6a] & & Hanlon et al. (2005) [8c, 9b] & \\
\hline & McGill and Outslay (2004) [6a] & & Jackson (2009) [8c] & \\
\hline & Mills et al. (2003) [6a] & & Lev and Nissim (2004) [8c, 9b] & \\
\hline & Plesko (2006) [6a] & & Lev and Thiagarajan (1993) [8c] & \\
\hline & Shevlin (1987) [6a] & & Lipe (1986) [8c] & \\
\hline & & & Schmidt (2006) [8c] & \\
\hline & & & Thomas and Zhang (2007) [8c] & \\
\hline & & & Weber (2009) [8c] & \\
\hline
\end{tabular}




\section{Appendix B: Glossary}

Accrual system

APB No. 23

Below-the-line items

Book basis

Book-tax difference (BTD)

Cash system

Contra-asset account

Cushion

Deferred tax asset
Accounting method in which revenues (expenses) are recognized when, in the normal course of operations, net assets increase (decrease), regardless of when cash is transferred to (from) the entity.

APB 23 Accounting for Income Taxes - Special Areas. Effective for fiscal years beginning after December 31, 1971, this standard governs the classification of permanently reinvested foreign earnings.

The "line" refers to net income from continuing operations (or net operating income) on the income statement. Items that appear below this line are profit or loss from discontinued operations, extraordinary items, or prior period adjustments. The amounts reported in these items are presented net of tax, unlike items that appear above the line on the income statement which are presented pre-tax with all tax effects aggregated into the tax expense line.

The amount of an asset's cost (liability's benefit) that has not yet been recorded as expense (revenue) on the income statement. Basis is normally calculated as purchase price minus accumulated depreciation. The book basis of an item that is expensed immediately is zero.

Differences between book (financial accounting) and tax (tax reporting) net income that arise when the reporting systems recognize the revenue or expense arising from a transaction differently. Differences can be temporary or permanent.

Accounting method in which revenues (expenses) are recognized when cash is transferred to (from) the entity.

A financial accounting (book) account that accumulates reductions to a specific asset account such that the net of the asset account and the contraasset account represents the net book value of the asset. An example is a building (asset) account and accumulated depreciation (contra-asset) account. The cost of acquiring the building is recorded in the asset account and remains constant period to period. As depreciation expense is recorded, the accumulated depreciation account increases in size and the net book value of the asset (cost less accumulated depreciation) decreases.

Colloquial term used to refer to the income tax contingency.

A financial accounting (book) asset that arises when temporary differences result in the book bases of assets being lower than their tax bases. The asset is calculated as the aggregate temporary difference times the tax rate 
of the entity.

Deferred tax liability

Effective tax rate (ETR)

FIN 48

Implicit taxes

Income tax contingency

Marginal tax rate

Matching principle

Non-tax costs

Permanent difference

Permanently reinvested foreign earnings
A financial accounting (book) liability that arises when temporary differences result in the book bases of assets being higher than their tax bases. The liability is calculated as the aggregate temporary difference times the tax rate of the entity.

A financial accounting measure of the tax rate faced by the entity in the period. Calculated as the sum of taxes currently payable and deferred tax expense, divided by net income before tax.

Financial Accounting Standards Board (FASB) Interpretation Number 48, Accounting for Uncertainty in Income Taxes - an interpretation of FASB Statement No. 109. Effective for fiscal years beginning after December 15, 2006, this interpretation increased the required disclosures related to the calculation of the income tax contingency.

The difference in the pre-tax rates of return available on tax-favored assets and similar tax-disfavored assets. For example, the rate of return on a taxexempt municipal bond is normally lower than that on a similar taxable corporate bond, the difference being the implicit tax on the "tax-exempt" bond.

A loss contingency (as defined in FAS 5) representing an entity's estimate of the additional tax liability that would be payable following a potential audit by tax authorities. This account is also known as cushion, uncertain tax benefit, unrecognized tax benefit, and tax reserve.

The change in the present value of total taxes arising from earning an additional dollar of taxable income today.

The financial accounting principle whereby expenses are recorded in the same accounting period as the revenue to which they are most directly related, regardless of when cash is paid by the entity.

All costs related to a transaction that are not paid in the form of a tax.

A book-tax difference that arises when book (tax) recognizes revenue or expense related to a transaction and tax (book) does not. An example is the interest received from tax-exempt municipal bonds: book recognizes interest revenue as it accrues while tax does not (and never will) recognize any interest revenue.

Under U.S. tax law, the worldwide income of corporations domiciled in the U.S. is subject to U.S. tax. However, the U.S. tax due on the earnings of a foreign subsidiary are deferred until they are repatriated to the U.S. parent 


\section{Revenue recognition principle}

SFAS No. 109

Tax basis

Temporary difference

Valuation allowance (VA) in the form of a dividend. Therefore, if the earnings are permanently reinvested in the foreign jurisdiction, no U.S. tax will ever be paid on the foreign earnings. For financial accounting purposes, APB 23 requires firms to accrue a tax expense for earnings that will be repatriated as a dividend in the future, but does not require such an accrual if the foreign earnings will be permanently reinvested.

The financial accounting principle contained in FAS No. 5: revenue should be recognized when it is realized and earned. The application of this principle can result in revenue being recognized before, at, or after the collection of cash.

SFAS 109, Accounting for Income Taxes. Effective for fiscal years beginning after December 15, 1992, this standard governs the accounting for income taxes.

The amount of an asset's cost (liability's benefit) that has not yet been recorded as a deduction (income) in taxable income.

A book-tax difference that arises when book accounting and tax accounting agree on the aggregate amount of revenue or expense that is recognized, but disagree on the timing of the recognition. An example is depreciation expense: both book and tax record the difference between cost and proceeds of disposition as expense over the life of the asset, but book records the expense over the useful life of the asset while tax records the expense according to a statutory rate schedule.

This is a contra-asset account to the deferred tax asset account. SFAS 109 requires an entity to estimate the portion of its deferred tax asset that is likely not to be recognized (the actual threshold is more likely than not). 


\section{Appendix C: Examples of Permanent and Temporary Book/Tax Differences}

\section{Permanent Differences:}

Income: Book > Tax:

Book revenue greater than income under the tax law

Municipal Interest Income

Dividend Received Deduction

Life Insurance Death Proceeds

Book expenses less than tax deductions

Domestic production activities deduction

Stock option deduction (until recent change in book)

Income: Tax > Book:

Book revenue less than income under the tax law

None to our knowledge

Book expenses greater than tax deductions

Fines and Penalties

2/3 Antitrust Treble Damages

Excess parachute payments

Section 162(m) compensation

Certain meals and entertainment

Life insurance premiums

Syndication expenses for fixed-term equity 
Temporary Differences (classified in terms of originating transaction):

Book Assets $>$ Tax Asset (DTL)

Revenue/Income Items:

Installment Sales

Increase in Life Insurance Cash

Surrender Value

$\underline{\text { Tax Treatment }}$

Recognize when paid

Recognize when realized

Expense/Deduction Items:

Accelerate Depreciation

Goodwill

Bank Loan Origination Costs

$\underline{\text { Tax Assets }>\text { Book Assets (DTA) }}$

Revenue/Income Items:

Tax Treatment

None to our knowledge

Expense/Deduction Items:

Net Capital Losses

Excess Charitable Contributions

Obsolete Inventory

Bad debt expense $\underline{\text { Tax Treatment }}$

MACRS

Amortize over 15 years

Deduct upon incurrence $\underline{\text { Book Treatment }}$

Recognize when sold

Recognize when value increases

Book Treatment

Usually straight line

Test for impairment

Amortize over loan life

Book Treatment

$\underline{\text { Book Treatment }}$

Expense

Expense

Written down

Accrued at time of sale 
Book Liabilities > Tax Liabilities (DTA)

Revenue/Income Items:

\section{$\underline{\text { Tax Treatment }}$}

Unearned Revenues (Advance receipts)

Expense/Deduction Items:

Contingent Liabilities

$\underline{\text { Tax Treatment }}$

Deduct when amounts are fixed
Recognize on receipt $\underline{\text { Book Treatment }}$

Recognize when earned $\underline{\text { Book Treatment }}$

Expense when probable and estimable

$\underline{\text { Tax Liabilities }>\text { Book Liabilities (DTL) }}$

Revenue/Income Items:

Tax Treatment

Certain Construction Contracts $\underline{\text { Book Treatment }}$

Recognize systematically over the life of the project

Expense/Deduction Items:

None to our knowledge 


\section{Appendix D: Deferred Tax Accounts}

The deferred tax accounts are among the more complex dimensions of AFIT. This appendix expands on the discussion about DTAs and DTLs in the main body of the paper.

Four possible scenarios give rise to DTLs and DTAs. First, the tax basis of assets could be greater than the book basis of assets, generating a DTA. (Note that investors and the IRS cannot observe the tax bases of assets and liabilities but the firms themselves can.) For example, inventory is written down for obsolescence under GAAP, but not for tax purposes. Thus, if a firm has obsolete inventory, the tax basis of inventory will be higher than the book basis. Eventually, when the inventory is sold at a loss (or disposed of), the firm will receive a tax benefit because this will create a tax deduction. Thus, until the timing difference reverses (i.e., until the inventory is sold or disposed of) the firm will report a deferred tax asset on their books, representing this future tax benefit.

Second, the tax basis of liabilities could be greater than their book basis, generating a DTL. One example involves long-term construction contracts. For book purposes, most firms recognize the profits periodically as the project is completed, a method known as percentage of completion. However, for tax purposes, some small contractors can choose to report no taxable income until the project has been completed (completed contract method). When a firm uses the completed contract method, payments received prior to completion are recorded as a liability, unearned revenue. The temporary differences arising from these alternative accounting methods result in a DTL. Under percentage of completion, the book basis of the liability (unearned revenue) is zero because the profits have been recognized throughout the project. Under completed contract, the tax balance basis of the liability equals the unreported profits. ${ }^{105}$ Therefore, at completion, the book profits and their associated income tax expenses have already been recorded, but no actual taxes have been paid to the government. Thus, a DTL arises in recognition of the taxes to be paid at completion, even though no income tax expense will be recognized at completion.

${ }^{105}$ The journal entry on the tax books is debit cash (as cash payments are received) and credit unearned income. 
Third, the book basis of assets could be greater than the tax basis of assets, generating a DTL. As discussed previously, fixed assets are typically depreciated (i.e., expensed) at a quicker rate for tax purposes than for book purposes. Thus, the basis in these assets is greater under GAAP reporting than it is under income tax reporting. Consequently, in future years the firm will have fewer tax deductions related to these assets, which will result in their income tax payment to the government being greater than the income tax expense reported on the books (as it relates to these assets).

Finally, the book basis of liabilities could be greater than the tax basis of liabilities, generating a DTA. For example, under GAAP reporting, a firm will recognize a contingent liability when the liability is both estimable and probable. However, it will typically not be reported as a liability under tax reporting until it is more certain. Thus, the book basis of the liability is greater than the tax basis. Since the firm has not yet deducted these amounts, this will result in a future tax benefit when the deduction occurs. Therefore, the firm books a deferred tax asset.

These four scenarios are summarized in the following table:

\begin{tabular}{|l|l|l|}
\hline & Assets & Liabilities \\
\hline Tax Basis $>$ Book Basis & DTA & DTL \\
\hline Book Basis $>$ Tax Basis & DTL & DTA \\
\hline
\end{tabular}

